\title{
COMPRESSIVE CREEP AND THERMOPHYSICAL PERFORMANCE OF MULLITE REFRACTORIES
}

\author{
J.G. Hemrick ${ }^{1}$, A.A. Wereszczak ${ }^{2,3}$, M. Karakus ${ }^{4,5}$, K.C. Liu ${ }^{1,4}$, H. Wang ${ }^{1,4}$, B.A. Pint ${ }^{1,4}$, \\ T.P. Kirkland ${ }^{1,4}$, and R.E. Moore ${ }^{4,5}$
}

\author{
Prepared for the \\ Industrial Materials for the Future (IMF) Program and the Glass Vision Team \\ Office of Industrial Technologies \\ Assistant Secretary for Energy Efficiency and Renewable Energy \\ U.S. Department of Energy \\ ED 1805000 \\ Prepared by the \\ OAK RIDGE NATIONAL LABORATORY \\ Oak Ridge, Tennessee 37931-6285 \\ managed by \\ UT - BATTELLE, LLC. \\ for the \\ U.S. DEPARTMENT OF ENERGY \\ under contract DE-AC05-00OR22725
}

\footnotetext{
${ }^{1}$ Oak Ridge National Laboratory, Metals and Ceramics Division, Oak Ridge, TN.

${ }^{2}$ Principle Investigator.

${ }^{3}$ U.S. Army Research Laboratory, Weapons and Materials Directorate, Aberdeen Proving Ground, MD.

${ }^{4}$ Contributing Investigator.

${ }^{5}$ University of Missouri-Rolla, Department of Ceramic Engineering, Rolla, MO.
} 


\section{EXECUTIVE SUMMARY}

Compressive creep testing of ten commercially available mullite refractories was performed at $1300-1450^{\circ} \mathrm{C}$ and at static stresses between 0.2-0.6 $\mathrm{MPa}$. These refractories were examined because they are used in borosilicate glass furnace crowns and superstructures along with in sidewall applications. Additionally, despite their high cost $\left(\approx \$ 500 / \mathrm{ft}^{3}\right)$ they are cheaper than other refractories such as chrome alumina $\left(\approx \$ 3000 / \mathrm{ft}^{3}\right)$ or fusion-cast alumina $\left(\approx \$ 900 / \mathrm{ft}^{3}\right)$ which are used as replacements for traditional silica refractories in harsh oxy-fuel environments. The corrosion resistances of these ten materials were also evaluated. In addition, measurements were made that tracked their dimensional stability, phase content, microstructure, and composition as a function of temperature and time. The techniques used for these characterizations and their respective analyses are described.

An intent of this study was to provide objective and factual results whose interpretations were left to the reader. The salient observations and conclusions were:

- The amount of compressive creep for the BP Mullite, Durital S75, and Frimul F brands was found to be low at temperatures between $1300-1450^{\circ} \mathrm{C}\left(2370-2640^{\circ} \mathrm{F}\right)$ and at compressive stresses between 0.2 and $0.6 \mathrm{MPa}(29-87 \mathrm{psi})$. Creep rates were on the order of $10^{-11} \mathrm{~s}^{-1}$ at the lower test temperature and on the order of $10^{-10} \mathrm{~s}^{-1}$ at the higher test temperature. Only one specimen per condition was tested so the authors were unable to statistically conclude that any one of these three brands had superior creep resistance to the others; however, if differences do indeed exist, then they are believed to be insignificant.

- The amount of compressive creep for the GEM, HF 17, MU75AF, and ZED FM brands was found to be slightly higher than that for the three refractories listed above, but still low at 1300$1450^{\circ} \mathrm{C}$ and $0.2-0.6 \mathrm{MPa}$. Creep rates were on the order of $10^{-10} \mathrm{~s}^{-1}$ at the lower test temperature and on the order of $10^{-9} \mathrm{~s}^{-1}$ at the higher test temperature. It should be noted that the GEM brand specimen showed higher amounts of creep than the other three brands in this group and a low stress exponent (0.4). This places its behavior closer to that described next for the brands exhibiting significant amounts of creep. Again, only one specimen per condition was tested so the authors were unable to statistically conclude that any one of the other three brands had superior creep resistance to the others; however, if differences do indeed exist, then they are believed to be insignificant. 
- The amount of compressive creep for the SL75AD, UFALA UCR, and ZED FMC brands was found to be significant at $1375-1450^{\circ} \mathrm{C}$ and at 0.4 and $0.6 \mathrm{MPa}$. Creep rates were on the order of $10^{-9} \mathrm{~s}^{-1}$ at the lower test temperature and on the order of $10^{-8} \mathrm{~s}^{-1}$ at the higher test temperature. It should be noted that all three of these brands exhibited low stress exponents $(<0.5)$ and changes in chemistry or microstructure due to the creep testing conditions. Again, only one specimen per condition was tested so the authors were unable to statistically conclude that any one of these three brands had superior or inferior creep resistance to the others; however, if differences do indeed exist, then they are believed to be insignificant.

- Durital S75 was found to have a stress exponent of 2.4 indicating that the rate controlling mechanism may be grain boundary creep. This is opposed to diffusion controlled or Coble creep, which is expected to be the rate controlling mechanism in the Frimul F, HF 17, and MU75AF brands which exhibited a stress exponent of approximately unity.

- It is believed that the low stress exponents seen for the BP Mullite, GEM, SL75AD, UFALA UCR, ZED FMC, and ZED FM brands is due to a non-steady state condition existing during the entire extent of testing. This condition is a consequence of contraction or time-hardening effects occurring during testing and the samples never reaching a state of equilibrium. The result is measurement of creep due to the applied compressive stress coupled with contraction of the sample due to time-hardening effects. Therefore, the assumption of a single deformation mechanism being active at all temperatures and stresses is not valid and multi-linear regression falsely yields extremely low stress exponent values.

- Those brands which possessed high levels of matrix porosity (HF 17, UFALA UCR, and ZED FMC) all showed compaction of the microstructure due to creep testing. This is believed to be the reason for the poor creep resistance of the UFALA UCR and ZED FMC brands. In addition, the UFALA UCR sample was found to possess a fine grain size, which could have contributed to the increased creep rate.

- SL75AD was found to be composed of andalusite grains containing free quartz, which was converted to cristobalite during firing. Further, the andalusite grains are fully converted to mullite during creep testing and the amount of glassy phase increased. These events in combination may lead to the brand's poor creep resistance. 
- Activation energies for the various refractory brands ranged from 50 to $223 \mathrm{kcal} / \mathrm{mol}$. Although no direct correlation between the magnitude of the activation energy and the amount of creep exhibited by a particular brand could be drawn from the data, it is known that materials possessing a high activation energy will have greater sensitivity to temperature than those possessing a lower activation energy. It should also be noted that the values for many of the calculated activation energies correspond to the activation energy of vitreous silica. This indicates that the glassy phases in these brands affect the overall creep behavior of the material.

- The distinction of a brand being fused-grained or non-fused grained mullite did not appear to have a bearing on the creep resistance of the individual brands.

- Room temperature thermal conductivity values were similar for all ten brands of mullite with the average being on the order of $3.1 \mathrm{~W} / \mathrm{mK}\left(21.5(\mathrm{Btu} * \mathrm{in}) /.\left(\mathrm{hr} . * \mathrm{ft}^{2} *^{0} \mathrm{~F}\right)\right)$. Frimul $\mathrm{F}$ was found to have the highest thermal conductivity at just below $3.5 \mathrm{~W} / \mathrm{mK}\left(24.3(\mathrm{Btu} * \mathrm{in}) /.\left(\mathrm{hr} .{ }^{*} \mathrm{ft}^{2}{ }^{20} \mathrm{~F}\right)\right)$. SL75AD, UFALA UCR and ZED FM were found to have the lowest thermal conductivities at around $2.5 \mathrm{~W} / \mathrm{mK}\left(17.4(\mathrm{Btu} * \mathrm{in}) /.\left(\mathrm{hr} . * \mathrm{ft}^{2}{ }^{* 0} \mathrm{~F}\right)\right)$.

- Eight of the ten refractory brands showed less than $0.2 \%$ change in mass and less than $0.6 \%$ change in volume due thermal aging in the absence of an applied load. The two exceptions, ZED FM and ZED FMC, exhibited extraneous amounts of change $(\approx 8.5 \%)$ in both mass and volume due to thermal exposure. All samples showed less than $0.5 \%$ change in bulk density.

- The corrosion rates of the ten mullite brands could not be determined through the use of ASTM C987, but it was determined visually that only minimal amounts of recession occurred due to exposure as defined by the ASTM lid test. 


\section{TABLE OF CONTENTS}

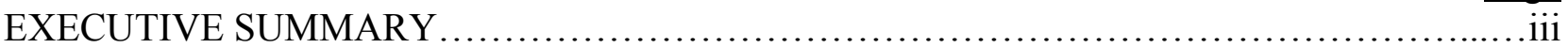

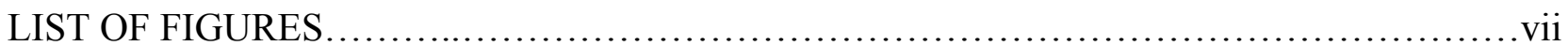

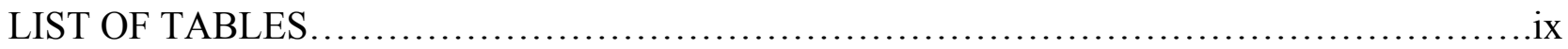

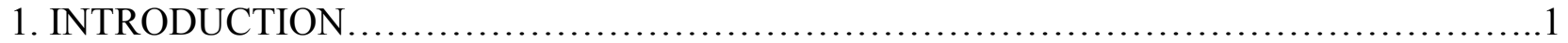

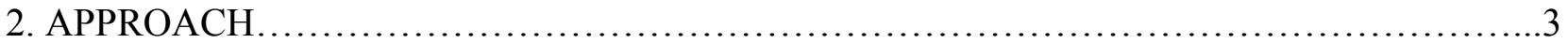

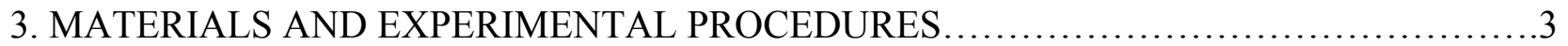

3.1. MATEERIALS TESTED \& MANUFACTURERS' REPORTED DATA.....................

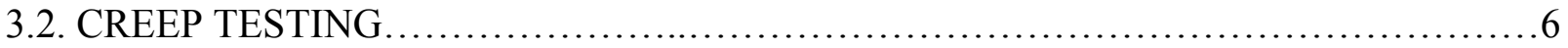

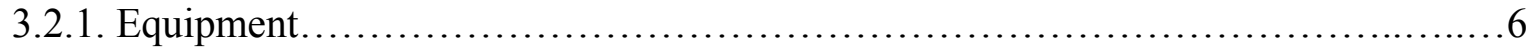

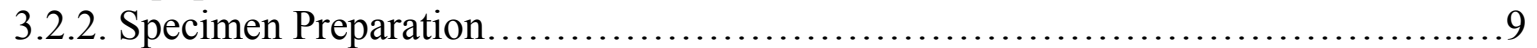

3.2.3. Test Matrix \& Procedure .................................................. 10

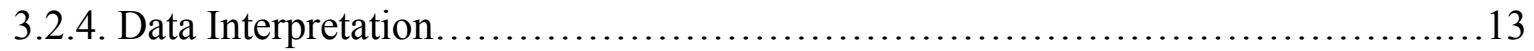

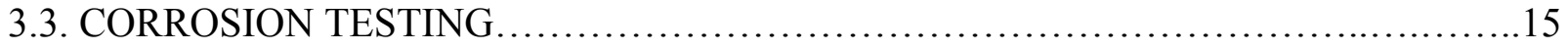

3.4. BULK CHARACTERISTICS (PRE- AND POST CREEP TESTING) ...................15

3.4.1. Bulk Densities.................................................................. 16

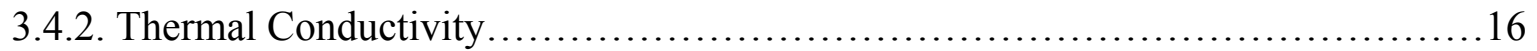

3.4.3. Crystalline Phases.......................................................... 17

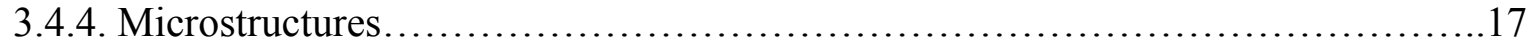

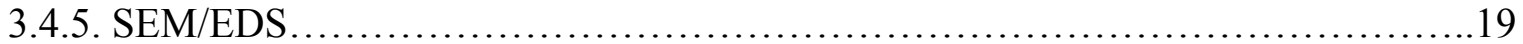

3.5. EFFECT OF TEMPERATURE (“AGING” STUDY) ...................................

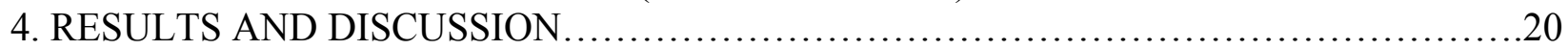

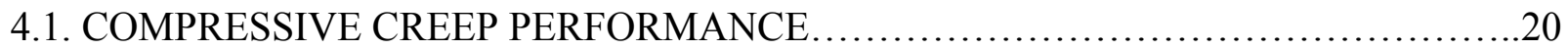

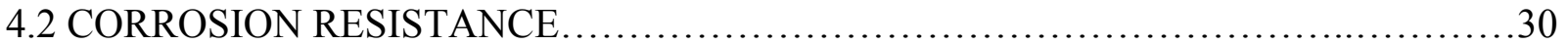

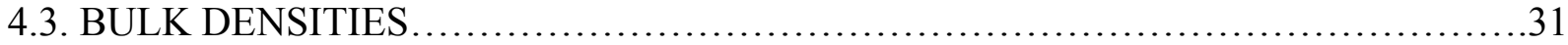

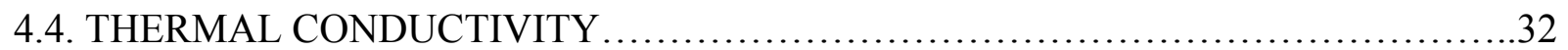

4.5. CHANGES IN BULK CHARACTERISTICS DUE TO CREEP TESTING...............33

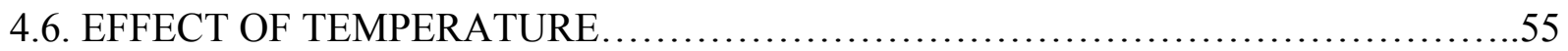

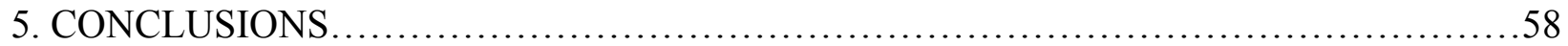

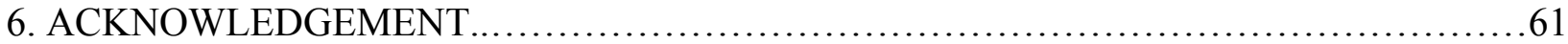

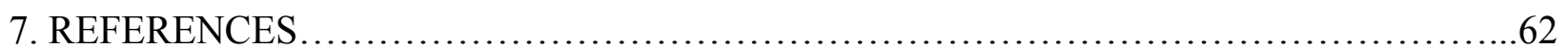

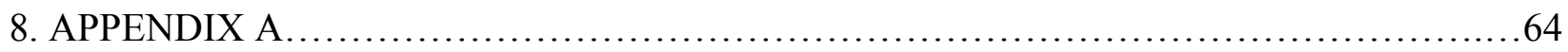




\section{LIST OF FIGURES}

Figure 1. Schematic of creep frame and supporting instruments... Page

Figure 2. Primary components of creep frame................................................................. 7

Figure 3. Schematic of creep frame extensometer. ............................................................... 8

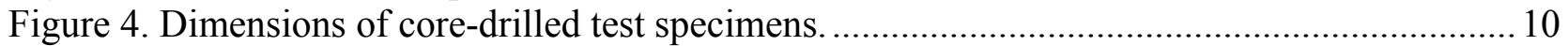

Figure 5. Schematic of how specimens were core-drilled from as-received bricks...................... 10

Figure 6. Temperature and stress history used in initial creep testing. ................................... 12

Figure 7. Temperature and stress history used in subsequent creep testing............................... 12

Figure 8. Example of a compressive creep curve (creep strain as a function of stress and time) and

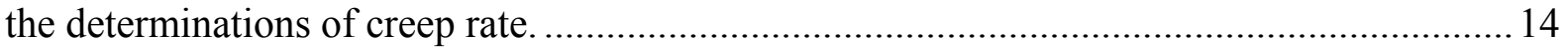

Figure 9. Example of an empirical power-law representation (eq. 1) of creep rate as a function of

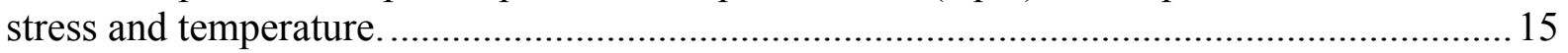

Figure 10. Schematic of transient plane source (tps) direct thermal conductivity method experimental set-up and picture of kapton sensor.................................................. 16

Figure 11. Schematic describing how disk sections were machined from core drilled specimens for "as-received" RL and CL imaging........................................................................ 17

Figure 12. Schematic describing how disk sections were machined from crept specimens for post-

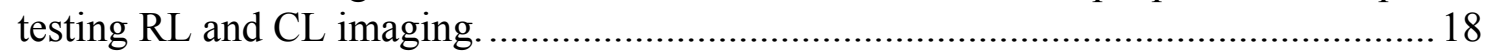

Figure 13. Schematic of specimens used for the "aging" study ...........................................20

Figure 14. Creep behavior of BP Mullite as a function of temperature and stress......................2 21

Figure 15. Creep behavior of Durital S75 as a function of temperature and stress. .....................2 21

Figure 16. Creep behavior of Frimul $\mathrm{F}$ as a function of temperature. ....................................... 21

Figure 17. Creep behavior of GEM as a function of temperature...........................................22

Figure 18. Creep behavior of HF 17 as a function of temperature. ............................................22

Figure 19. Creep behavior of MU75AF as a function of temperature ......................................22

Figure 20. Creep behavior of SL75AD as a function of temperature........................................ 23

Figure 21. Creep behavior of UFALA UCR as a function of temperature................................. 23

Figure 22. Creep behavior of ZED FMC as a function of temperature. ................................... 23

Figure 23. Creep behavior of ZED FM as a function of temperature......................................2 24

Figure 24. Empirical power-law representation of BP Mullite as a function of stress and

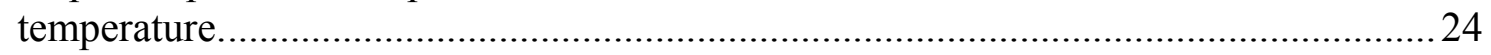

Figure 25. Empirical power-law representation of Durital S75 as a function of stress and

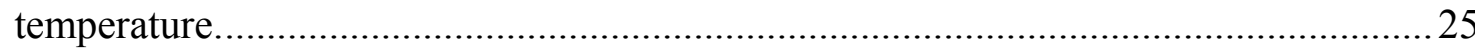

Figure 26. Empirical power-law representation of Frimul $\mathrm{F}$ as a function of stress and temperature.

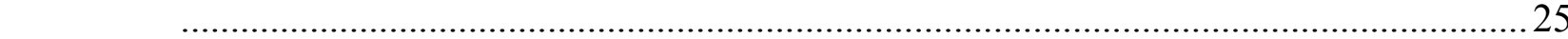

Figure 27. Empirical power-law representation of GEM as a function of stress and temperature. . 26

Figure 28. Empirical power-law representation of HF 17 as a function of stress and temperature. 26

Figure 29. Empirical power-law representation of MU75AF as a function of stress and

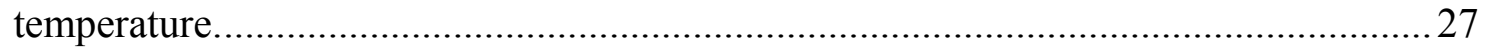

Figure 30. Empirical power-law representation of SL75AD as a function of stress and temperature.

Figure 31. Empirical power-law representation of UFALA UCR as a function of stress and

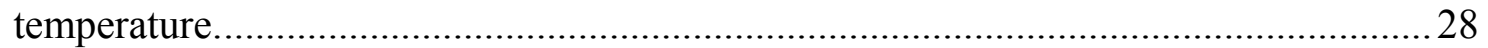

Figure 32. Empirical power-law representation of ZED FMC as a function of stress and temperature 
Figure 33. Empirical power-law representation of ZED FM as a function of stress and temperature.

Figure 34. Refractory recession when exposed to sodium carbonate at $1400^{\circ} \mathrm{C}$ for 24 hours using ASTM C987.

Figure 35 Thermal conductivity of mullite refractories as measured using "hot-disk".................. 32

Figure 36. RL and CL microscopy of BP Mullite.................................................................. 34

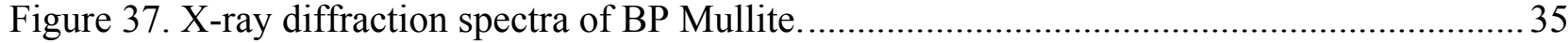

Figure 38. Scanning electron microscopy of BP Mullite......................................................... 35

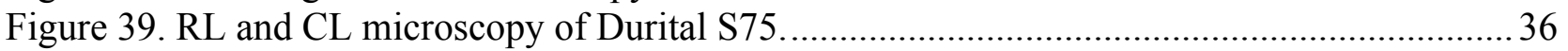

Figure 40. X-ray diffraction spectra of Durital S75 ........................................................ 37

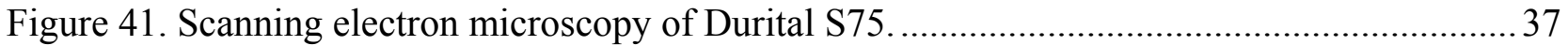

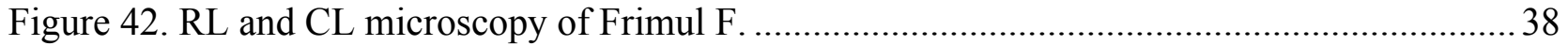

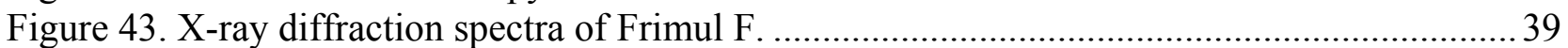

Figure 44. Scanning electron microscopy of Frimul F. ......................................................... 39

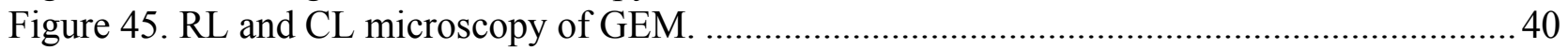

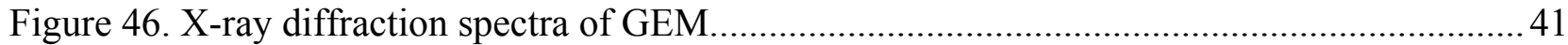

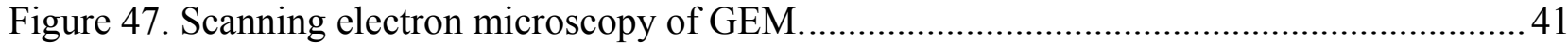

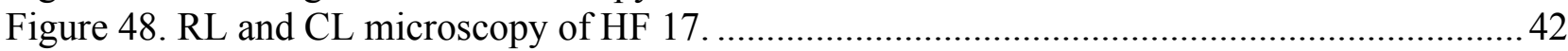

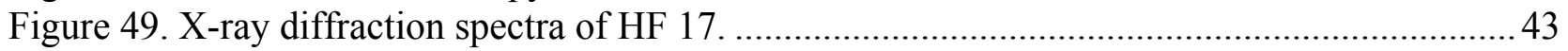

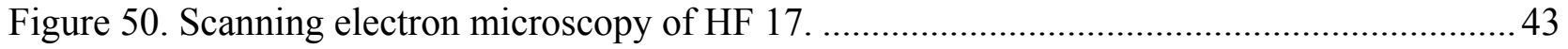

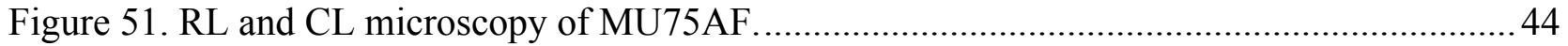

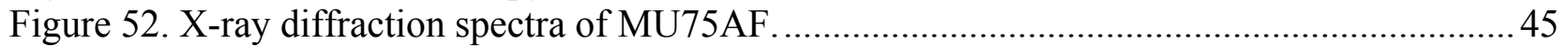

Figure 53. Scanning electron microscopy of MU75AF ....................................................... 45

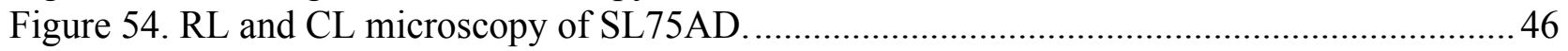

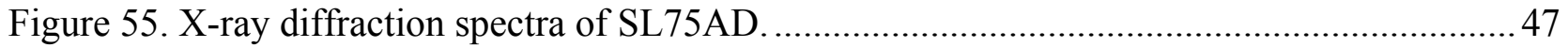

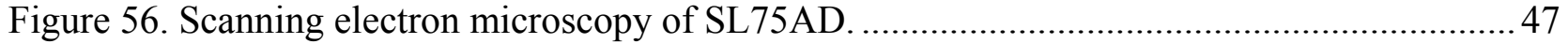

Figure 57. RL and CL microscopy of UFALA UCR ........................................................... 49

Figure 58. X-ray diffraction spectra of UFALA UCR ........................................................5 50

Figure 59. Scanning electron microscopy of UFALA UCR ..................................................5 50

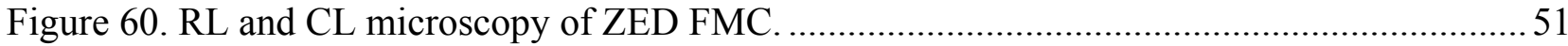

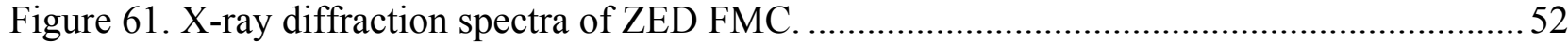

Figure 62. Scanning electron microscopy of ZED FMC . .................................................... 52

Figure 63. RL and CL microscopy of ZED FM................................................................. 53

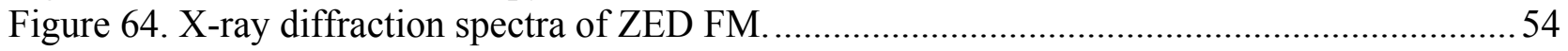

Figure 65. Scanning electron microscopy of ZED FM....................................................5

Figure 66. Change in mass of "aged" specimens as a function of time.....................................55

Figure 67. Change in volume of "aged" specimens as a function of time. .................................56

Figure 68. Change in density of "aged" specimens as a function of time. .................................57 


\section{LIST OF TABLES}

$\underline{\text { Page }}$

Table 1. Refractories tested in the present study and their manufacturers.................................. 4

Table 2. Chemical data for tested refractory brands as reported by the manufacturers.................. 4

Table 3. Physical and mechanical data for tested refractory brands as reported by the

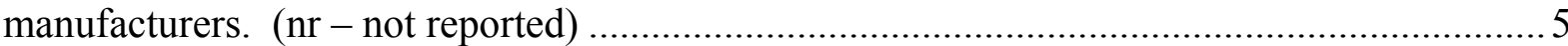

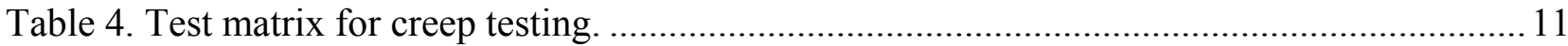

Table 5. Results of multilinear regression of creep data .........................................................29

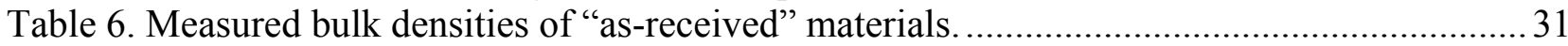




\section{INTRODUCTION}

Sillimanite $\left(\mathrm{Al}_{2} \mathrm{SiO}_{5}\right)$ and mullite $\left(\mathrm{Al}_{6} \mathrm{Si}_{3} \mathrm{O}_{15}\right)$ have been of interest since as early as 1919 when they were first investigated as a possible high refractory materials [1]. Early work showed the optimal alumina silica ratio for high refractory materials to be 72 parts alumina to 28 parts silica, similar to the currently accepted stoichiometric mullite compositional ratio of $\left(3 \mathrm{Al}_{2} \mathrm{O}_{3} * 2 \mathrm{SiO}_{2}\right)$. Yet, initially bricks produced with this composition were of poor quality due to magnesia and lime contamination that caused severe fluidity of the glass matrix surrounding the mullite grains. The introduction of fused mullite grains made the situation even worse due to a high content of corundum and glass in the fused product. Therefore, early hope of using mullite for refractory purposes was nearly abandoned.

Later, the low strength of early mullite refractories was attributed to the weakness of the glass matrix surrounding the pure mullite crystals in the formed bricks [1]. This deficiency was improved by strengthening the glass phase with finely divided mullite particles through calcination of high alumina clay materials. This process was found to produce a structure of interlocking mullite crystals surrounded by a film of glassy phase, which was strengthened, by needle-like mullite crystals. Refractories could then be bonded from this material. This practice is still often followed today as powdered calcined alumina and natural silica sand or rock are fused in an arc furnace, solidified and ground into aggregate and powder which forms the needlelike crystal structure.

The structure of interlocking mullite grains surrounded by glass as a matrix is favorable for corrosion resistance, as it produces low porosity and good pore distribution [2]. The composition of mullite refractories is also favorable since it will build up a stiff or viscous protective coating on its exposed face during service when in the presence of glass melt or dust. Additionally, the mullite will decompose to alumina and alkali silicate, which can be incorporated into most glass systems.

Current mullite refractories take on a structure composed of large cornered mullite crystals with the pore spaces between the grains filled by fine needle-like mullite that thickens the surrounding glass [1]. This makes them ideal for use in harsh oxy-fuel environments as a replacement material for traditional silica refractories, which do not possess the same level of resistance to attack by alkali, water vapor, and borate in the combustion product. Silica bricks 
are also not able to operate at the higher temperatures tolerated by mullite refractories. In addition, their cost $\left(\approx \$ 500 / \mathrm{ft}^{3}\right)$ is lower than that of other candidate alternative refractories under consideration such as chrome alumina $\left(\approx \$ 3000 / \mathrm{ft}^{3}\right)$ or fusion-cast alumina $\left(\approx \$ 900 / \mathrm{ft}^{3}\right)$. Therefore, mullite refractories are commonly found in borosilicate, E-glass, and low alkali alumino-silicate glass furnace crowns and superstructures, in sidewall applications, in slide gates for continuous casting and as refractories for cement kilns [2],[3]. Thus, one must be concerned with their high temperature service and issues of creep during prolonged exposure. Furnace designers can ensure that superstructure structural integrity is maintained and promoted if the creep behavior of the refractory material is well understood and well represented by appropriate engineering creep models.

Several issues limit the abilities of furnace designers to (1) choose the optimum refractory for their applications, (2) optimize the engineering design, or (3) predict the mechanical service integrity of their furnace superstructures. Published engineering creep data are essentially non-existent for almost all commercially available refractories used for glass furnace superstructures. The limited data that do exist are supplied by the various refractory suppliers. Unfortunately, these suppliers generally have different ways of conducting their mechanical testing and they also interpret and report their data differently. This makes it difficult for furnace designers to draw fair comparisons between competing grades of candidate refractories. Furthermore, the refractory supplier's data are often not available in a form that can be readily used for furnace design and for the prediction and design of long-term structural integrity of furnace superstructures.

With the aim of providing such comparable data, the US DOE's Office of Industrial Technologies and its Advanced Industrial Materials program sponsored work to conduct creep testing and analysis on refractories of interest to the glass industry. An earlier stage of the project involved identifying which refractories to test and this is described elsewhere [4]. Initial work was performed on characterization of the compressive creep performance and high temperature dimensional stability of conventional silica refractories and was previously published as an ORNL Technical report [5]. Mullite was another such identified refractory category, and the present report describes the creep behavior of this class of refractories. To portray a more complete understanding of how these refractories perform at service 
temperatures, their fundamental corrosion resistances, dimensional stabilities, and microstructures were characterized as well.

\section{APPROACH}

The creep performance of ten refractories was examined. The equipment that was used, the specimen preparation, the employed test matrix, and how the creep data were interpreted are described along with presentation and comparison of the creep results.

Corrosion resistance of the ten refractories was also examined. Like the creep data, the equipment, specimen preparation, test matrix and how the corrosion resistances were interpreted are described along with presentation and comparison of the results.

The bulk characteristics of the refractories were then characterized before and after their creep testing in an attempt to correlate the creep responses with any changes observed. Phase content, microstructure, and secondary phase composition were examined and their changes as a function of test temperature analyzed.

Lastly, the effect of temperature and time (in the absence of stress) on the dimensional stability of these refractories was examined. Specimens were aged at an equivalent temperature to that at which creep testing was performed and the temperature component effects on microstructure were examined. The procedures used and the generated results are discussed.

\section{MATERIALS AND EXPERIMENTAL PROCEDURES}

\subsection{MATERIALS TESTED \& MANUFACTURERES' REPORTED DATA}

Ten mullite refractories were analyzed in the present study. Seven of the materials were fused-grained mullite refractories and three were not (although one non-fused-grain material did contain a small amount of fine fused mullite grains). The fused-grained mullite refractories were BP Mullite, Frimul F, GEM, HF 17, MU75AF, ZED FMC and ZED FM. The non-fused-grained refractories were DURITAL S75, SL75AD, and UFALA UCR. The manufacturers for these refractories at the time of the program's initiation, along with whether they are fused-grained or not are listed in Table 1. It should be noted that many of the manufacturers listed have merged 
or changed names since program initiation. Tables 2 and 3 provide the chemical and physical properties, respectively, of the 10 refractories.

Table 1. Refractories tested in the present study and their manufacturers.

\begin{tabular}{|c|c|c|}
\hline Brand Name & Type & Manufacturer \\
\hline BP Mullite & fused-grained & Corhart \\
\hline DURITAL S75 & non-fused-grained & NARCO \\
\hline Frimul F & fused-grained & DSF \\
\hline GEM & fused-grained & NARCO \\
\hline HF 17 & fused-grained & DSF \\
\hline MU75AF & fused-grained & VGT-DYKO \\
\hline SL75AD & non-fused-grained & VGT-DYKO \\
\hline UFALA UCR & non-fused-grained & Harbison-Walker \\
\hline ZED FMC & fused-grained & Minteq \\
\hline ZED FM & fused-grained & Minteq \\
\hline
\end{tabular}

Table 2. Chemical data for tested refractory brands as reported by the manufacturers.

$(\mathrm{nr}-$ not reported)

\begin{tabular}{|c|c|c|c|c|c|}
\hline \multirow{2}{*}{ Brand } & \multicolumn{5}{|c|}{$\begin{array}{c}\text { Constituent } \\
(\%)\end{array}$} \\
\cline { 2 - 6 } & $\mathrm{Al}_{2} \mathrm{O}_{3}$ & $\mathrm{SiO}_{2}$ & $\mathrm{Fe}_{2} \mathrm{O}_{3}$ & $\mathrm{TiO}_{2}$ & other \\
\hline BP Mullite & 75.5 & 24.0 & 0.2 & 0.0 & 0.3 \\
\hline DURITAL 575 & 75.0 & 24.0 & 0.5 & 0.1 & 0.4 \\
\hline Frimul F & 75.7 & 23.6 & 0.1 & 0.0 & 0.6 \\
\hline GEM & 74.6 & 24.2 & 0.1 & 0.1 & 1.0 \\
\hline HF 17 & 78.2 & 21.6 & 0.1 & 0.0 & 0.1 \\
\hline MU75AF & 74.0 & 25.0 & 0.2 & $\mathrm{nr}$ & 0.8 \\
\hline SL75AD & 72.0 & 25.0 & 1.0 & $\mathrm{nr}$ & 2.0 \\
\hline UFALA UCR & 62.3 & 36.1 & 0.8 & 0.2 & 0.6 \\
\hline ZED FMC & 77.4 & 22.0 & 0.1 & 0.1 & 0.4 \\
\hline ZED FM & 78.5 & 20.9 & 0.1 & 0.1 & 0.4 \\
\hline
\end{tabular}


Table 3. Physical and mechanical data for tested refractory brands as reported by the manufacturers. $(\mathrm{nr}-$ not reported)

\begin{tabular}{|c|c|c|c|c|c|c|}
\hline Brand & $\begin{array}{c}\text { Reheat } \\
\text { Change in } \\
\text { Dimension }\end{array}$ & $\begin{array}{c}\text { Bulk } \\
\text { Density }\end{array}$ & $\begin{array}{c}\text { Apparent } \\
\text { Porosity } \\
(\%)\end{array}$ & $\begin{array}{c}\text { Thermal } \\
\text { Conductivity }\end{array}$ & $\begin{array}{l}\text { Modulus of } \\
\text { Rupture }\end{array}$ & $\begin{array}{c}\text { Cold } \\
\text { Crushing } \\
\text { Strength }\end{array}$ \\
\hline BP Mullite & $\mathrm{nr}$ & $\begin{array}{c}169 \mathrm{lb} / \mathrm{ft}^{3} \\
2.70 \mathrm{~g} / \mathrm{cm}^{3}\end{array}$ & 13.0 & $\begin{array}{c}2.0 \mathrm{~W} / \mathrm{mK} \\
13.9 \\
\left(\mathrm{Btu}^{*} \mathrm{in} .\right) / \\
\left(\mathrm{hr}{ }^{*} \mathrm{ft}^{2} *{ }^{\circ} \mathrm{F}\right)\end{array}$ & $\mathrm{nr}$ & $\begin{array}{c}14.5 \mathrm{ksi} \\
100 \mathrm{MPa}\end{array}$ \\
\hline $\begin{array}{l}\text { DURITAL } \\
\text { S75 }\end{array}$ & $\begin{array}{c}+0.5 \% \\
(a) 1700^{\circ} \mathrm{C}\end{array}$ & $\begin{array}{c}162 \mathrm{lb} / \mathrm{ft}^{3} \\
2.60 \mathrm{~g} / \mathrm{cm}^{3}\end{array}$ & 19.0 & $\begin{array}{c}2.1 \mathrm{~W} / \mathrm{mK} \\
14.6 \\
\left(\mathrm{Btu}^{*} \mathrm{in} .\right) / \\
\left(\mathrm{hr} . \mathrm{ft}^{2} *^{\circ} \mathrm{F}\right)\end{array}$ & $\begin{array}{c}1.1 \mathrm{ksi} \\
7.5 \mathrm{MPa}\end{array}$ & $\begin{array}{l}9.0 \mathrm{ksi} \\
62 \mathrm{MPa}\end{array}$ \\
\hline Frimul F & $\begin{array}{c}\text { NIL } \\
\text { @ } 1600^{\circ} \mathrm{C}\end{array}$ & $\begin{array}{c}160 \mathrm{lb} / \mathrm{ft}^{3} \\
2.56 \mathrm{~g} / \mathrm{cm}^{3}\end{array}$ & 17.5 & $\begin{array}{c}2.4 \mathrm{~W} / \mathrm{mK} \\
16.7 \\
\left(\mathrm{Btu}^{*} \mathrm{in} .\right) / \\
\left(\mathrm{hr} . \mathrm{ft}^{2} *^{\circ} \mathrm{F}\right)\end{array}$ & $\mathrm{nr}$ & $\begin{array}{l}9.7 \mathrm{ksi} \\
67 \mathrm{MPa}\end{array}$ \\
\hline GEM & $\begin{array}{c}\text { NIL } \\
@ 1600^{\circ} \mathrm{C}\end{array}$ & $\begin{array}{c}165 \mathrm{lb} / \mathrm{ft}^{3} \\
2.65 \mathrm{~g} / \mathrm{cm}^{3}\end{array}$ & 15.0 & $\begin{array}{c}2.3 \mathrm{~W} / \mathrm{mK} \\
16.0 \\
\left(\mathrm{Btu}^{*} \mathrm{in} .\right) / \\
\left(\mathrm{hr}{ }^{*} \mathrm{ft}^{2} *^{\circ} \mathrm{F}\right)\end{array}$ & $\begin{array}{c}2.5 \mathrm{ksi} \\
17.2 \mathrm{MPa}\end{array}$ & $\begin{array}{l}14.0 \mathrm{ksi} \\
97 \mathrm{MPa}\end{array}$ \\
\hline HF 17 & $\mathrm{nr}$ & $\begin{array}{r}162 \mathrm{lb} / \mathrm{ft}^{3} \\
2.60 \mathrm{~g} / \mathrm{cm}^{3}\end{array}$ & 17.5 & $\mathrm{nr}$ & $\mathrm{nr}$ & $\begin{array}{c}8.7 \mathrm{ksi} \\
60 \mathrm{MPa} \\
\end{array}$ \\
\hline MU75AF & $\mathrm{nr}$ & $\begin{array}{c}159 \mathrm{lb} / \mathrm{ft}^{3} \\
2.55 \mathrm{~g} / \mathrm{cm}^{3}\end{array}$ & 18.0 & $\begin{array}{c}2.0 \mathrm{~W} / \mathrm{mK} \\
13.9 \\
\left(\mathrm{Btu}^{*} \mathrm{in} .\right) / \\
\left(\mathrm{hr} .{ }^{*} \mathrm{ft}^{2} *^{\circ} \mathrm{F}\right)\end{array}$ & $\mathrm{nr}$ & $\begin{array}{l}11.6 \mathrm{ksi} \\
80 \mathrm{MPa}\end{array}$ \\
\hline SL75AD & $\mathrm{nr}$ & $\begin{array}{c}172 \mathrm{lb} / \mathrm{ft}^{3} \\
2.75 \mathrm{~g} / \mathrm{cm}^{3}\end{array}$ & 12.0 & $\begin{array}{c}2.1 \mathrm{~W} / \mathrm{mK} \\
14.6 \\
\left(\mathrm{Btu}^{*} \mathrm{in} .\right) / \\
\left(\mathrm{hr} . \mathrm{ft}^{2} *^{\circ} \mathrm{F}\right)\end{array}$ & $\mathrm{nr}$ & $\begin{array}{l}11.6 \mathrm{ksi} \\
80 \mathrm{MPa}\end{array}$ \\
\hline $\begin{array}{l}\text { UFALA } \\
\text { UCR }\end{array}$ & $\begin{array}{c}-0.2 \% \\
@ 1600^{\circ} \mathrm{C}\end{array}$ & $\begin{array}{r}160 \mathrm{lb} / \mathrm{ft}^{3} \\
2.56 \mathrm{~g} / \mathrm{cm}^{3}\end{array}$ & 14.1 & $\mathrm{nr}$ & $\begin{array}{c}2.2 \mathrm{ksi} \\
15.0 \mathrm{MPa} \\
\end{array}$ & $\mathrm{nr}$ \\
\hline ZED FMC & $\mathrm{nr}$ & $\begin{array}{c}163 \mathrm{lb} / \mathrm{ft}^{3} \\
2.61 \mathrm{~g} / \mathrm{cm}^{3}\end{array}$ & 16.0 & $\begin{array}{c}2.7 \mathrm{~W} / \mathrm{mK} \\
18.7 \\
\left(\mathrm{Btu}^{*} \mathrm{in} .\right) / \\
\left(\mathrm{hr}^{*} \mathrm{ft}^{2}{ }^{\circ} \mathrm{F}\right)\end{array}$ & $\begin{array}{c}1.7 \mathrm{ksi} \\
11.7 \mathrm{MPa}\end{array}$ & $\begin{array}{l}10.6 \mathrm{ksi} \\
73 \mathrm{MPa}\end{array}$ \\
\hline ZED FM & $\mathrm{nr}$ & $\begin{array}{c}156 \mathrm{lb} / \mathrm{ft}^{3} \\
2.50 \mathrm{~g} / \mathrm{cm}^{3}\end{array}$ & 20.0 & $\begin{array}{c}2.7 \mathrm{~W} / \mathrm{mK} \\
18.7 \\
\left(\mathrm{Btu}^{*} \mathrm{in} .\right) / \\
\left(\mathrm{hr} \cdot \mathrm{ft}^{2} *^{\circ} \mathrm{F}\right)\end{array}$ & $\begin{array}{c}2.3 \mathrm{ksi} \\
15.9 \mathrm{MPa}\end{array}$ & $\begin{array}{l}13.0 \mathrm{ksi} \\
90 \mathrm{MPa}\end{array}$ \\
\hline
\end{tabular}




\subsection{CREEP TESTING}

The creep testing equipment, specimen preparation, test matrix and testing procedures, and creep data interpretation method are described below.

\subsubsection{Equipment}

The testing frame used for the compressive creep testing consisted of a large clamshell furnace that used resistance-heating, a contacting extensometer that was used to measure axialdimension-changes, and silicon carbide push rods that transferred the applied compressive load from an actuator to the test specimen.

A schematic and picture of the creep frame that was used are shown in Figure 1 and Figure 2. Creep tests were accomplished using either digitally controlled pneumatic power (by LabVIEW $^{\mathrm{TM}}$ software, National Instruments, Austin, TX) or hydraulic power controlled by an analog controller. The latter feature provides both static (creep) and dynamic loading. The test specimen, not visible in Figure 2, was heated with a high temperature furnace capable of $1800^{\circ} \mathrm{C}$. Within ASTM guidelines [6], temperature fluctuations were approximately $\pm 2{ }^{\circ} \mathrm{C}$ and load fluctuations were less than $1 \%$ of test load. The specimen was compressed by two long pushrods (each $0.3 \mathrm{~m}$ long) with the unheated ends connecting to water-cooled anvils. The upper compression anvil was fixed to the upper platen by a universal joint and leveled using four turnbuckles. The lower compression anvil rests on a self-aligning coupler that plays an important role in maintaining load-train stability and uniform compression to the specimen. Details of the compressive creep testing system are given elsewhere [7].

The generated creep strain was measured using a scissors-type mechanical extensometer [8], a schematic of which is shown in Figure 3. The extensometer employs a capacitance sensor whose gap was conditioned, calibrated and measured as a function of time. The lever-arm assembly was made from a continuous rod of silicon carbide. The probes monitored creep deformation of the specimen continuously in real time with a capacitive transducer attached to the cool end of the extension rod. Concurrently, a laser-based scanner was used to measure the movement of two fiducial flags attached to the ends of the extension rods for verification. The extensometer provided an accuracy and resolution of about $5 \mu \mathrm{m}$, which is equivalent to the 
sensitivity yielded by conventional strain gages. Strain measurements with the transducer and the laser system were in good agreement.

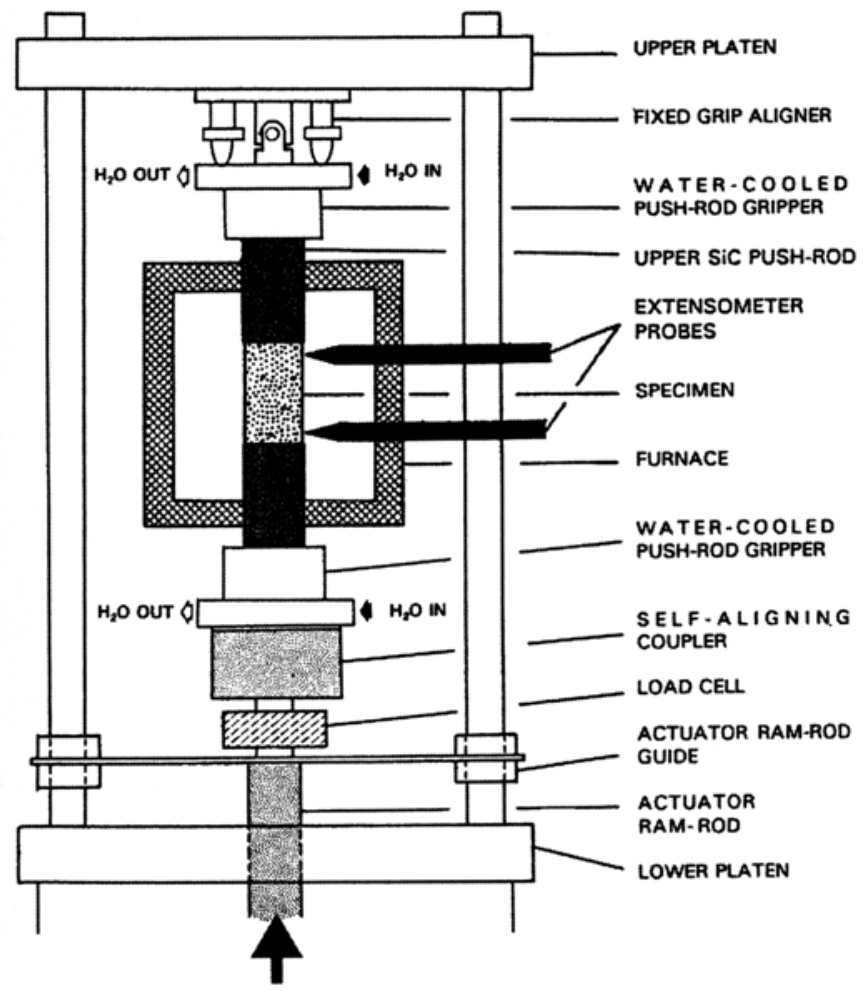

Figure 1. Schematic of creep frame and supporting instruments.

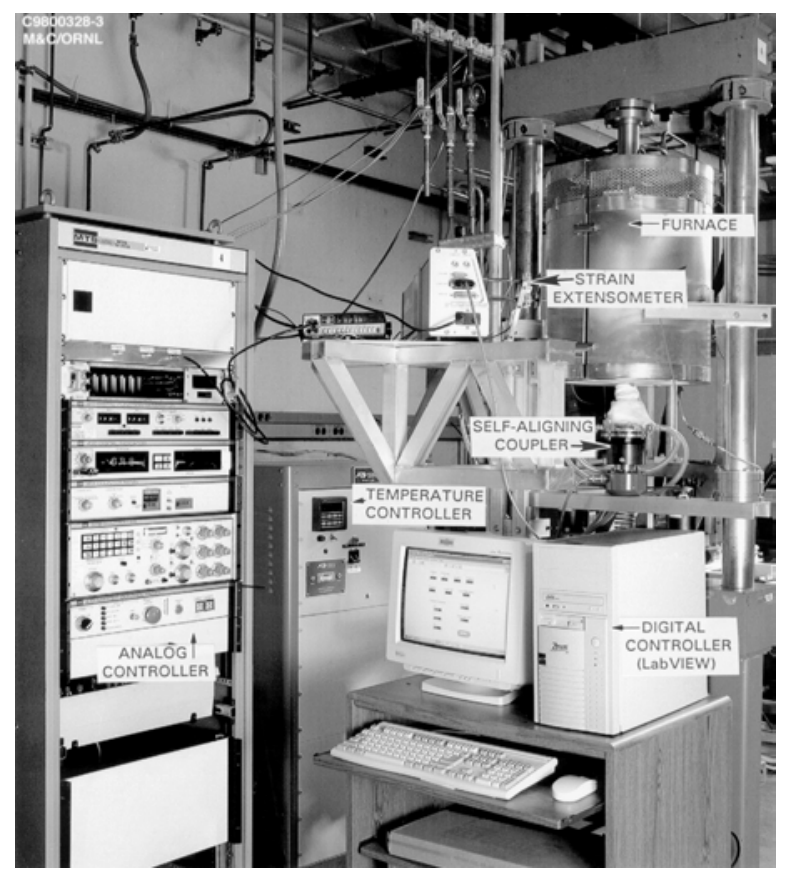

Figure 2. Primary components of creep frame. 


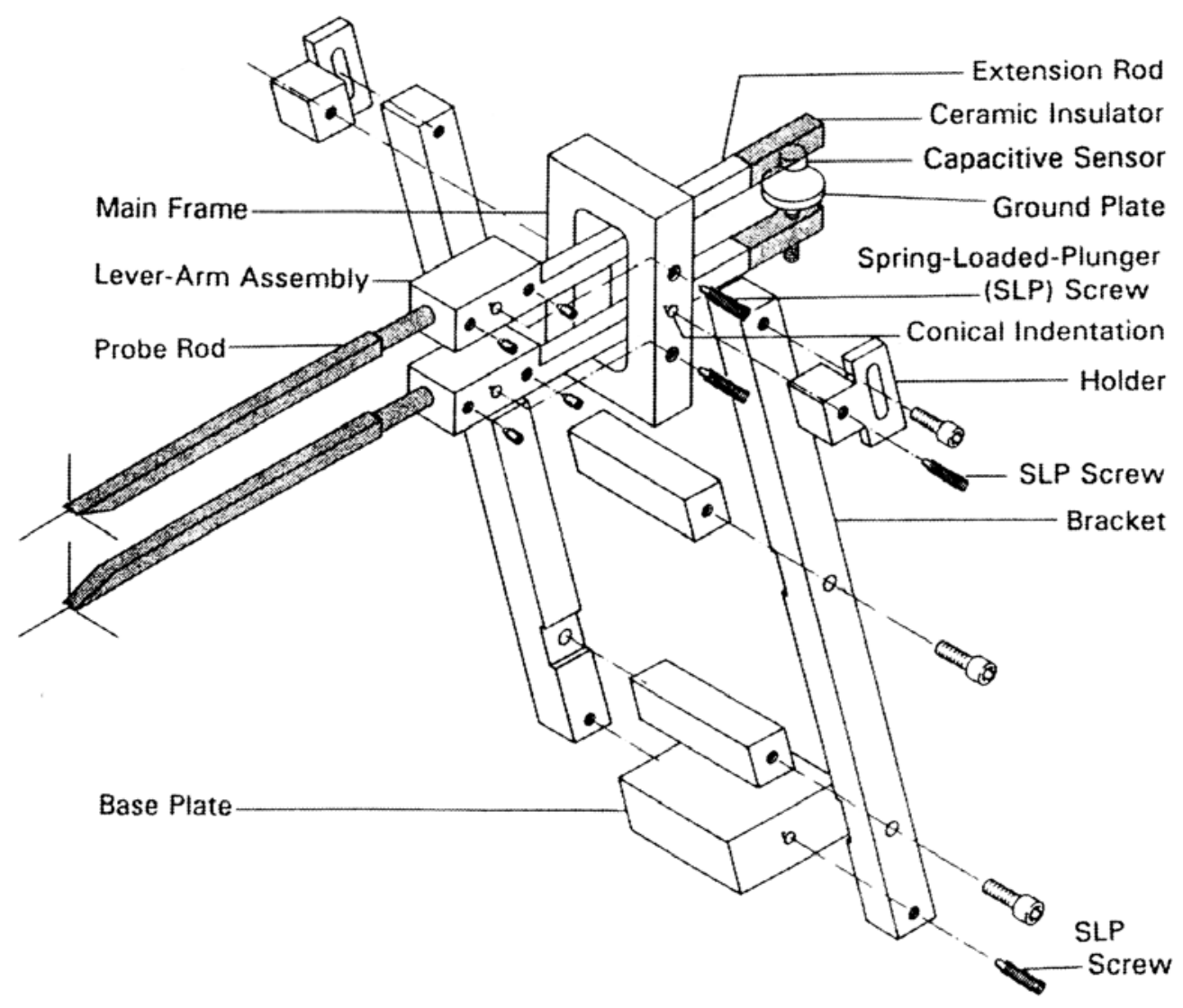

Figure 3. Schematic of creep frame extensometer.

Extensometry methods other than the capacitance contacting extensometers used in this study are often used for the measurement of refractory creep; however, the capacitance contacting extensometer circumvents problems that other techniques inherently possess. The deformation of refractories is frequently measured continuously during compressive creep testing using two (sometimes more) linear variable differential transducers (LVDTs) whose mutual displacement coincide with the continuous position of the specimen ends. The creep results generated from this technique are accurate only as long as the accumulated measured deformation coincides with the actual specimen heights measured before and after testing. Deformation and/or translation of the load train during the creep testing of the specimen, reaction of the specimen ends with the fixturing, and "bedding-down" or intrusion of the specimen into the fixturing all have been shown to cause a lack of correlation between the measured deformation during testing and the change in pre- and post-test specimen height. If any of these 
events are occurring then the measured contraction during testing is not solely due to creep. Consequently, caution must be exercised when interpreting deformation data generated using this LVDT technique because it will only be representative creep data if the experimenter verified and correlated pre- and post-test specimen height with the accumulated measured deformation. The advantage of the contacting extensometers used in the present study is that their accurate operation is independent of any rigid body motion or deformation of the test hardware, specimen (e.g., "end-crushing"), and push rods.

\subsubsection{Specimen Preparation}

Cylindrical test specimens were prepared with the dimensions shown in Figure 4. Each specimen was core-drilled from the supplied mullite bricks in the manner illustrated in Figure 5. The primary axis of each machined cylinder-shaped specimen was oriented parallel to the pressing direction. Although not verified in the present study, the measured creep deformation was assumed to be isotropic, so specimens were not machined from the mullite bricks in different orientations. After core drilling, the ends of each specimen were ground parallel to within $0.013 \mathrm{~mm}(0.001$ inches $)$. All specimens were dried in an oven at $300^{\circ} \mathrm{C}\left(570^{\circ} \mathrm{F}\right)$ for 4 hours after they were core drilled and before they were creep tested.

Using an appropriate aspect ratio of compression test specimens is an important consideration. A specimen aspect ratio of 2.6 or greater is recommended for compressive strength tests so that the friction effects between the specimen ends and loading ram are small compared to the axially applied compressive stresses [9]. However, in the present study (aspect ratio $=2.0$ ), the applied axial compressive stresses during creep testing were already low (i.e., much less than the refractories' compressive strengths). Consequently, the stresses and strains due to such friction were likely negligible, so adherence to the height/diameter ratio of 2.6 or greater was deemed unnecessary. 


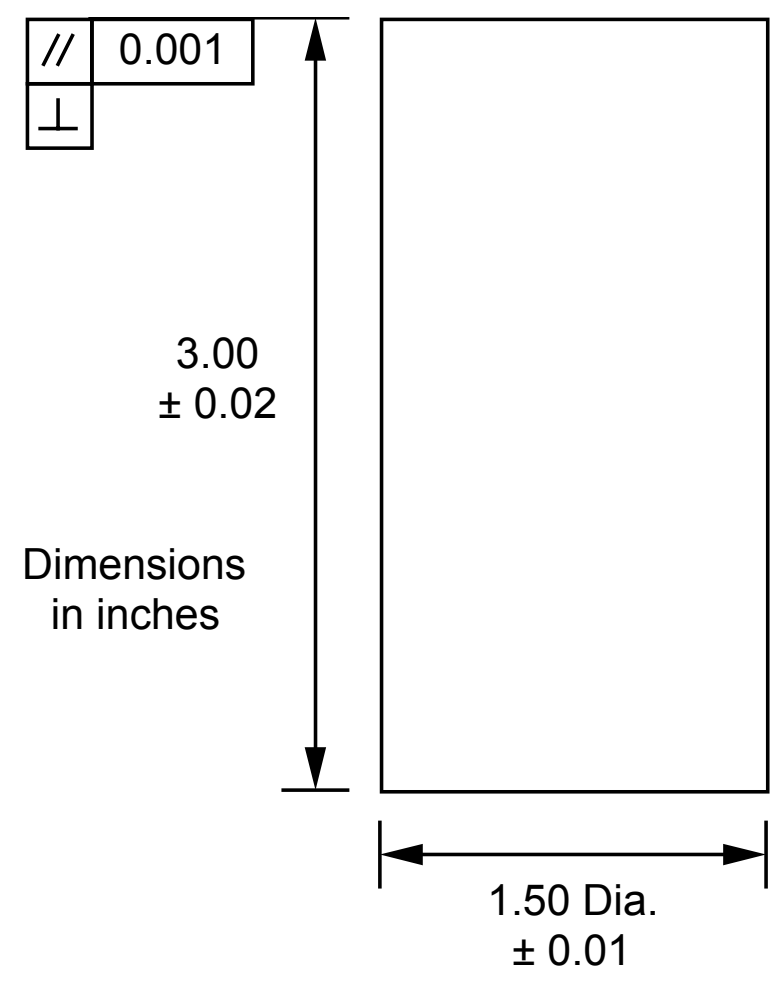

Figure 4. Dimensions of core-drilled test specimens.

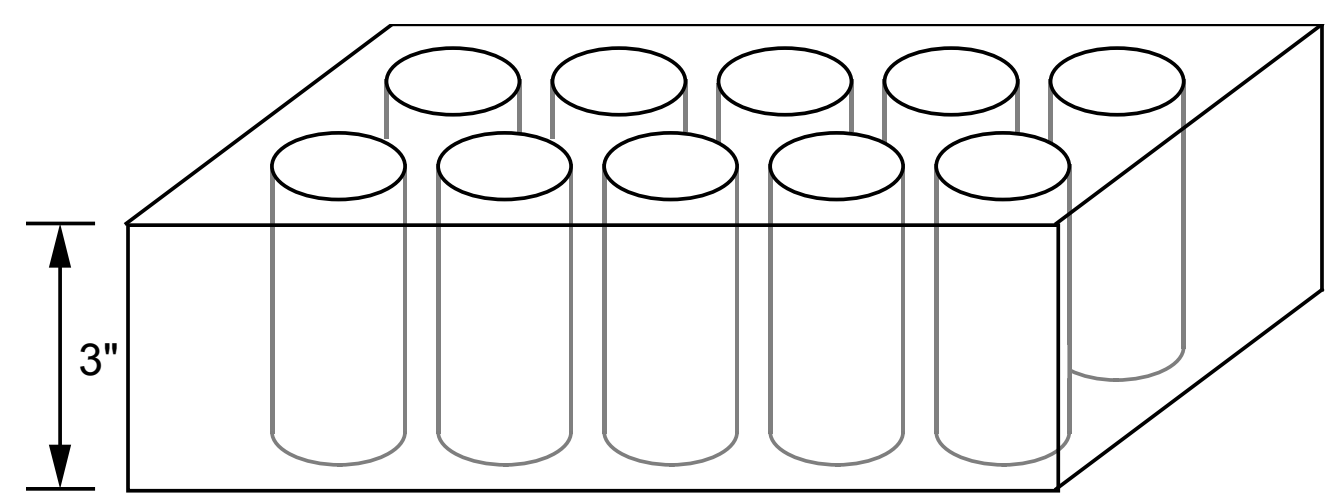

Figure 5. Schematic of how specimens were core-drilled from as-received bricks.

\subsubsection{Test Matrix \& Procedure}

A total of twenty specimens were tested following the test matrix shown in Table 4. Initially, testing was performed at 1300 and $1450^{\circ} \mathrm{C}\left(2370\right.$ and $\left.2640^{\circ} \mathrm{F}\right)$ and stresses of $0.2,0.4$ and 0.6 $\mathrm{MPa}(29,58$, and $87 \mathrm{psi})$, but it was found that little or no creep was measured at the lower temperature and stress combinations. Therefore, subsequent testing was performed at $1375\left(2500^{\circ} \mathrm{F}\right)$ and $1450^{\circ} \mathrm{C}\left(2640^{\circ} \mathrm{F}\right)$ and only at stresses of 0.4 and $0.6 \mathrm{MPa}$. Repeatability of the creep performances was not examined. 
Table 4. Test matrix for creep testing.

\begin{tabular}{|c|c|c|c|}
\hline Refractory & $\begin{array}{c}\mathbf{1 3 0 0}^{\mathbf{}} \mathbf{C} \\
\left.\mathbf{( 2 3 7 0}^{\mathbf{T}} \mathbf{F}\right)\end{array}$ & $\begin{array}{c}\mathbf{1 3 7 5}^{\mathbf{}} \mathbf{C} \\
\mathbf{( 2 5 0 0} \mathbf{F})\end{array}$ & $\begin{array}{c}\mathbf{1 4 5 0}^{\mathbf{0}} \mathbf{C} \\
\mathbf{( 2 6 4 0} \mathbf{F})\end{array}$ \\
\hline BP Mullite & $*$ & $0.4 \& 0.6 \mathrm{MPa}$ & $0.4 \& 0.6 \mathrm{MPa}$ \\
\hline DURITAL S75 & $0.2,0.4 \& 0.6 \mathrm{MPa}$ & $*$ & $0.2,0.4 \& 0.6 \mathrm{MPa}$ \\
\hline Frimul F & $*$ & $0.4 \& 0.6 \mathrm{MPa}$ & $0.4 \& 0.6 \mathrm{MPa}$ \\
\hline GEM & $0.2,0.4 \& 0.6 \mathrm{MPa}$ & $*$ & $0.2,0.4 \& 0.6 \mathrm{MPa}$ \\
\hline HF 17 & $*$ & $0.4 \& 0.6 \mathrm{MPa}$ & $0.4 \& 0.6 \mathrm{MPa}$ \\
\hline MU75AF & $*$ & $0.4 \& 0.6 \mathrm{MPa}$ & $0.4 \& 0.6 \mathrm{MPa}$ \\
\hline SL75AD & $*$ & $0.4 \& 0.6 \mathrm{MPa}$ & $0.4 \& 0.6 \mathrm{MPa}$ \\
\hline UFALA UCR & $*$ & $0.4 \& 0.6 \mathrm{MPa}$ & $0.4 \& 0.6 \mathrm{MPa}$ \\
\hline ZED FMC & $*$ & $0.4 \& 0.6 \mathrm{MPa}$ & $0.4 \& 0.6 \mathrm{MPa}$ \\
\hline ZED FM & $*$ & $0.4 \& 0.6 \mathrm{MPa}$ & $0.4 \& 0.6 \mathrm{MPa}$ \\
\hline
\end{tabular}

$(0.2 \mathrm{MPa}=29.0 \mathrm{psi}, 0.4 \mathrm{MPa}=58.0 \mathrm{psi}, 0.6 \mathrm{MPa}=87 \mathrm{psi})$

The applied stress and temperature histories are illustrated in Figure 6 and Figure 7. All specimens were preloaded in compression to approximately $0.04 \mathrm{MPa}$ ( $\approx 6 \mathrm{psi}$ ) during furnace heat-up to keep all the load train components and the specimen in continuous contact. The specimens were then heated from room temperature up to the test temperature in 4 hours. Each of the specimens was soaked at temperature for 25 hours prior to the application of the first stress. Initial specimens were loaded sequentially at three stresses: 0.2, 0.4, and 0.6 MPa (29, 58, and $87 \mathrm{psi}$ ) with a 75 hour hold at each level. As discussed above, due to the lack of creep at the lowest stress of $0.2 \mathrm{MPa}$, this stress regime was dropped from testing. Subsequent specimens were only loaded at two stresses: 0.4 and $0.6 \mathrm{MPa}$ (58 and $87 \mathrm{psi}$ ) with a 75 hour hold at each level. Creep strain was measured as a function of stress, time, and temperature using the previously described extensometers and computer data acquisition system. 


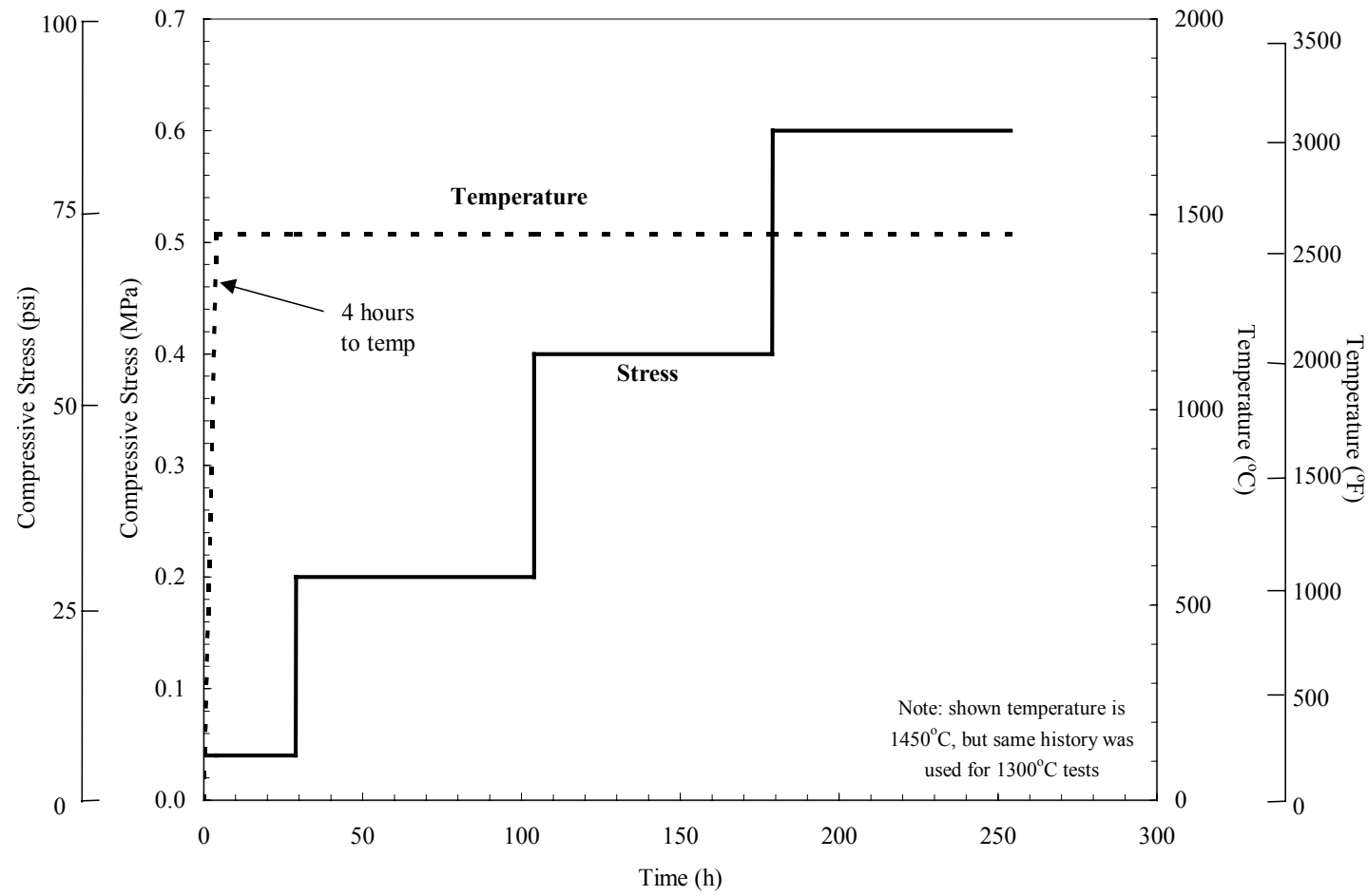

Figure 6. Temperature and stress history used in initial creep testing.

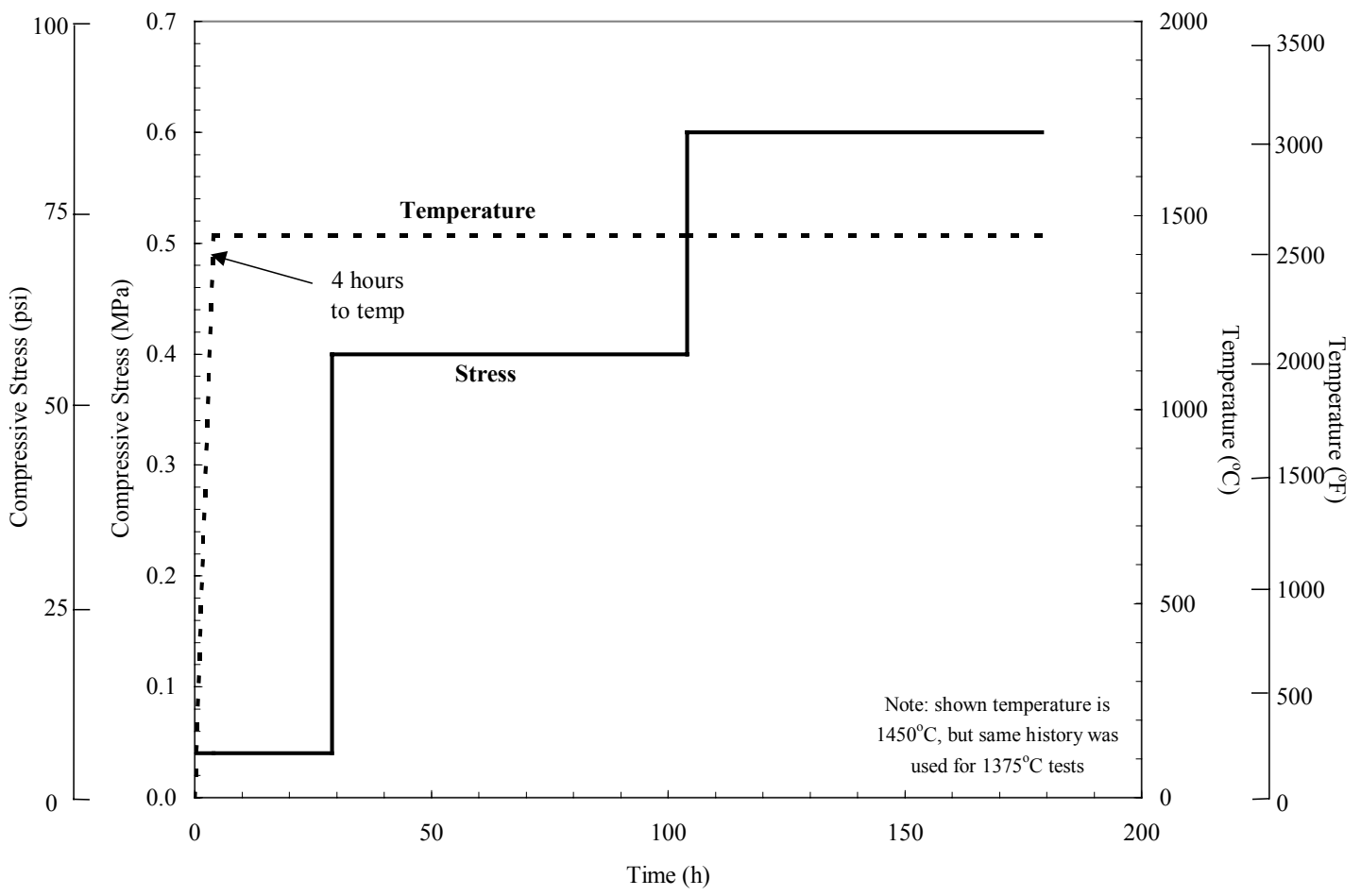

Figure 7. Temperature and stress history used in subsequent creep testing. 
There are load testing protocols for refractories [6],[10], but they were not strictly adhered to here for the reasons that follow. The testing procedure used in the present study either circumvents some of the shortcomings of those tests, or involves the testing of more creep resistant refractory materials at higher temperatures. The "Standard Test Method for Load Testing Refractory Brick at High Temperatures" [10] involves loading a refractory brick for a prescribed duration and temperature and then determining the material's resistance to deformation by comparing its before- and after-test axial dimension. A shortcoming of this test is the introduction of error in the analysis if the refractory brick's ends "bed-down." The procedures and equipment recommended in the "Standard Test Method of Measuring the Thermal Expansion and Creep of Refractories Under Load" [6] are similar to those used in the present study. A shortcoming of this procedure involves the recommended measurement of dimensional change in the creep specimen. The use of LVDTs to measure the contraction of the specimen ends is advocated but can be problematic for reasons described in Section 3.2.1. The extensometry system described in Figure 2 of ASTM C832 [6] closely matches the extensometry system used in the present study; however, in the present study a capacitance gage is used while in the standard the use of a LVDT for the measurement is shown. The load that activates an LVDT can be enough to affect the intimacy of the extensometer contact with the specimen and yield a misleading creep measurement if there is insufficient horizontal load applied to the specimen. Because of its differing operating principle, the capacitance gage on the extensometry systems used in the present study requires no load for activation and does not introduce uncertainties associated with the horizontal load and the use of a LVDT.

\subsubsection{Data Interpretation}

Most creep analyses for long-term applications (i.e., where steady state creep accumulation dominates the accumulation of strain, not the amount of primary creep) involve the determination of a steady-state or minimum creep rate and its examination as a function of applied stress and temperature. The steady-state or minimum compressive creep rate $\left(\mathrm{d} \varepsilon / \mathrm{dt}_{\min }\right)$ can be related to the applied compressive stress and temperature using an empirical Arrhenius power law or the familiar Norton-Bailey creep equation [11]: 


$$
\mathrm{d} \varepsilon / \mathrm{dt}_{\min }=\mathrm{A} \sigma^{\mathrm{n}} \exp (-\mathrm{Q} / \mathrm{RT})
$$

where $\mathrm{A}$ is a constant, $\sigma$ is the applied stress, $\mathrm{n}$ is the stress exponent, $\mathrm{Q}$ is the activation energy, $\mathrm{R}$ is the universal gas constant, and $\mathrm{T}$ is the absolute temperature. Multilinear regression may be performed to determine the constants $\mathrm{A}, \mathrm{n}$, and $\mathrm{Q}$ for each material. By performing the analysis in this manner, it is implied that the same dominant (or rate-controlling) creep mechanism is active at all temperatures and stresses. The validity of this assumption is assessed by the qualityof-fit of this equation to the experimental data and the reasonableness of the obtained values for $\mathrm{n}$ and $\mathrm{Q}$.

An example of this analysis is demonstrated using compressive creep data of a $\mathrm{MgO}$ refractory [12]. Compressive creep strain as a function of stress and time is shown in Figure 8 for a $96.1 \% \mathrm{MgO}$ refractory tested at $1550^{\circ} \mathrm{C}\left(2820^{\circ} \mathrm{F}\right)$ that is used as checker packing in furnace regenerators.

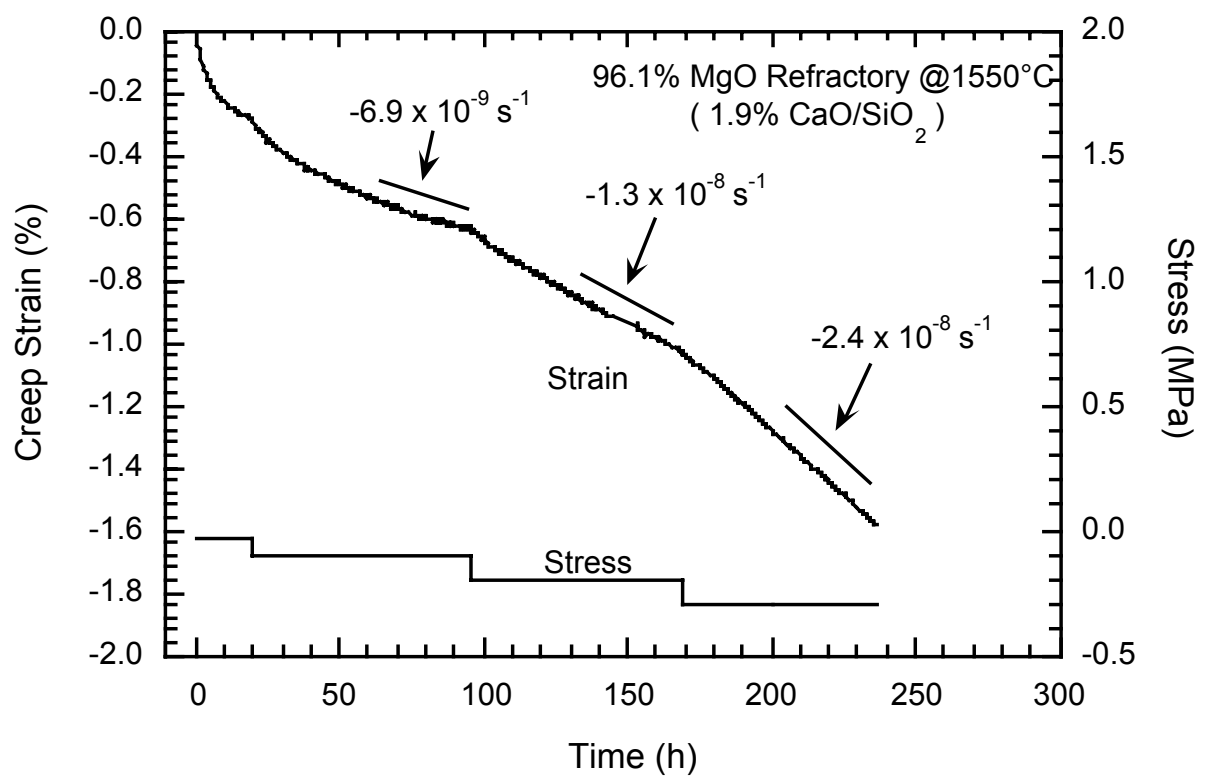

Figure 8. Example of a compressive creep curve (creep strain as a function of stress and time) and the determinations of creep rate [12].

The steady-state or minimum creep rate is then determined and related to the applied stress and temperature. If more than one temperature is used for the creep tests, then these creep rate data may be applied to Eq. 1 (see Figure 9). Such data may then be used by superstructure designers to calculate (interpolate) any creep rate as a function of stress and temperature: this allows for 
superstructure design optimization and its prediction of time-dependent mechanical integrity. A goal of the present study was to determine such creep rate data for each examined mullite refractory.

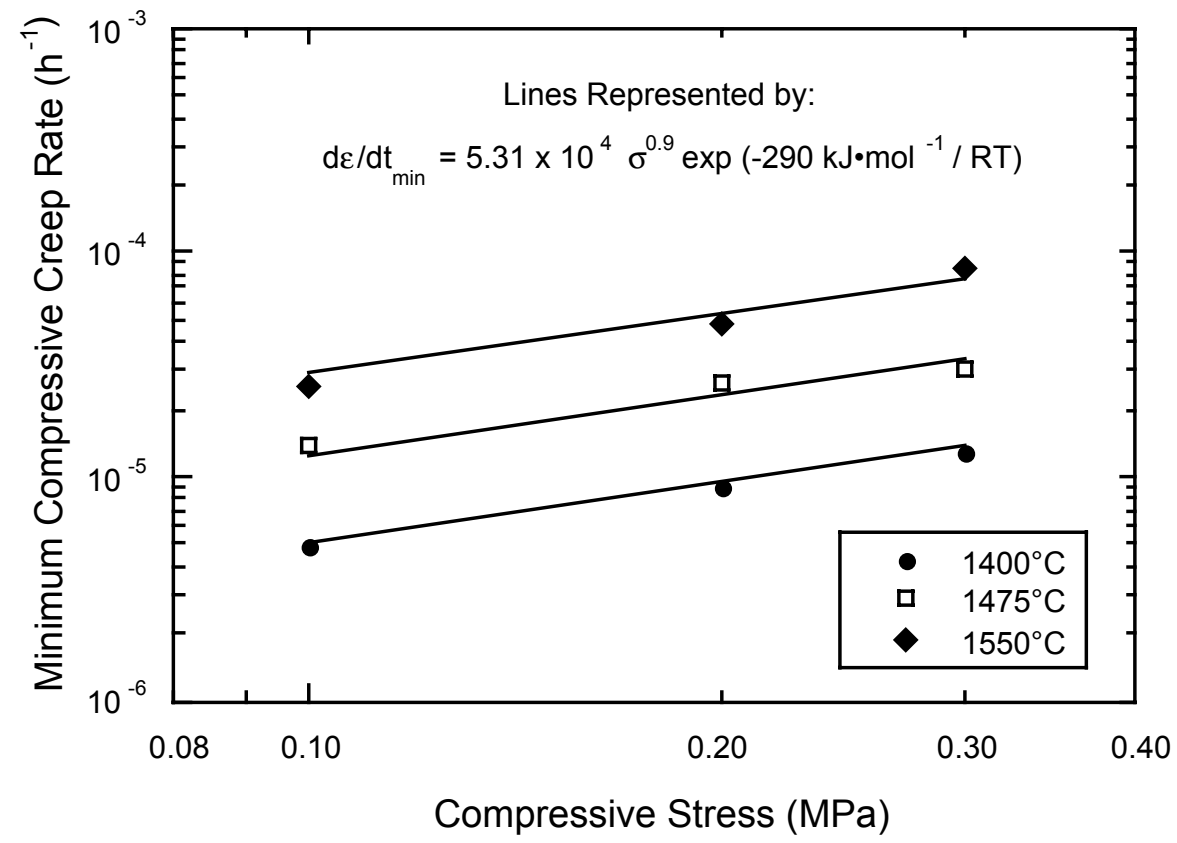

Figure 9. Example of an empirical power-law representation (Eq. 1) of creep rate as a function of stress and temperature [12].

\subsection{CORROSION TESTING}

Corrosion of the ten mullite refractories was evaluated using the ASTM "lid test" [13]. A refractory specimen $(2.5 \mathrm{~cm} \times 2.5 \mathrm{~cm} \times 1 \mathrm{~cm})$ sectioned from the as-received mullite bricks was placed over a small alumina crucible containing $12.5 \mathrm{~g}$ of sodium carbonate. The crucible and "lid" refractory specimen were then placed in a secondary alumina container and isothermally exposed at $1400^{\circ} \mathrm{C}$ for $24 \mathrm{~h}$. After exposure, samples were removed and examined for recession.

\subsection{BULK CHARACTERISTICS (PRE- AND POST-CREEP TESTING)}

Supplemental efforts were performed to characterize some physical and chemical properties of the mullite refractories. The phase content, microstructure (as revealed by reflected light and cathodoluminescent imaging), and secondary phase composition of each brand before and after testing were measured or characterized. Bulk density, volume, and weight changes due 
to temperature exposure were additionally examined (in the absence of stress) with each of the ten mullite refractories.

\subsubsection{Bulk Densities}

The bulk densities of various core-drilled specimens were measured prior to creep testing with the masses being measured using a balance that had a resolution of $\pm 0.0005 \mathrm{~g}$. The masses were then divided by the respective specimens' volumes (diameters and lengths measured with calipers having a resolution of $\pm 0.005 \mathrm{~mm}$ ) to calculate density. Each mullite brick yielded 4 to 5 specimens, so the average bulk density for each brick was calculated using the values from these specimens.

\subsubsection{Thermal Conductivity}

Room temperature thermal conductivity of the "as-received" bricks was measured by a transient plane source (TPS) technique using the "hot-disk" arrangement [14]. In this arrangement, a Kapton transient plane source element was used as both a heat source and a temperature sensor to measure the time required to conduct a known amount of heat across a prescribed distance of sample. Measurements were taken in the "standard method" by sandwiching the Kapton element between two identical cylindrical creep specimens and passing 1 Watt of power through the sample for 20 seconds. Five measurements were taken on each specimen type with 15 minutes or longer between measurements. The specimen configuration along with the sensor itself is shown in Figure 10.
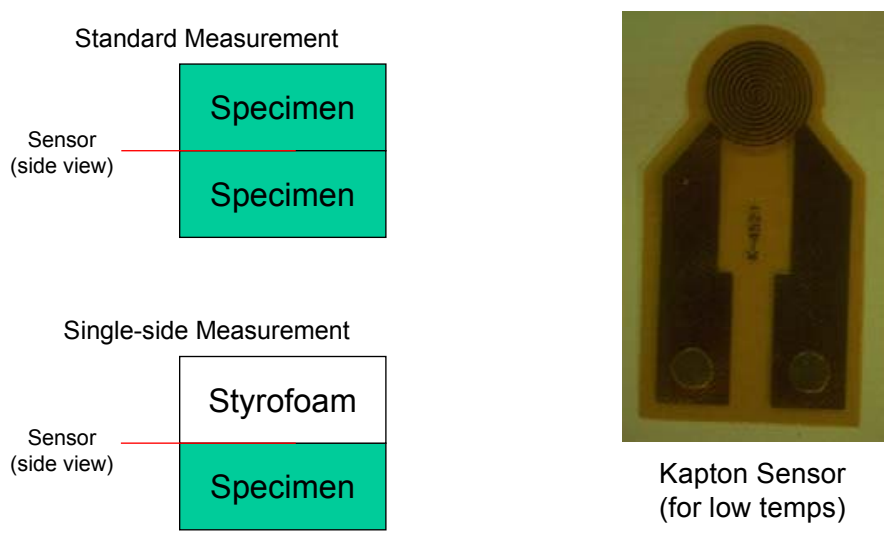

Figure 10 Schematic of Transient Plane Source (TPS) direct thermal conductivity method experimental set-up and picture of Kapton sensor. 


\subsubsection{Crystalline Phases}

The phase content of the materials in their "as-received" state was characterized and compared with that after creep testing at $1450^{\circ} \mathrm{C}$. Specimen preparation involved grinding the mullite refractory to approximately 325 mesh in an agate mortar and pestle.

X-ray diffraction (XRD) was performed with all ten mullite materials using a Scintag 2000 diffractometer. The samples were scanned at a rate of $1 \%$ min with $\mathrm{Cu}-\mathrm{K}_{\alpha}$ radiation $(\lambda=1.54059 \AA)$, and a step size of $0.02^{\circ}$ over a scan range of 10 to $120^{\circ}$ two-theta.

\subsubsection{Microstructures}

Disks were sectioned from core-drilled "as-received" specimens, as well as from specimens crept at $1450^{\circ} \mathrm{C}$, in preparation for reflected light (RL) and cathodoluminescent (CL) imaging. Disks were cut from the top of each "as-received" specimen as shown in Figure 11 while disks were sectioned from crept specimens in their centers as shown in Figure 12.

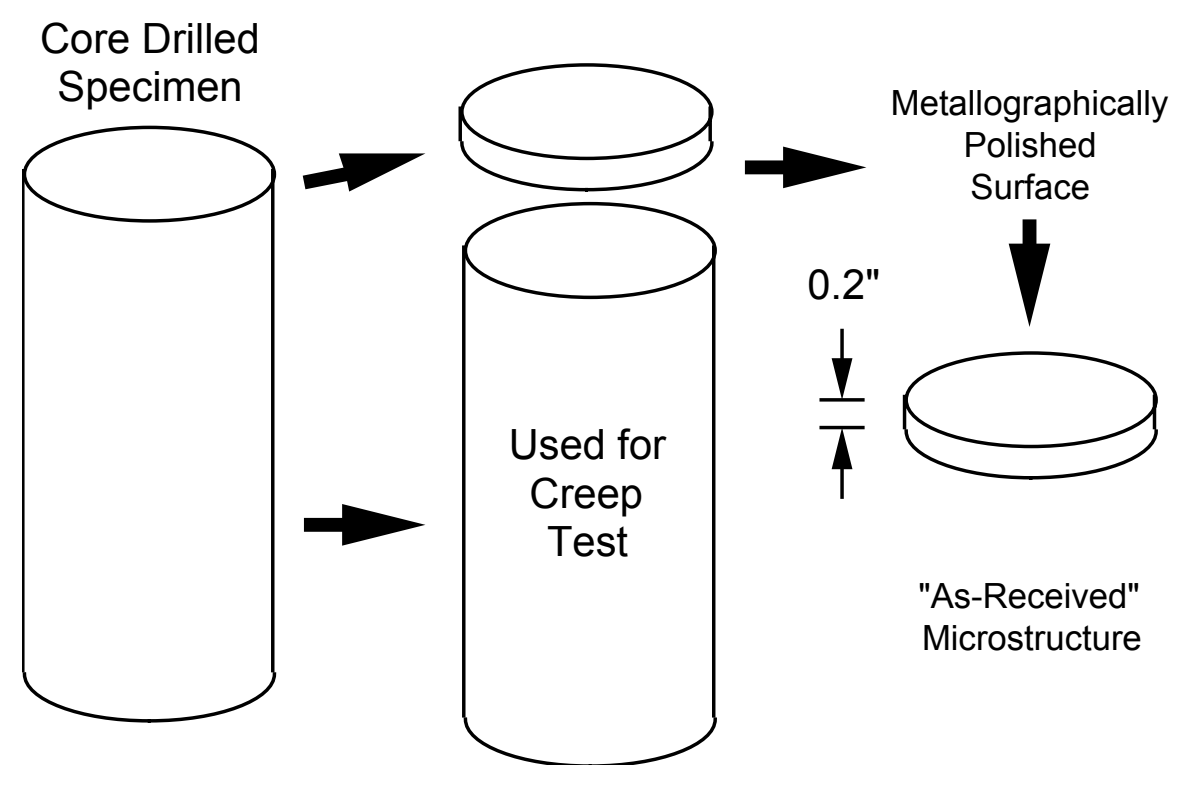

Figure 11. Schematic describing how disk sections were machined from core drilled specimens for "as-received" RL and CL imaging. 


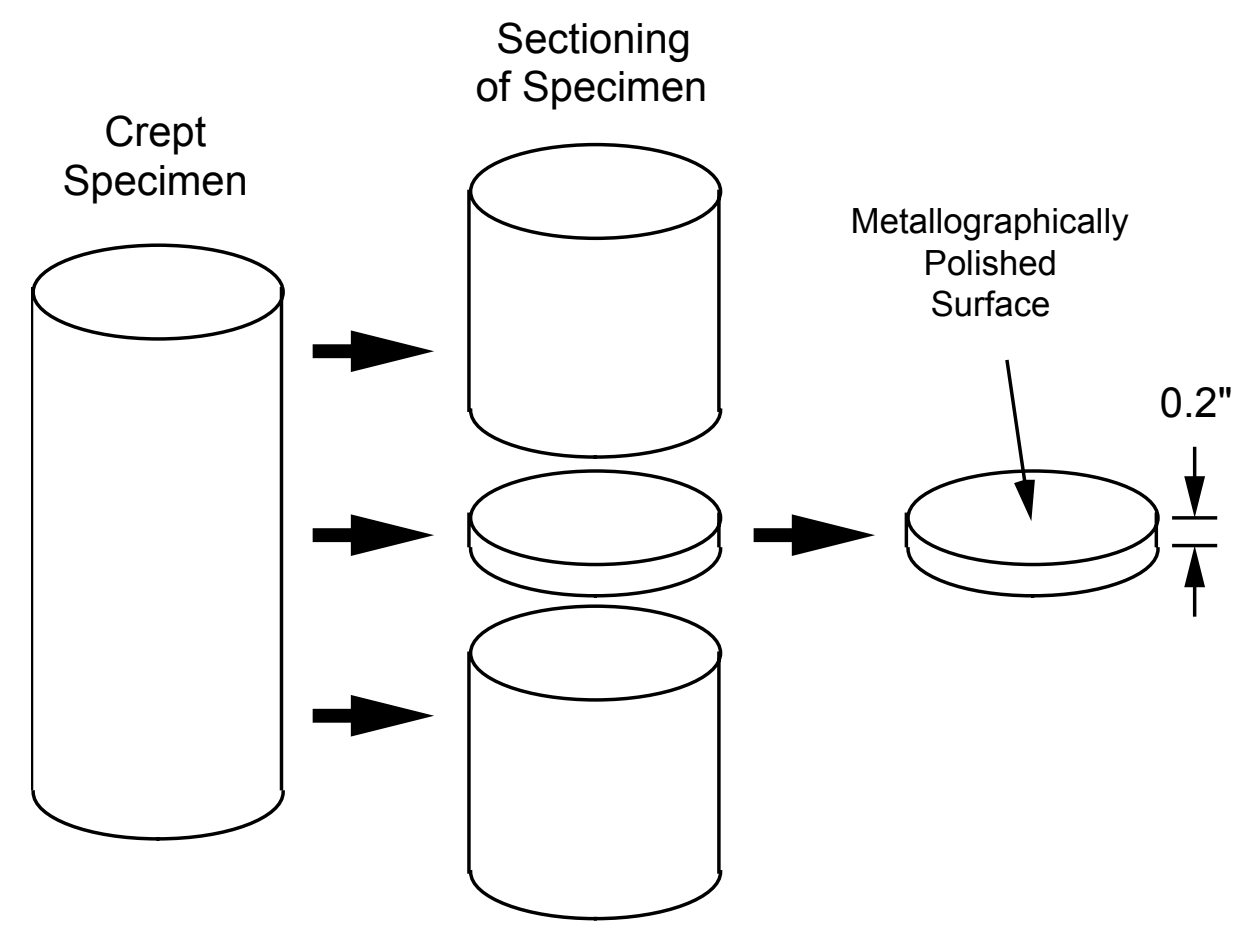

Figure 12. Schematic describing how disk sections were machined from crept specimens for post-testing RL and CL imaging.

The disk sections were polished using the following procedures in preparation for microscopy. The disks were cleaned, dried and then impregnated with a low viscosity resin to fill the pores. The impregnated specimens were then mounted on a Co-Cast mounting media. Cured sections were ground with diamond wheels down to 600 grit, and then finally polished with diamond paste and lapping oil.

RL and CL microscopy were utilized for the characterization. A cold-cathode CL microscopy system (Model Mk4, Cambridge Imaging Technology, Cambridge, UK) mounted on a standard Nikon petrographic microscope (Model Labophot-Pol with a Nikon UFX-DX photomicrographic system) was used for these microstructural analyses.

The CL microscopy characterization technique has been described in detail by Karakus and Moore [15], but is briefly described here. The CL imaging system utilizes an energetic electron beam that is produced from a cold cathode ray tube. The electron beam is trained on the surface of uncovered polished or unpolished specimens in a low vacuum environment. As a result of the electron beam-solid specimen interaction, minerals or phases in the specimen produce characteristic colored light known as "cathodoluminescent" emission. The CL 
technique is unique and provides microstructural information that often cannot be obtained by any other technique. The CL microscopy system can provide immediate assessment of the phases in refractory materials through the identification of characteristic CL color and crystal habits that minerals exhibit. The CL microscopy system can also be used in conjunction with RL and SEM for elemental analysis of individual phases.

Certain minerals produce characteristic CL color. For example, corundum $\left(\alpha-\mathrm{Al}_{2} \mathrm{O}_{3}\right)$ is characterized by a characteristic bright red CL color while spinel $\left(\mathrm{MgAl}_{2} \mathrm{O}_{4}\right)$ produces a characteristic green color. These CL emissions are due to "activator" elements present in trace amounts in these mineral structures; $\mathrm{Cr}^{3+}$ in corundum produces a characteristic $\mathrm{CL}$ emission at approximately $694 \mathrm{~nm}$ and tetrahedrally coordinated $\mathrm{Mn}^{2+}$ in spinel produces a CL emission at approximately $520 \mathrm{~nm}$. Activator elements related to CL emission centers in these minerals often require low voltages $(\approx 8 \mathrm{kV})$ for excitation.

Important for the materials analyzed in this study are the CL behavior of mullite, alumina, and silica grains along with that of the glassy matrix phase. Regular mullite grains do not produce bright CL but rather exhibit a dull response. Contrary to this, fused mullite grains produce intense dark blue or violet CL. Secondary mullite bonds between primary fused mullite grains can produce intense violet reddish CL distinguishing them from primary mullite. Fused alumina grains exhibit very bright violet blue CL, while tabular alumina grains appear as an intense violet. Andalusite grains give off dark reddish CL and zirconia blue-white CL.

\subsubsection{SEM/EDS}

Scanning electron microscopy (SEM) with electron dispersive spectroscopy (EDS) was used to further characterize the ten "as-received" mullite refractories. A JEOL T330 SEM with Kevex EDS system was used.

\subsection{EFFECT OF TEMPERATURE (“AGING” STUDY)}

To determine dimensional stability due entirely to exposure at temperature, prismatic bars from each mullite refractory (10 total specimens) were prepared and each was subjected to a temperature regime that was equivalent to times and temperatures to which the creep specimens were subjected. Dimensions of these bars are shown in Figure 13 with the 2" length of the 
specimen being oriented parallel to each brick's pressing direction. These specimens were dried in an oven at $300^{\circ} \mathrm{C}\left(570^{\circ} \mathrm{F}\right)$ for 4 hours after they were machined and before they were aged. The aging procedure consisted of the following. Ten specimens (one of each material) were heated to $1375^{\circ} \mathrm{C}$ in 4 hours. They were then soaked at temperature for 25 hours and then the furnace was cooled to ambient temperature. The specimens were then removed, weighed and their dimensions measured before being put back in the furnace and being reheated to $1375^{\circ} \mathrm{C}$ in 4 hours. They were then soaked for an additional 75 hours (100 cumulative hours) and then the furnace was again cooled to ambient temperature. The cooled specimens were reweighed and the dimensions were remeasured. The mass and dimensions (volume) of the bars were measured. Density was then calculated and analyzed as a function of cumulative time and temperature.

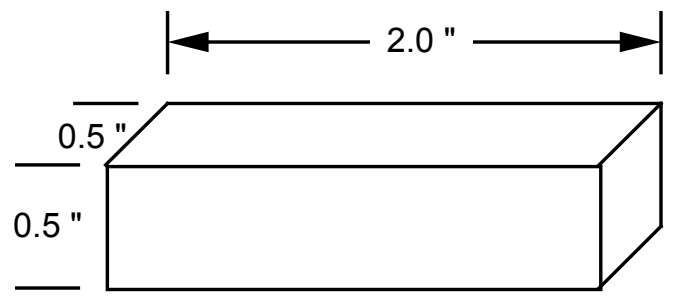

Figure 13. Schematic of specimens used for the "aging" study.

\section{RESULTS AND DISCUSSION}

\subsection{COMPRESSIVE CREEP PERFORMANCE}

The results from creep testing are shown below in Figure 14 through Figure 23. The amount of compressive creep for the various refractories fell into three levels. BP Mullite, DURITAL S75, and Frimul F all showed low amounts of creep at temperatures between 1300$1450^{\circ} \mathrm{C}\left(2370-2640^{\circ} \mathrm{F}\right)$ and at compressive stresses between 0.2 and $0.6 \mathrm{MPa}(29-57 \mathrm{psi})$. Creep rates for these brands were found to be on the order of $10^{-11} \mathrm{~s}^{-1}$ at the lower test temperature and $10^{-10} \mathrm{~s}^{-1}$ at the higher test temperature. Slightly greater amounts of creep were seen in the GEM, $\mathrm{HF} 17, \mathrm{MU} 75 \mathrm{AF}$, and ZED FM brands at temperatures between $1300-1450^{\circ} \mathrm{C}\left(2370-2640^{\circ} \mathrm{F}\right)$ and at compressive stresses between 0.2 and $0.6 \mathrm{MPa}$ (29-57 psi). ). Creep rates for these refractories were found to be on the order of $10^{-10} \mathrm{~s}^{-1}$ at the lower test temperature and $10^{-9} \mathrm{~s}^{-1}$ at the higher test temperature. The SL75AD, UFALA UCR, and ZED FMC brands all showed 
significant amounts of creep at temperatures between $1375-1450^{\circ} \mathrm{C}\left(2500-2640^{\circ} \mathrm{F}\right)$ and at compressive stresses between 0.4 and $0.6 \mathrm{MPa}$ (58-87 psi). Creep rates for these brands were on the order of $10^{-9} \mathrm{~s}^{-1}$ at the lower test temperature and $10^{-8} \mathrm{~s}^{-1}$ at the higher test temperature. Since only one specimen per condition was tested, the authors were unable to statistically conclude that any one of the refractories in each group had superior creep resistance to the others. If differences do exist within a grouping, they are believed to be insignificant.
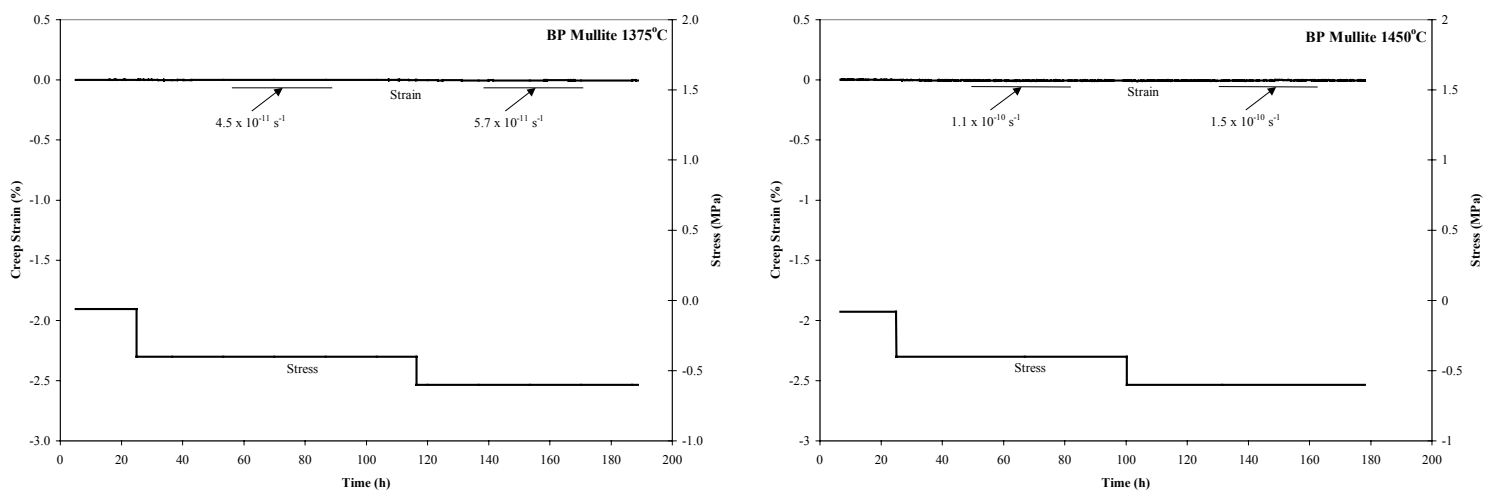

Figure 14. Creep Behavior of BP Mullite as a function of temperature and stress.
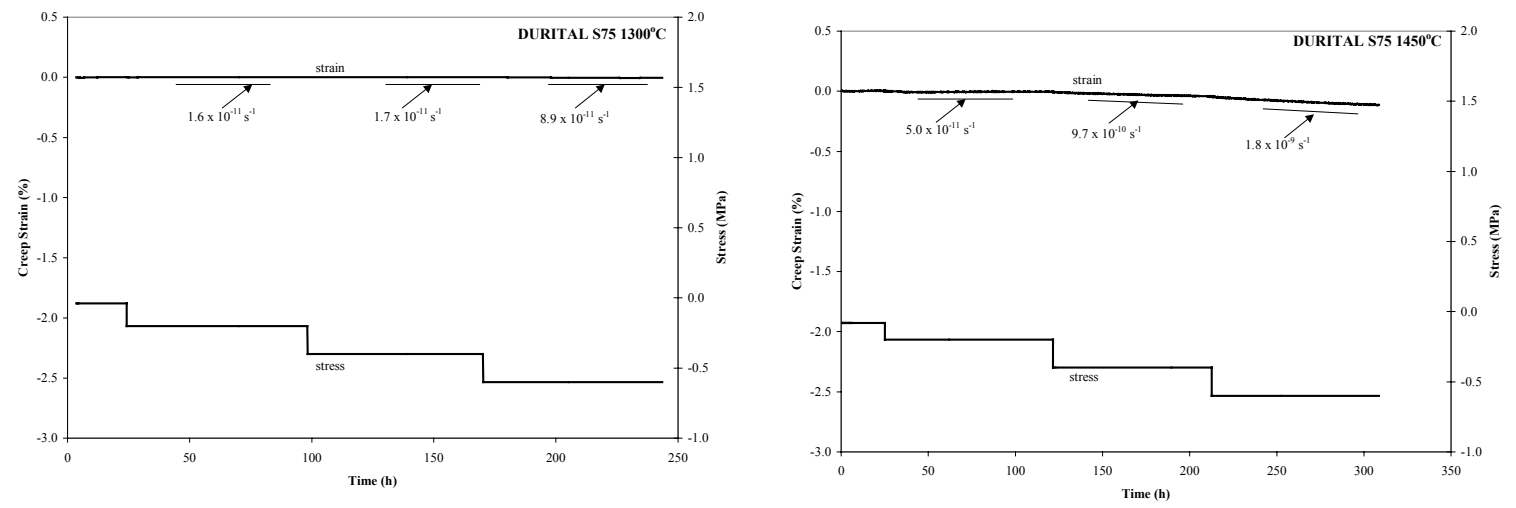

Figure 15. Creep Behavior of DURITAL S75 as a function of temperature and stress.
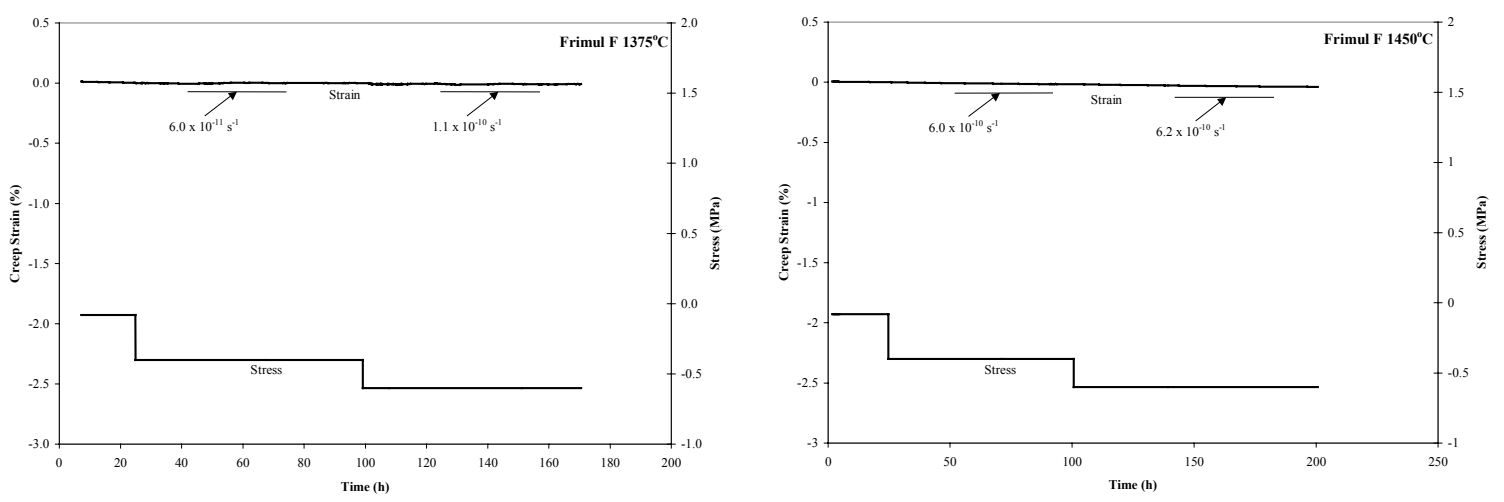

Figure 16. Creep Behavior of Frimul $\mathrm{F}$ as a function of temperature. 

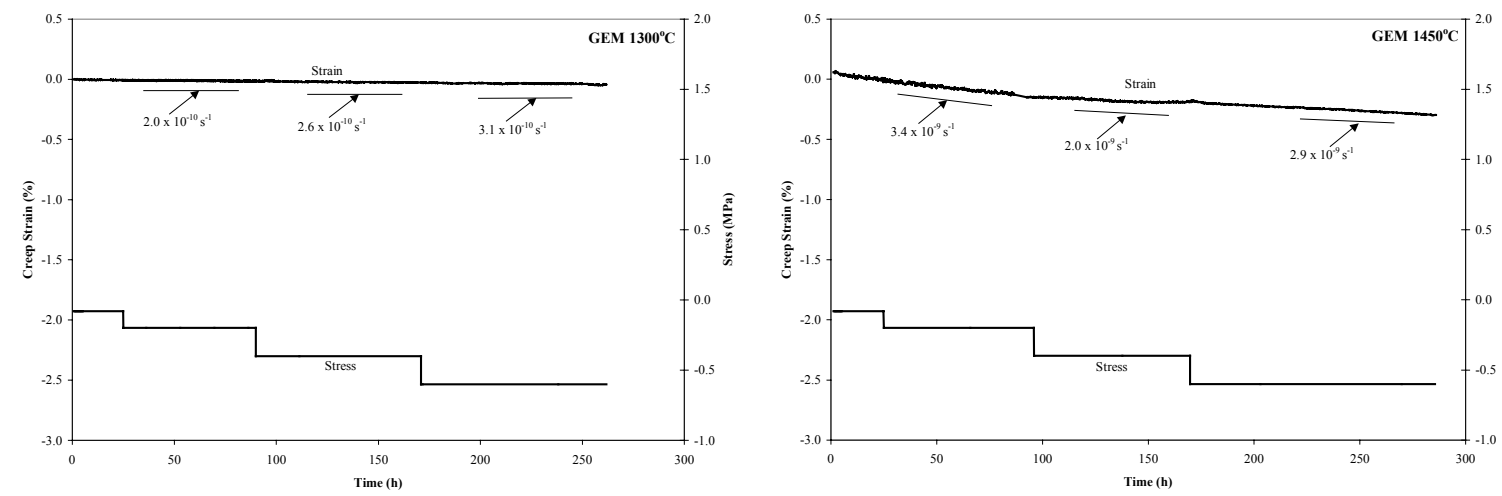

Figure 17. Creep Behavior of GEM as a function of temperature.
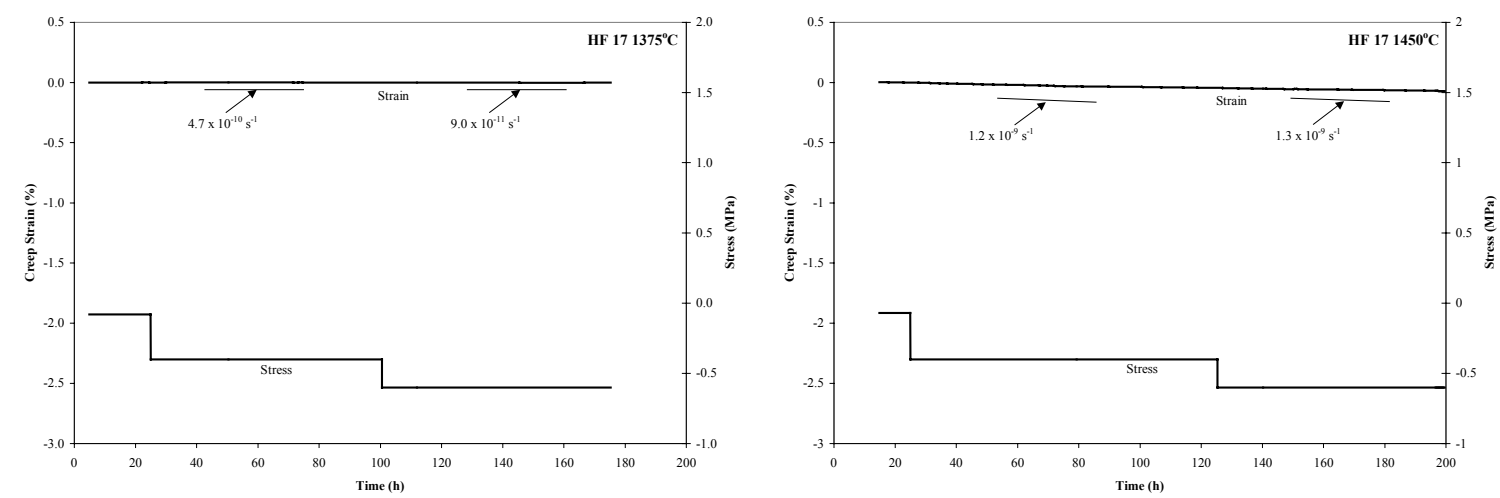

Figure 18. Creep Behavior of HF 17 as a function of temperature.
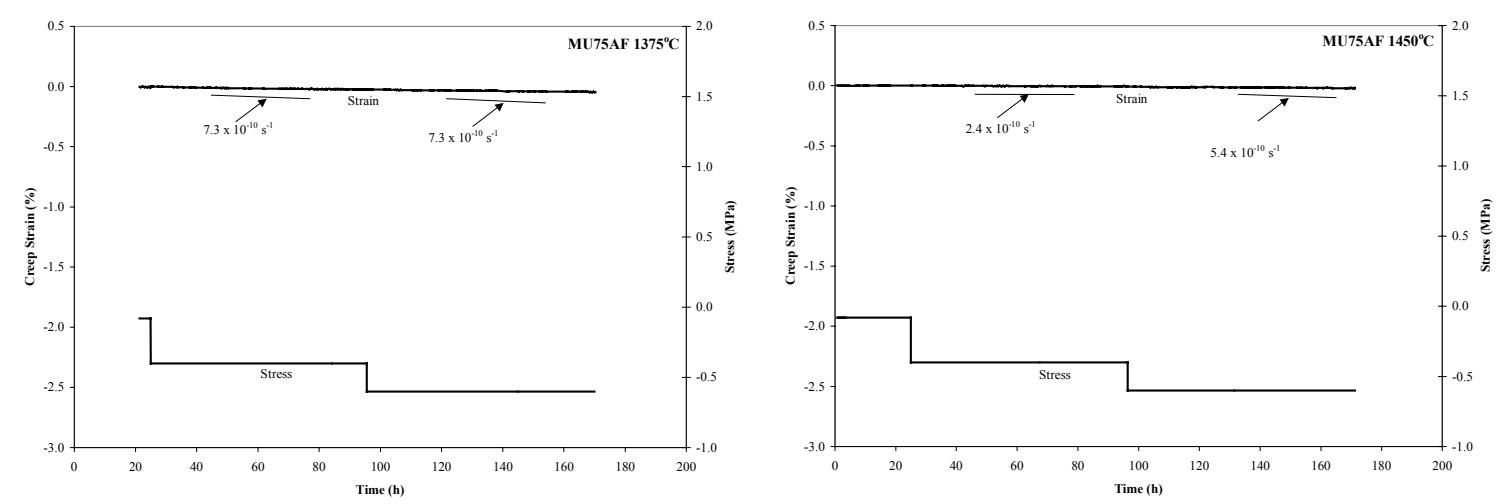

Figure 19. Creep Behavior of MU75AF as a function of temperature. 

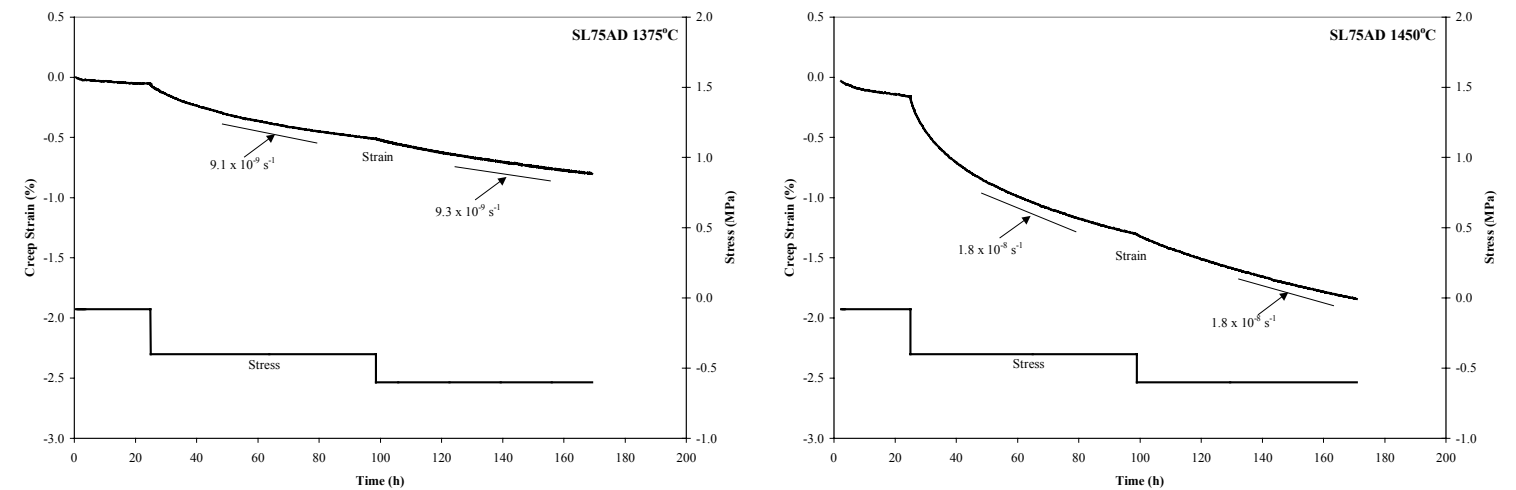

Figure 20. Creep Behavior of SL75AD as a function of temperature.
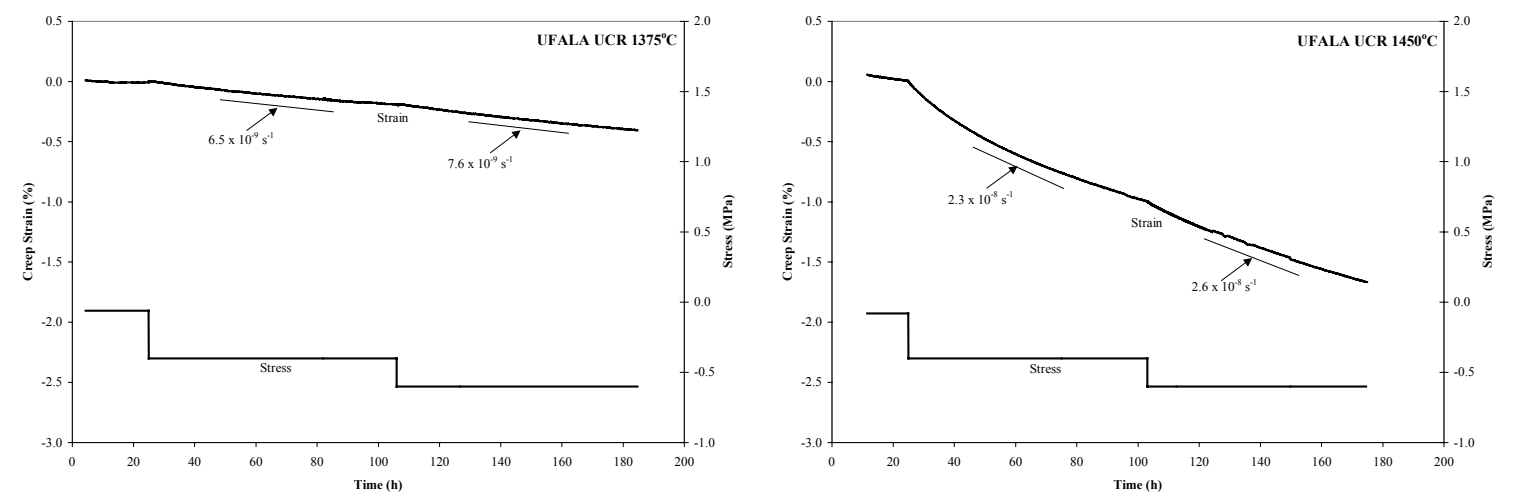

Figure 21. Creep Behavior of UFALA UCR as a function of temperature.
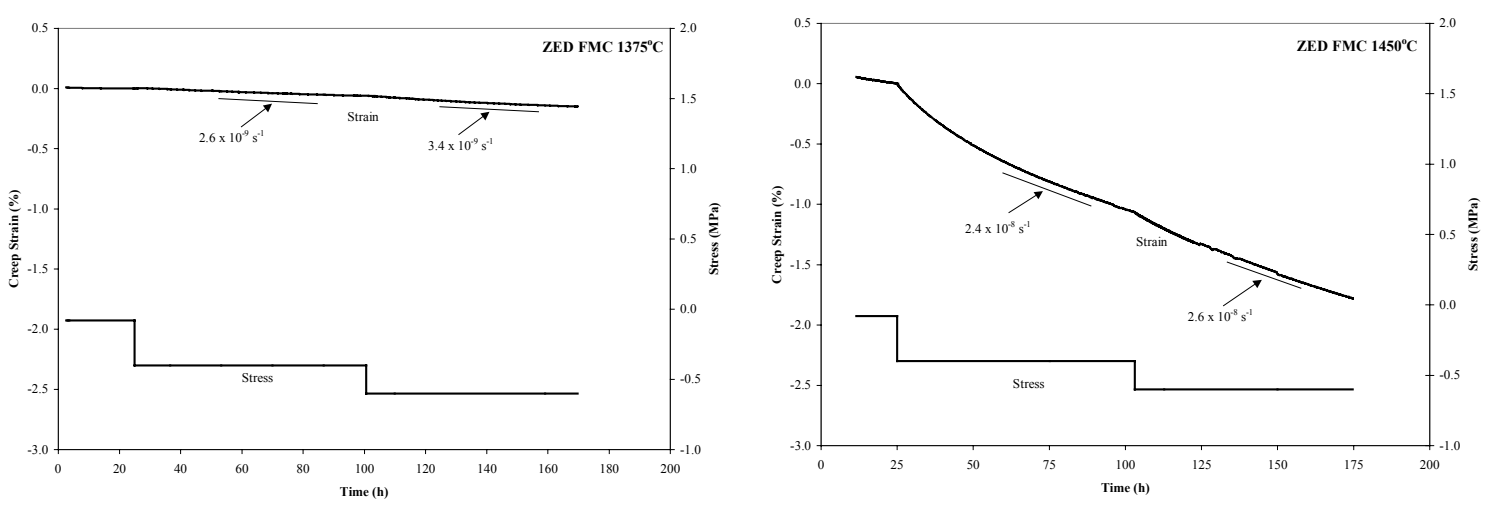

Figure 22. Creep Behavior of ZED FMC as a function of temperature. 

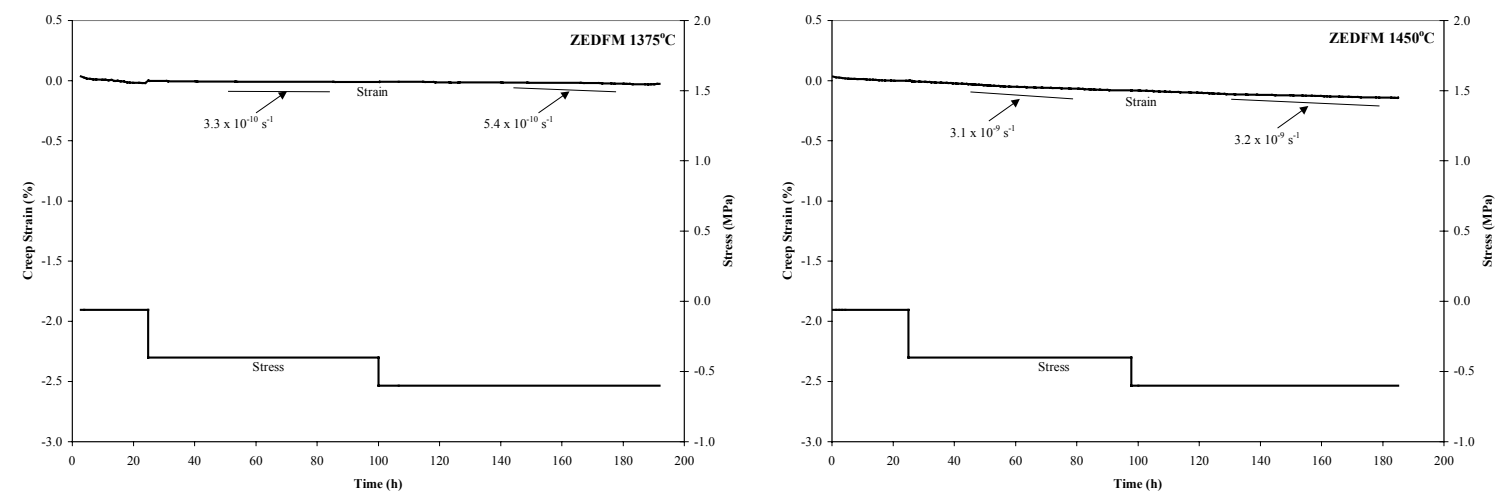

Figure 23. Creep Behavior of ZED FM as a function of temperature.

The constants of the Norton-Bailey creep equation were found for each brand through multilinear regression of the creep data as described previously in Section 3.2.4. The results are shown in Figure 24 through Figure 33 and are summarized in Table 5.

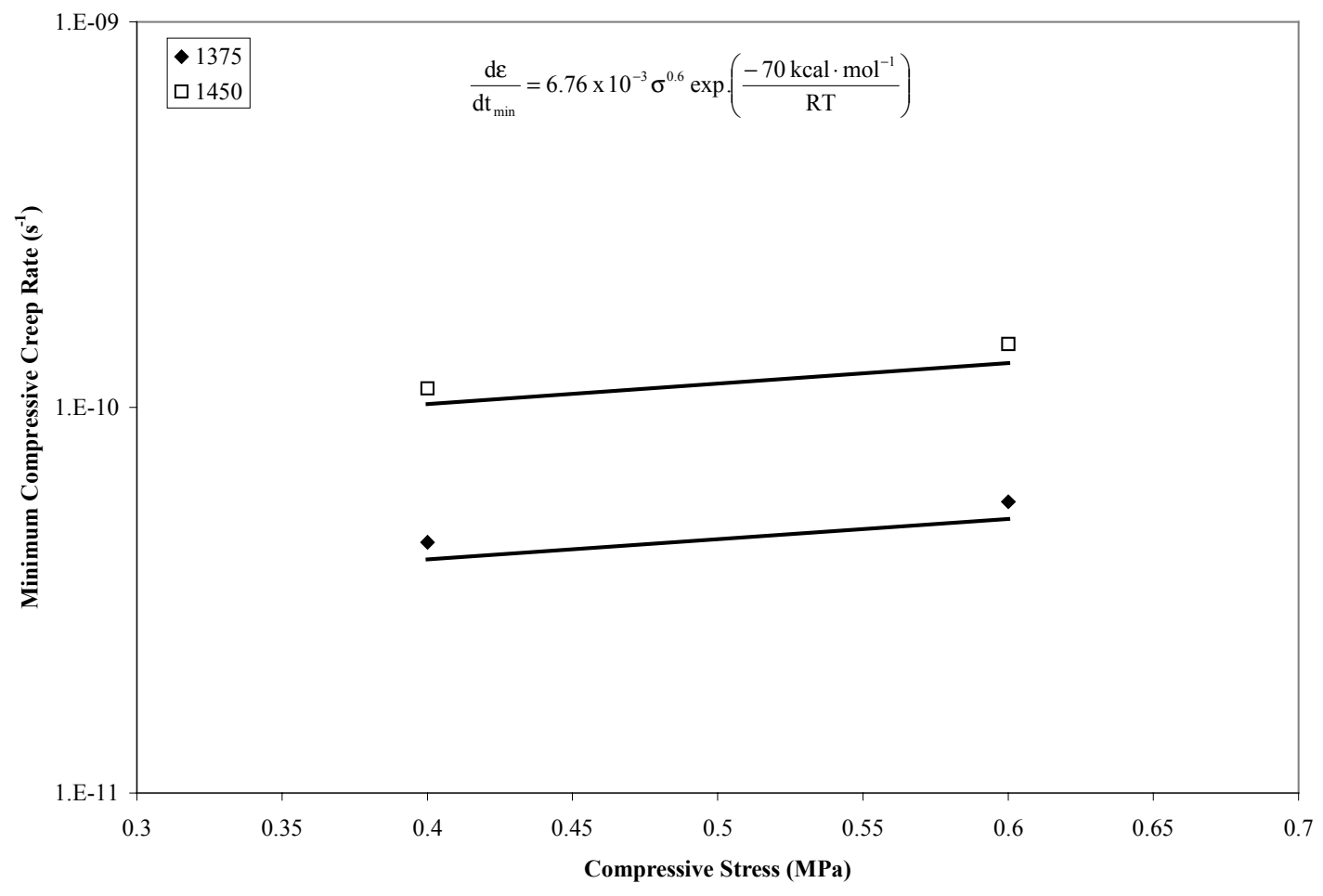

Figure 24. Empirical power-law representation of BP Mullite as a function of stress and temperature. 


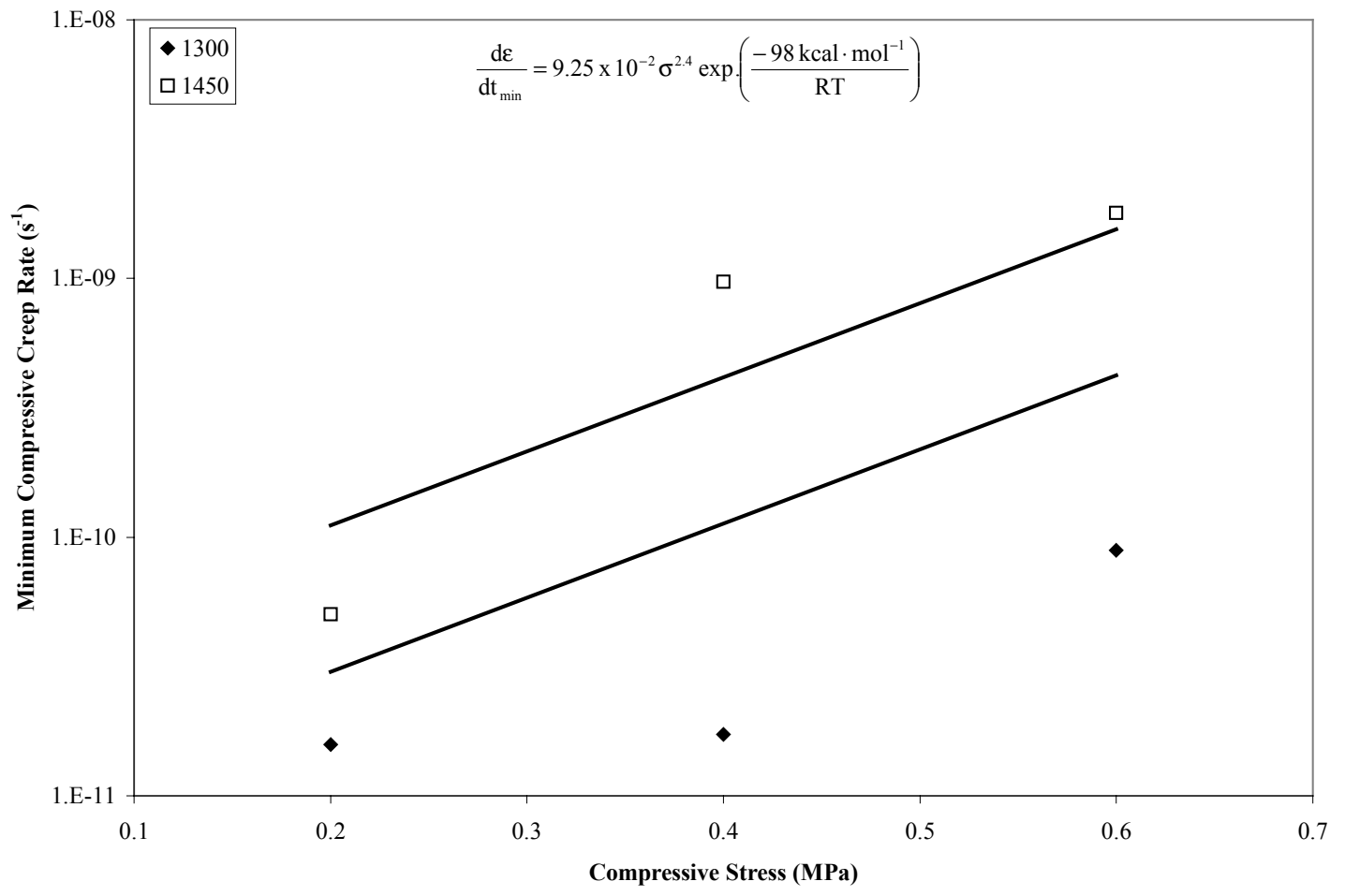

Figure 25. Empirical power-law representation of DURITAL S75 as a function of stress and temperature.

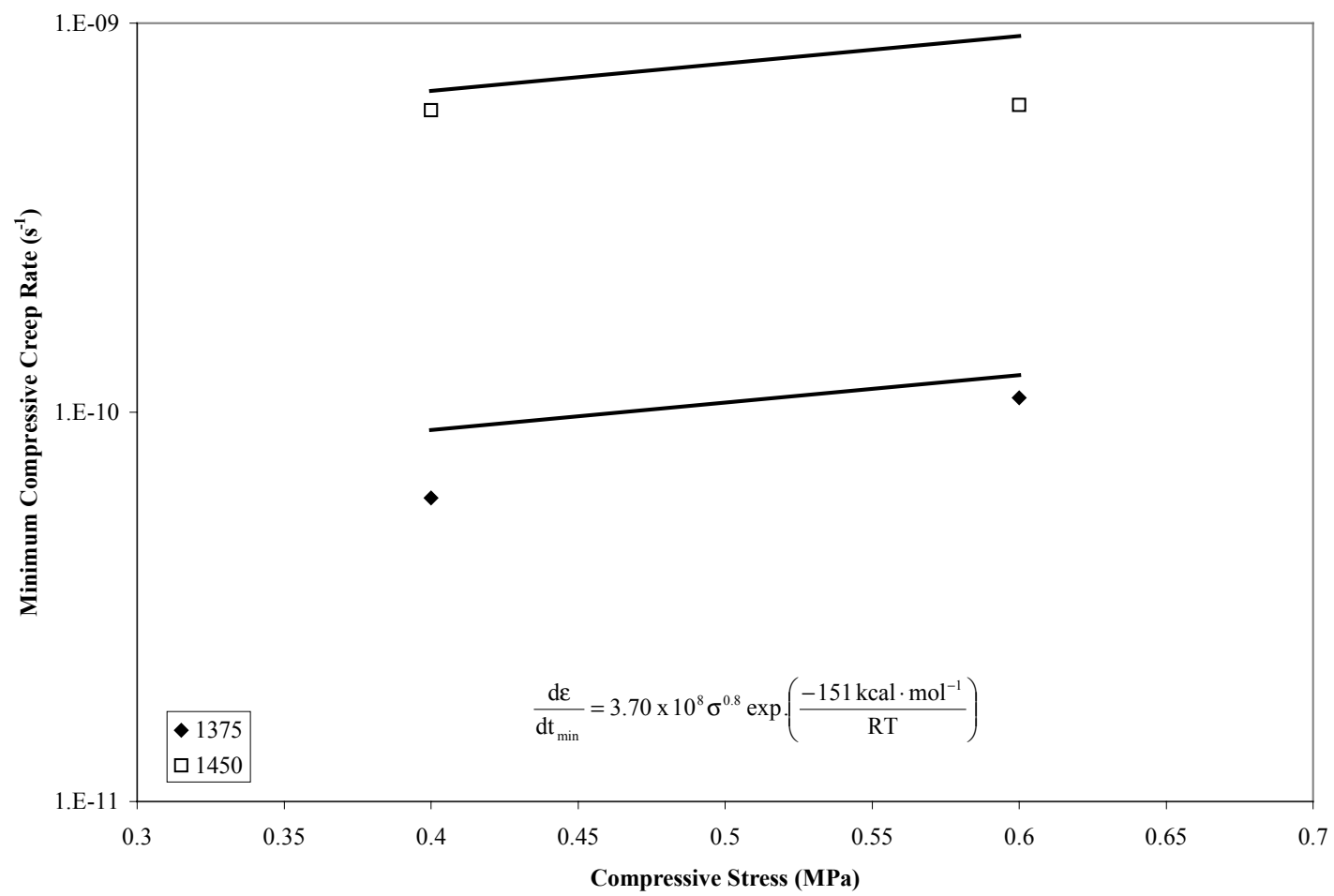

Figure 26. Empirical power-law representation of Frimul $\mathrm{F}$ as a function of stress and temperature. 


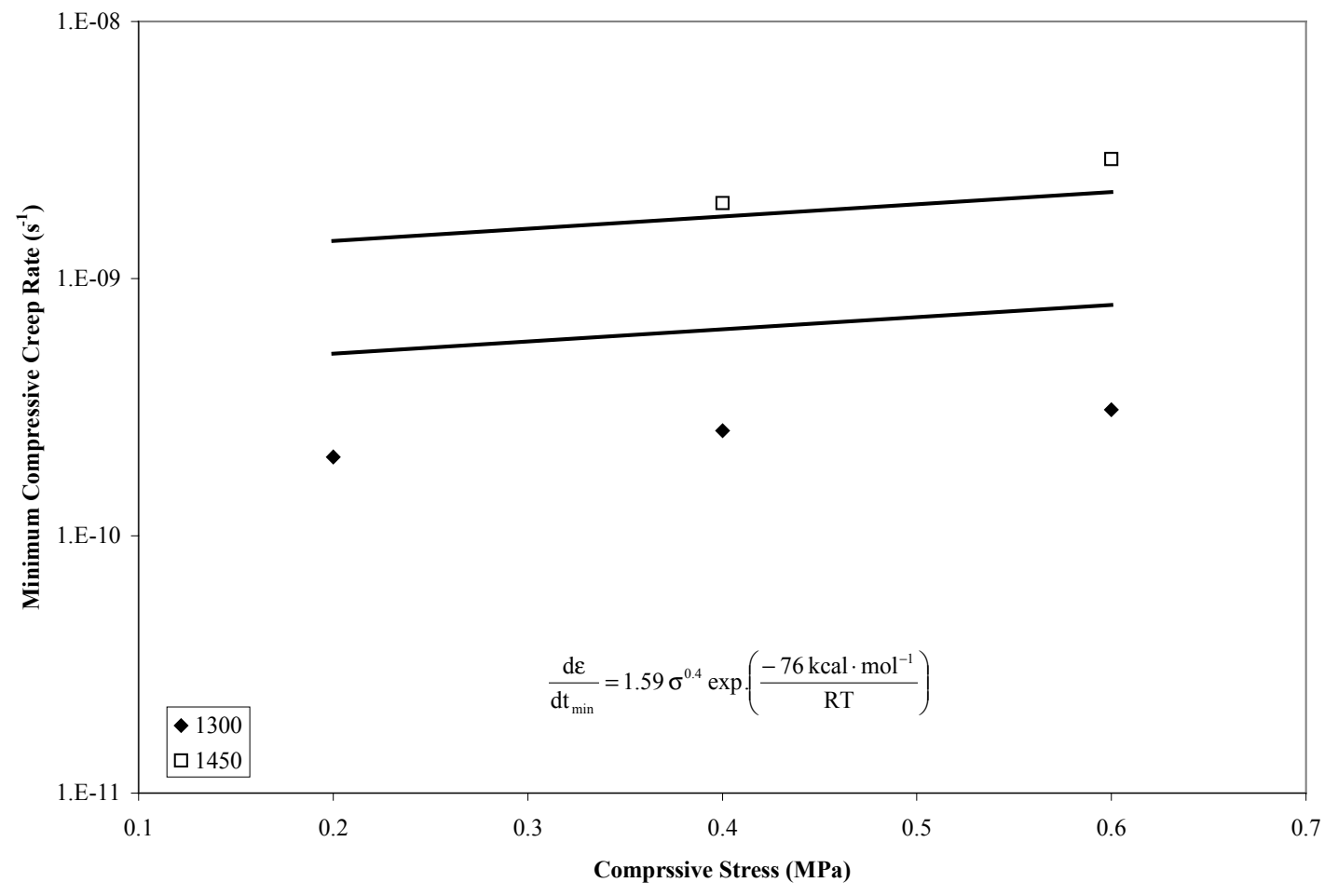

Figure 27. Empirical power-law representation of GEM as a function of stress and temperature.

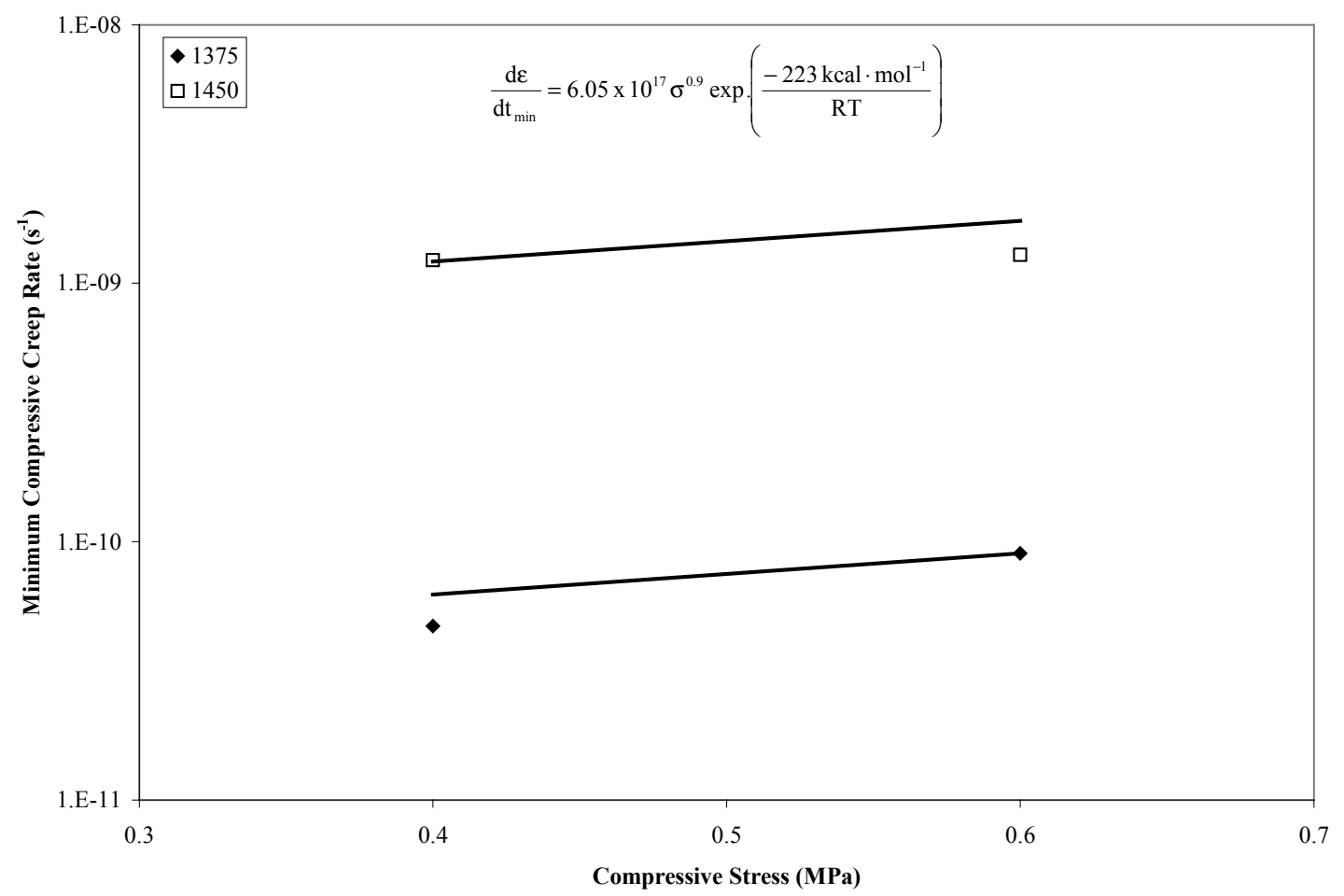

Figure 28. Empirical power-law representation of HF 17 as a function of stress and temperature. 


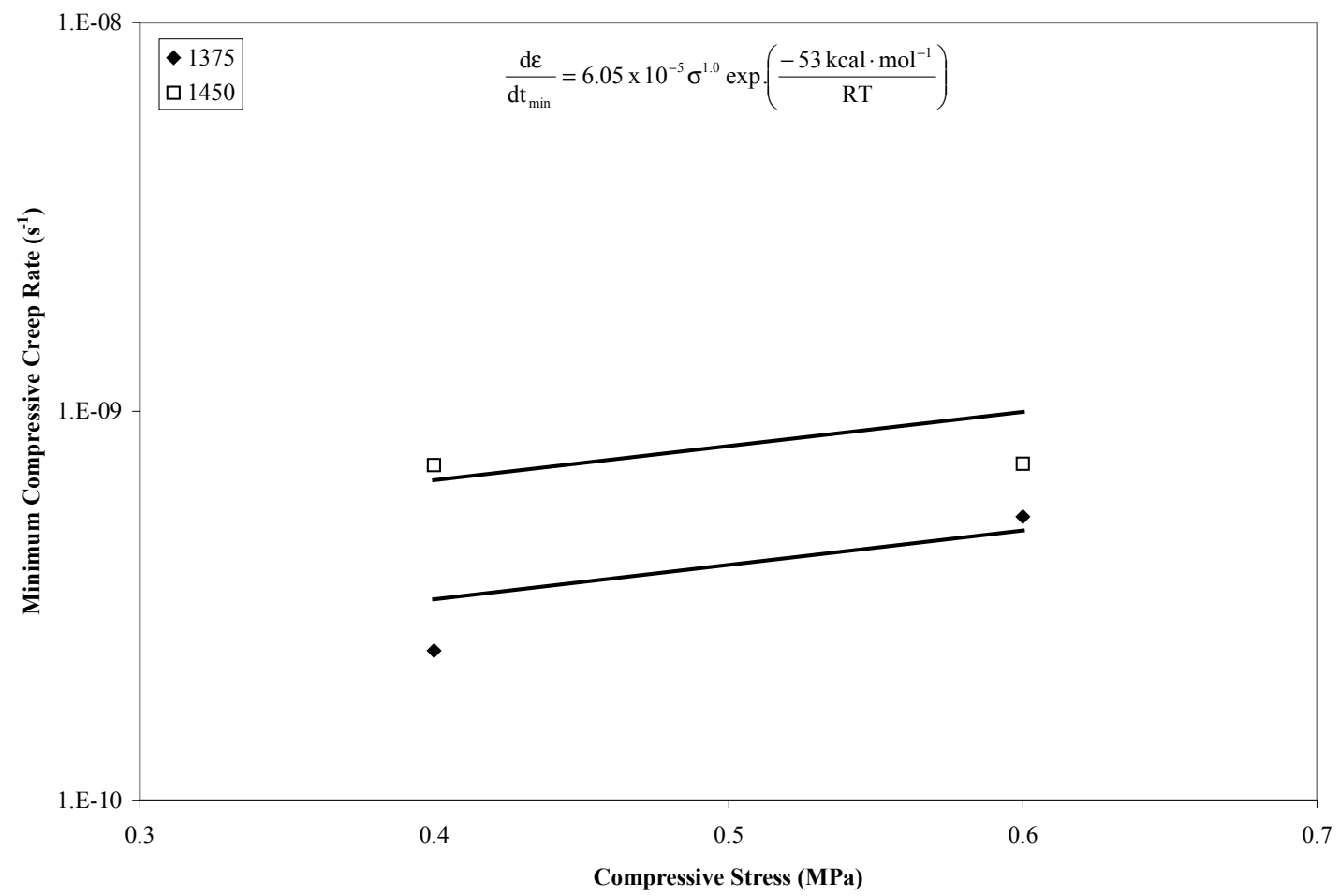

Figure 29. Empirical power-law representation of MU75AF as a function of stress and temperature.

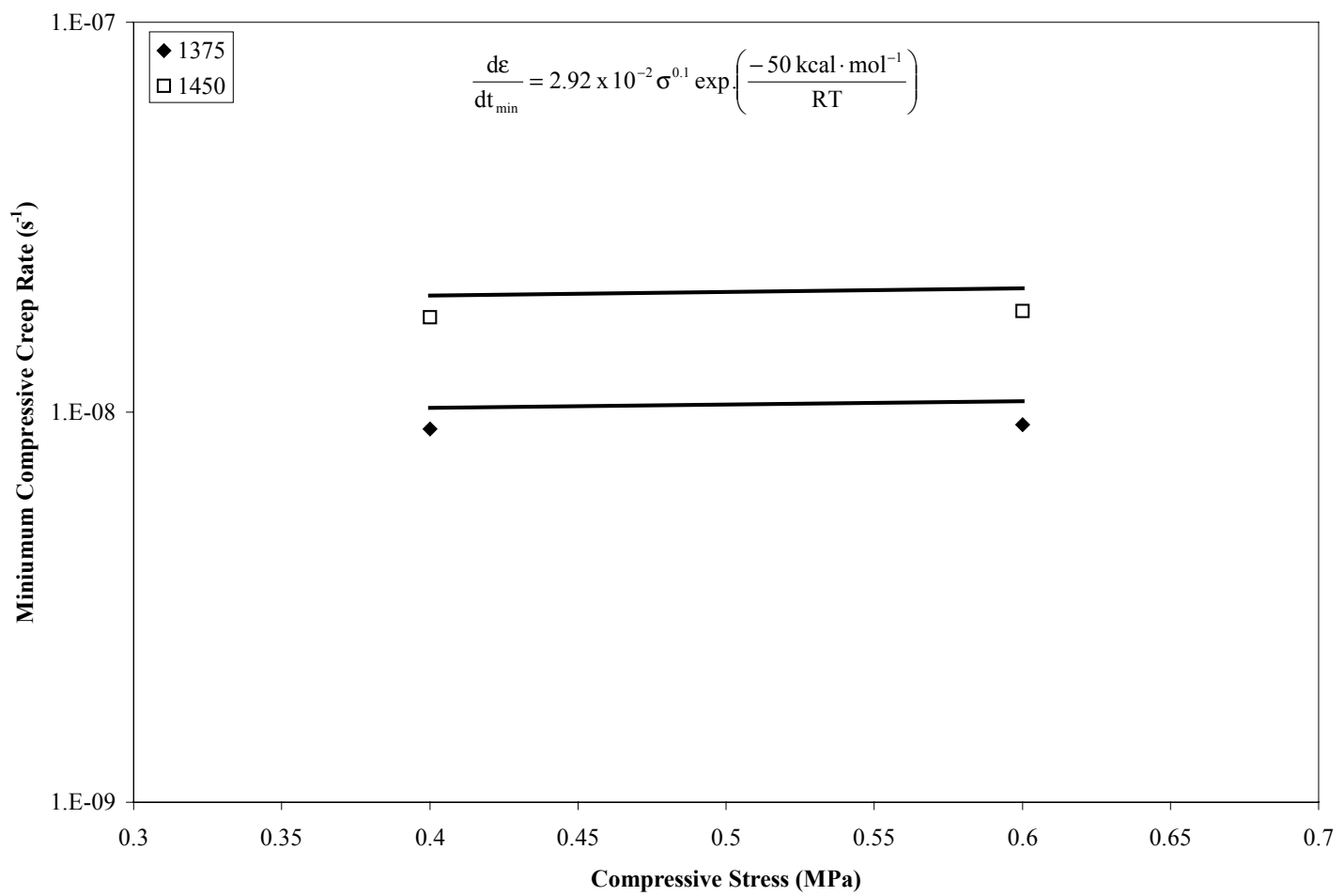

Figure 30. Empirical power-law representation of SL75AD as a function of stress and temperature. 


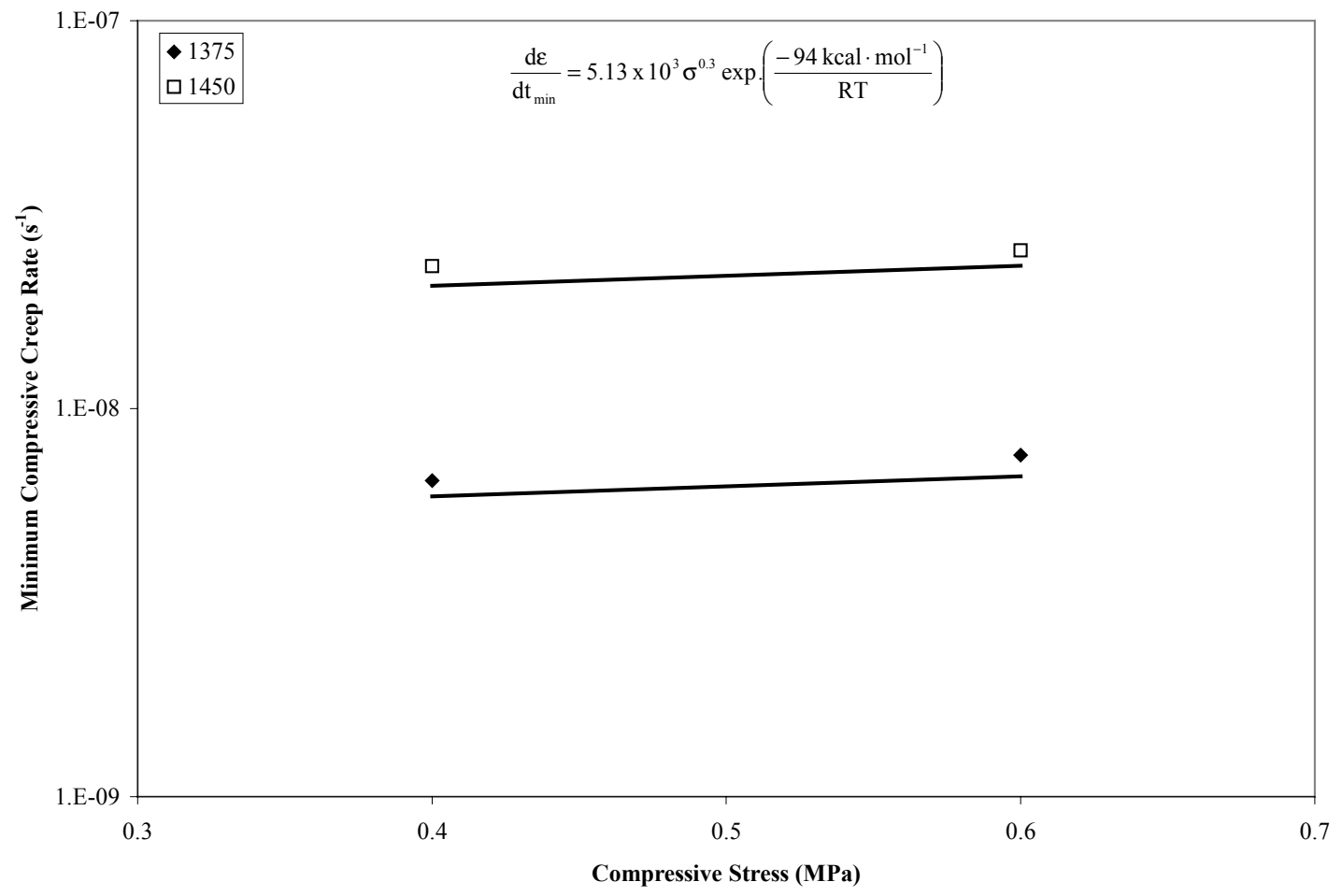

Figure 31. Empirical power-law representation of UFALA UCR as a function of stress and temperature.

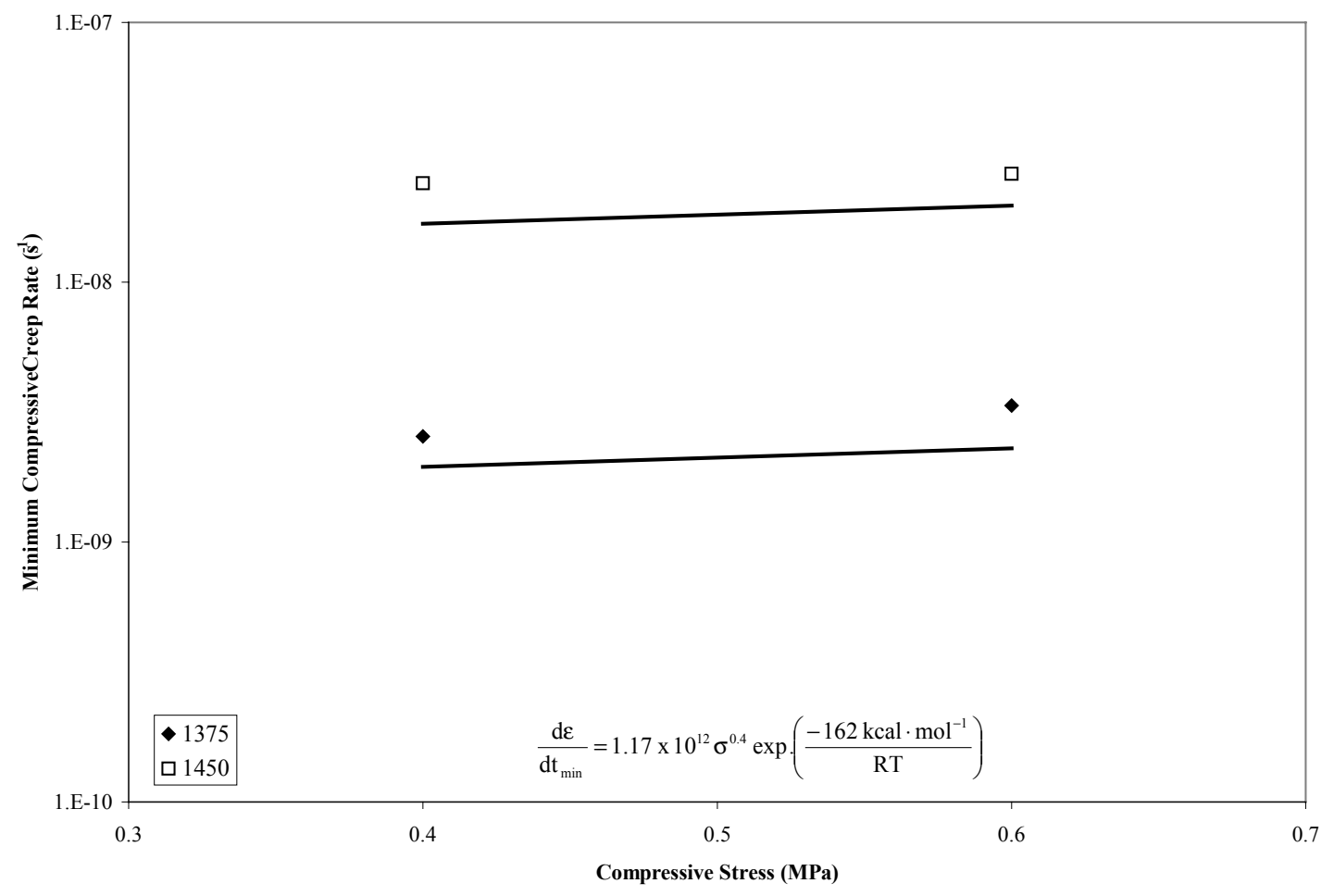

Figure 32. Empirical power-law representation of ZED FMC as a function of stress and temperature. 


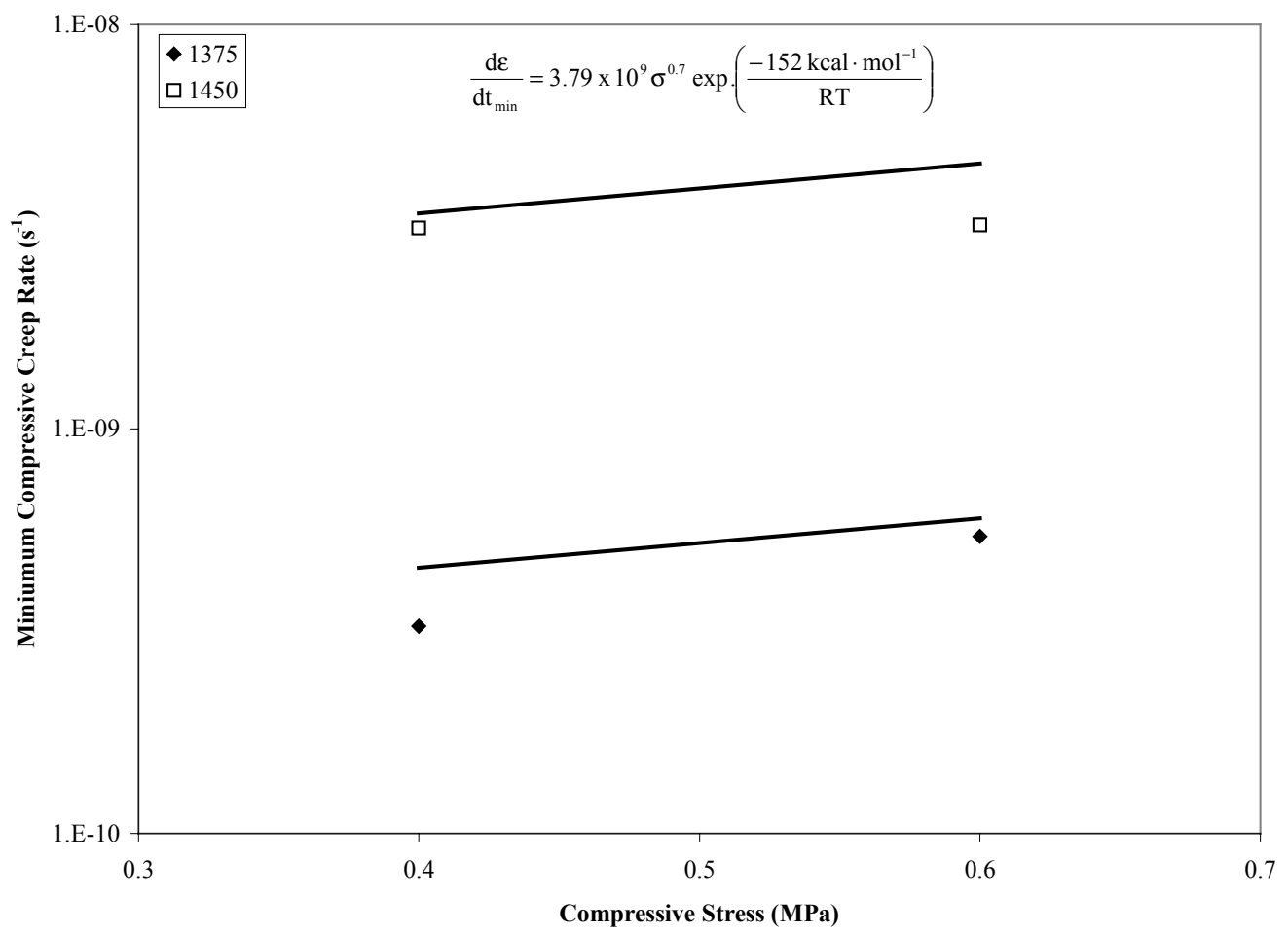

Figure 33. Empirical power-law representation of ZED FM as a function of stress and temperature.

Table 5. Results of multilinear regression of creep data

\begin{tabular}{|c|c|c|}
\hline Brand & Stress Exponent (n) & $\begin{array}{c}\text { Activation (Q) } \\
\left(\frac{\mathrm{kcal}}{\mathrm{mol}}\right)\end{array}$ \\
\hline BP Mullite & 0.6 & -70 \\
\hline DURITAL S75 & 2.4 & -98 \\
\hline Frimul F & 0.8 & -151 \\
\hline GEM & 0.4 & -76 \\
\hline HF 17 & 0.9 & -223 \\
\hline MU75AF & 1.0 & -53 \\
\hline SL75AD & 0.1 & -50 \\
\hline UFALA UCR & 0.3 & -94 \\
\hline ZED FMC & 0.4 & -162 \\
\hline ZED FM & 0.7 & -152 \\
\hline
\end{tabular}

Activation energies for the various refractory brands ranged from 50 to $223 \mathrm{kcal} / \mathrm{mol}$. Although no direct correlation between the magnitude of the activation energy and the amount of creep exhibited by a particular brand could be drawn from the data, it is known that materials 
possessing a high activation energy will have greater sensitivity to temperature than those possessing a lower activation energy. It should also be noted that the values for three of the calculated activation energies correspond to the activation energy of vitreous silica which falls in the range of $120-170 \mathrm{kcal} / \mathrm{mol}[16],[17]$. This would indicate that the glassy phases in these brands affect the overall creep behavior of the material.

\subsection{CORROSION RESISTANCE}

Results from the ASTM lid test showed that only minimal amounts of recession occurred for these refractories under the testing conditions set forth by the standard. Also, the mass change data was found to be ambiguous as some of the specimens had deposits on their surfaces and actually gained weight while others lost a small amount of mass. Therefore, this data is not reported here. Figure 34 shows the small amounts of refractory recession occurring on the various refractory samples. It can be seen that the non-fused grained refractories (Durital S75, SL75AD, and UFALA UCR) show a minimal amount of recession and some discoloring while the fused grained materials show practically no recession at all.

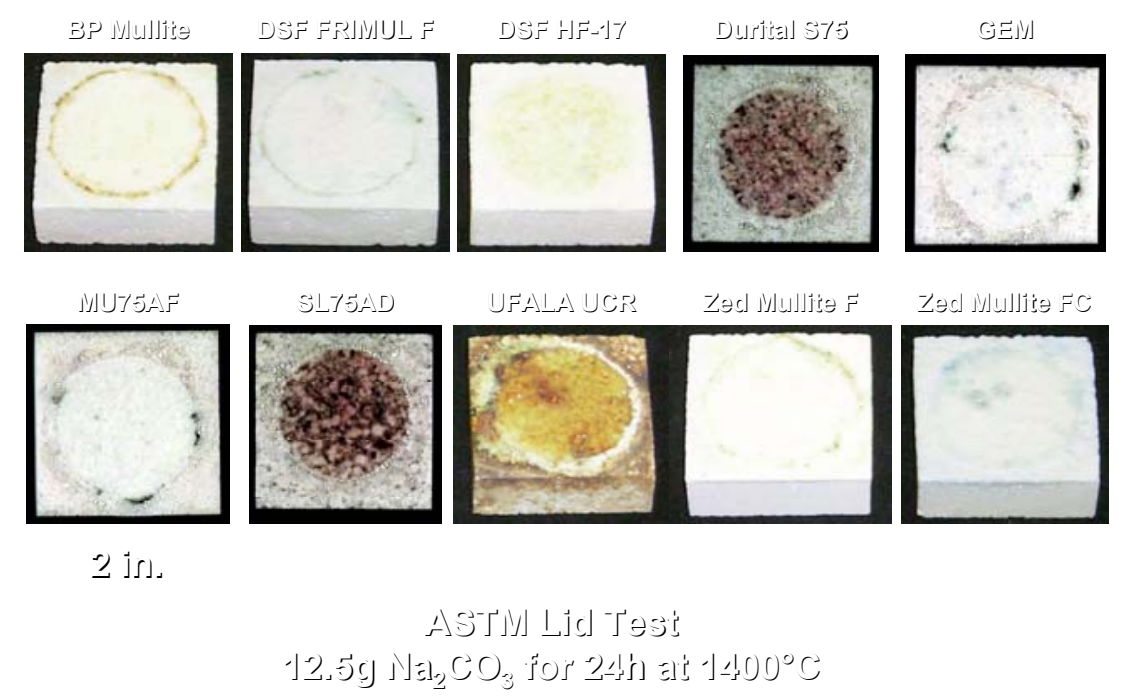

Figure 34. Refractory recession when exposed to sodium carbonate at $1400^{\circ} \mathrm{C}$ for 24 hours using ASTM C987 [13]. 


\subsection{BULK DENSITIES}

The measured average bulk densities for the ten mullite refractories are shown in Table 6 . Comparing these values to those reported by the manufacturer (see Table 3) shows that the measured densities are within $3 \%$ or less of the reported value with the exception of DURITAL S75 and Frimul F (measured density 4.2\% and 3.5\% higher, respectively than that reported by the manufacturer).

Table 6. Measured bulk densities of "as-received" materials. (manufactured reported values in parenthesis)

\begin{tabular}{|c|c|c|c|c|c|}
\hline & BP Mullite & $\begin{array}{c}\text { DURITAL } \\
\text { S75 }\end{array}$ & Frimul F & GEM & HF17 \\
\hline $\begin{array}{c}\text { Average } \\
\text { Bulk Density } \\
\left(\mathrm{g} / \mathrm{cm}^{3}\right)\end{array}$ & $\begin{array}{c}2.73 \\
(2.70)\end{array}$ & $\begin{array}{c}2.71 \\
(2.60)\end{array}$ & $\begin{array}{c}2.65 \\
(2.56)\end{array}$ & $\begin{array}{c}2.64 \\
(2.65)\end{array}$ & $\begin{array}{c}2.59 \\
(2.60)\end{array}$ \\
\hline $\begin{array}{c}\text { Standard } \\
\text { Deviation } \\
\left(\mathrm{g} / \mathrm{cm}^{3}\right)\end{array}$ & 0.005 & 0.016 & 0.015 & 0.013 & 0.015 \\
\hline $\begin{array}{c}\text { Number of } \\
\text { specimens }\end{array}$ & 4 & 5 & 4 & 5 & 4 \\
\hline
\end{tabular}

\begin{tabular}{|c|c|c|c|c|c|}
\hline & MU75AF & SL75AD & $\begin{array}{c}\text { UFALA } \\
\text { UCR }\end{array}$ & ZED FMC & ZED FM \\
\hline $\begin{array}{c}\text { Average } \\
\text { Bulk Density } \\
\left(\mathrm{g} / \mathrm{cm}^{3}\right)\end{array}$ & $\begin{array}{c}2.62 \\
(2.55)\end{array}$ & $\begin{array}{c}2.73 \\
(2.75)\end{array}$ & $\begin{array}{c}2.53 \\
(2.56)\end{array}$ & $\begin{array}{c}2.56 \\
(2.61)\end{array}$ & $\begin{array}{c}2.54 \\
(2.50)\end{array}$ \\
\hline $\begin{array}{c}\text { Standard } \\
\text { Deviation } \\
\left(\mathrm{g} / \mathrm{cm}^{3}\right)\end{array}$ & 0.012 & 0.010 & 0.013 & 0.005 & 0.007 \\
\hline $\begin{array}{c}\text { Number of } \\
\text { specimens }\end{array}$ & 5 & 5 & 4 & 4 & 4 \\
\hline
\end{tabular}




\subsection{THERMAL CONDUCTIVITY}

Room temperature thermal conductivity testing resulted in the average values shown in Figure 35. Frimul $\mathrm{F}$ showed the highest thermal conductivity at just under $3.5 \mathrm{~W} / \mathrm{mK}$. This was followed by Durital S75, GEM, MU75AF, and ZED FMC which all had a thermal conductivity of approximately $3.0 \mathrm{~W} / \mathrm{mK}$. BP Mullite and HF 17 both had similar thermal conductivity values of 2.7-2.8 W/mK followed by ZED FM with a value of just over $2.5 \mathrm{~W} / \mathrm{mK}$. The two brands with the lowest thermal conductivity values were SL75AF and UFALA UCR which had values of approximately $2.5 \mathrm{~W} / \mathrm{mK}$. These values were all higher than those given in the manufactures' literature, which ranged from 2.0-2.4 W/mK.

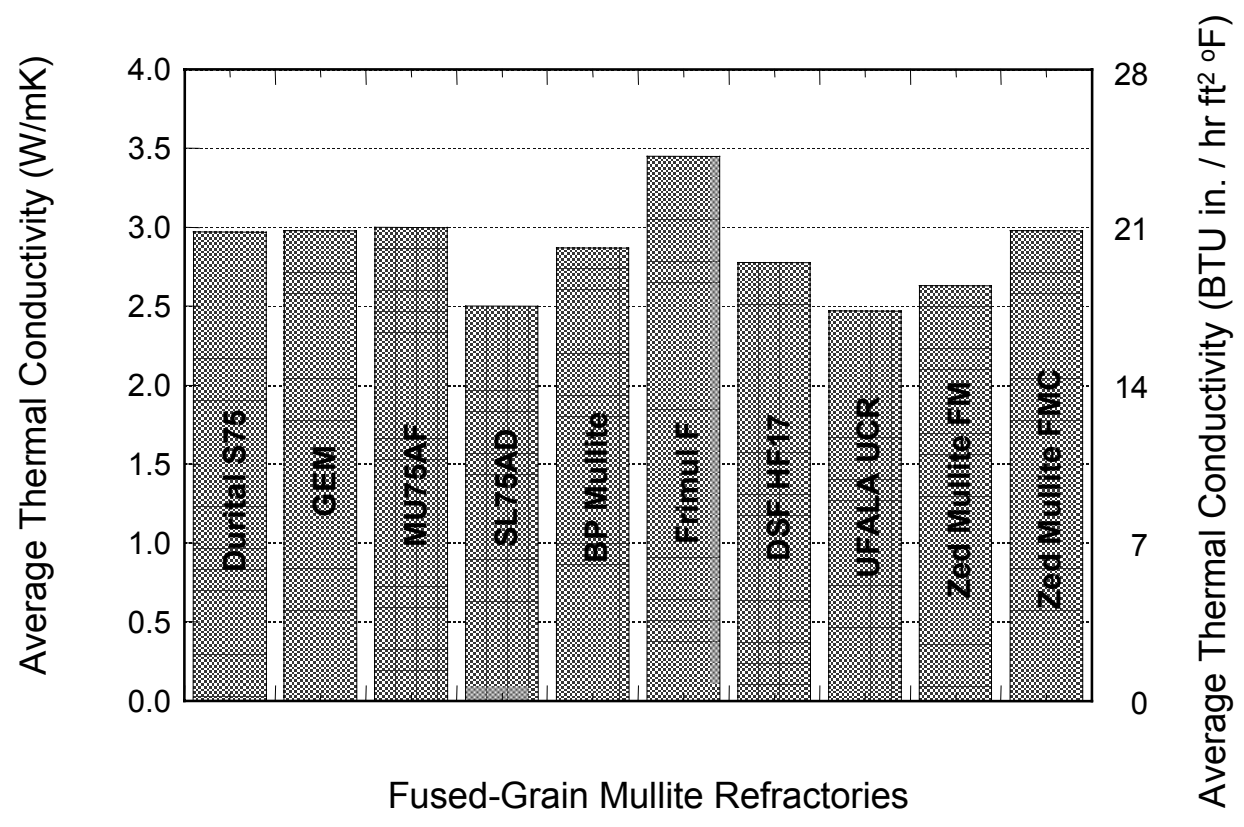

Figure 35 Thermal conductivity of mullite refractories as measured using "hot-disk" method [14]. 


\subsection{CHANGES IN BULK CHARACTERISTICS DUE TO CREEP TESTING}

The crystalline phases present in each of the ten mullite refractories varied from material to material but some trends or similarities existed between brands. The ten brands can be broadly categorized as either fused-grained or non-fused-grained as shown previously in

Table 1. The non-fused-grained materials all contain mullite grains derived from andalusite or kyanite while the fused-grained mullite is made by fusion (melting) of alumina and silica.

All the refractories are composed of various sized mullite grains floating in a matrix of secondary mullite with various levels of glass and porosity present in the matrix. The DURITAL S75, HF 17, and ZED FMC brands all contain very little glassy phase; while the remainder of the brands all possess significant quantities of glassy phase. The HF 17, UFALA UCR, and ZED FMC brands were all found to possess high levels of matrix porosity when examined by optical microscopy and SEM; while the remainder of the brands showed little or no matrix porosity. This finding was contrary to the manufacturers' reported data shown in Table 3.

More explicit descriptions of each brand along with their reaction to creep testing follow below. X-ray diffraction patterns for the various compounds found in these materials are included in Appendix A.

\section{BP Mullite}

The microstructure of this material contains both large and small fused mullite grains (blue or purple in the CL image) in a dense matrix of secondary mullite and glass (pink in CL image) as shown in Figure 36. Small alumina crystals were also present in the matrix phase. This analysis is supported by XRD as shown in Figure 37 that only shows diffraction lines for mullite (PDF 15-0776) and alumina (PDF 10-0173). SEM (Figure 38) shows the dense matrix microstructure and that the secondary mullite crystals developed around fine mullite grains and take on a prismatic shape. The composition of the secondary mullite crystals was found through EDS to be stoichiometric while the glassy phase was found to contain $\mathrm{K}_{2} \mathrm{O}, \mathrm{Na}_{2} \mathrm{O}$, and $\mathrm{CaO}$.

The mineralogy and microstructure of the crept sample was identical to that of the original material as shown in Figure 36 and Figure 37. This may be due to the dense matrix microstructure. 
(a)
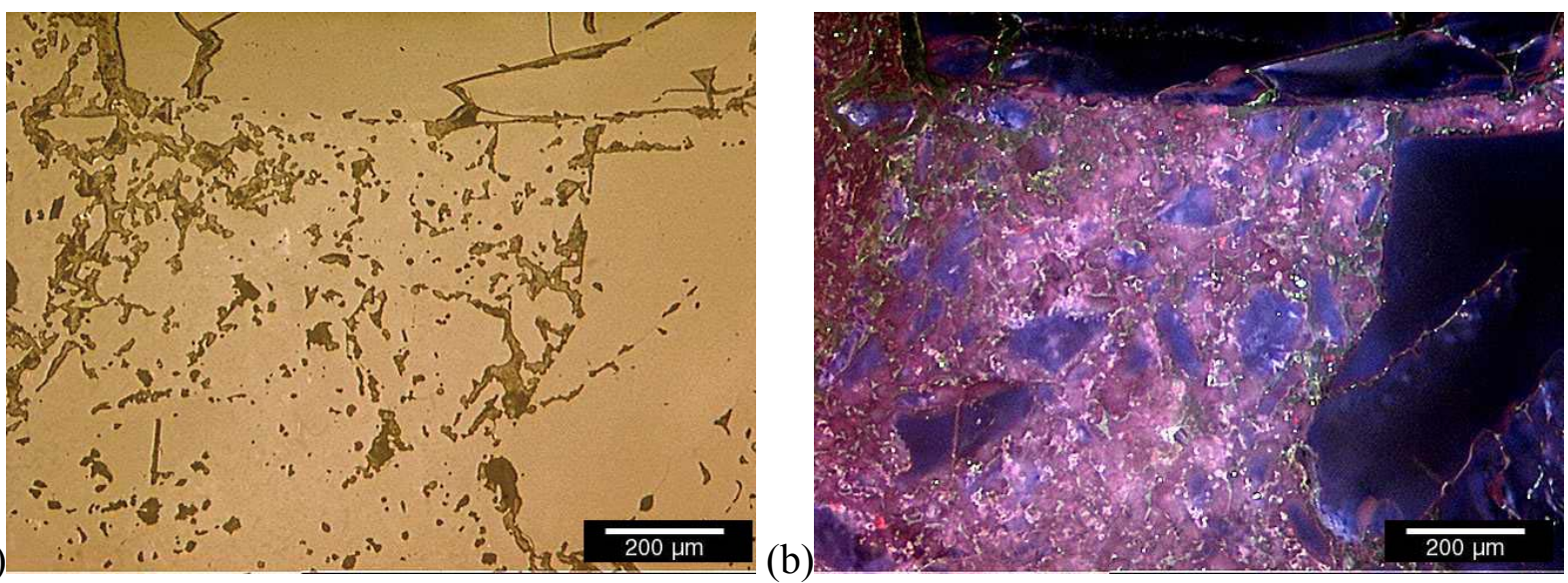

(c)
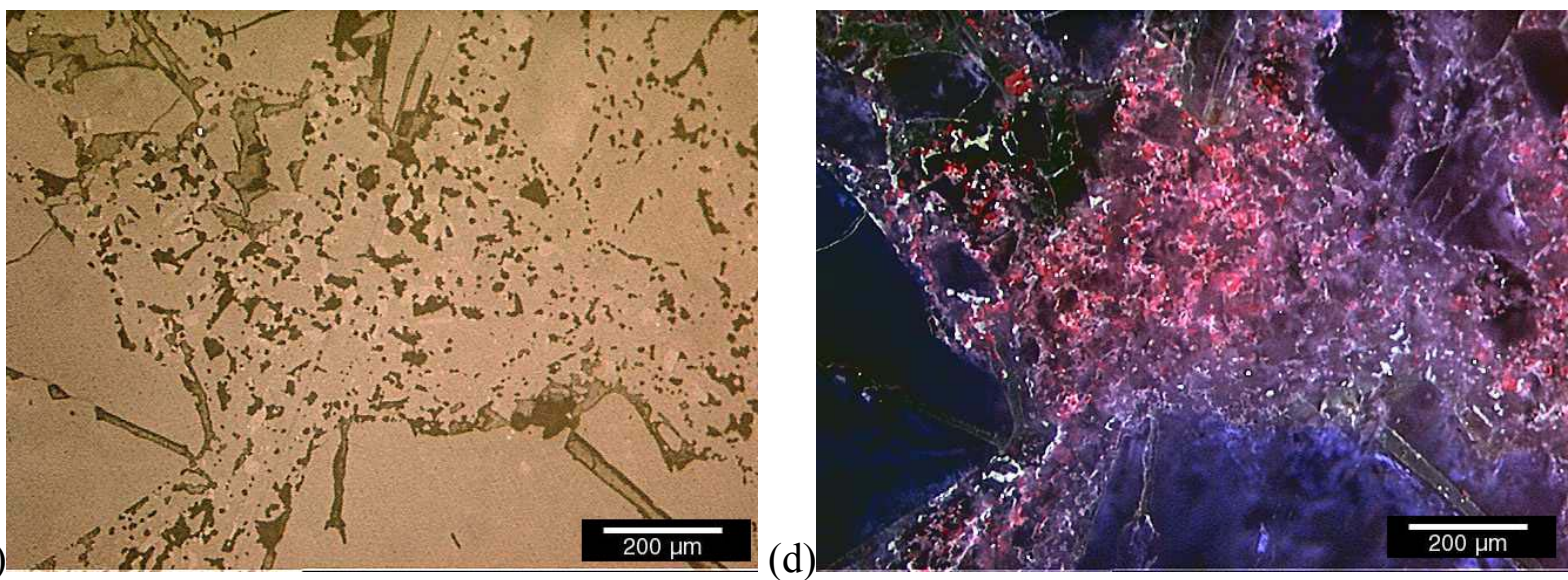

Figure 36. RL and CL microscopy of BP Mullite.

(a and b- "as-received", $c$ and $\mathrm{d}-$ crept at $1450^{\circ} \mathrm{C}$ ) 


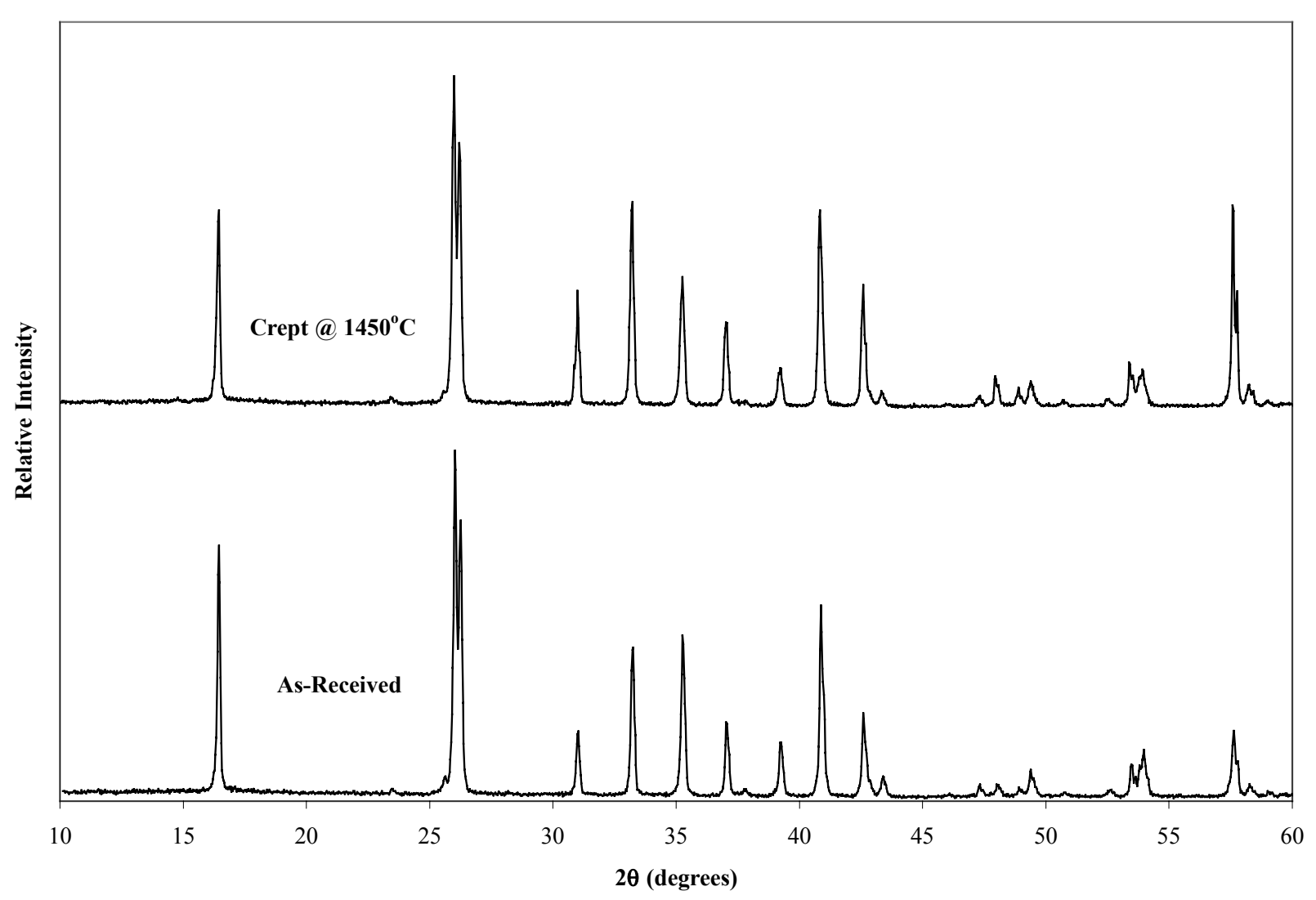

Figure 37. X-ray diffraction spectra of BP Mullite.

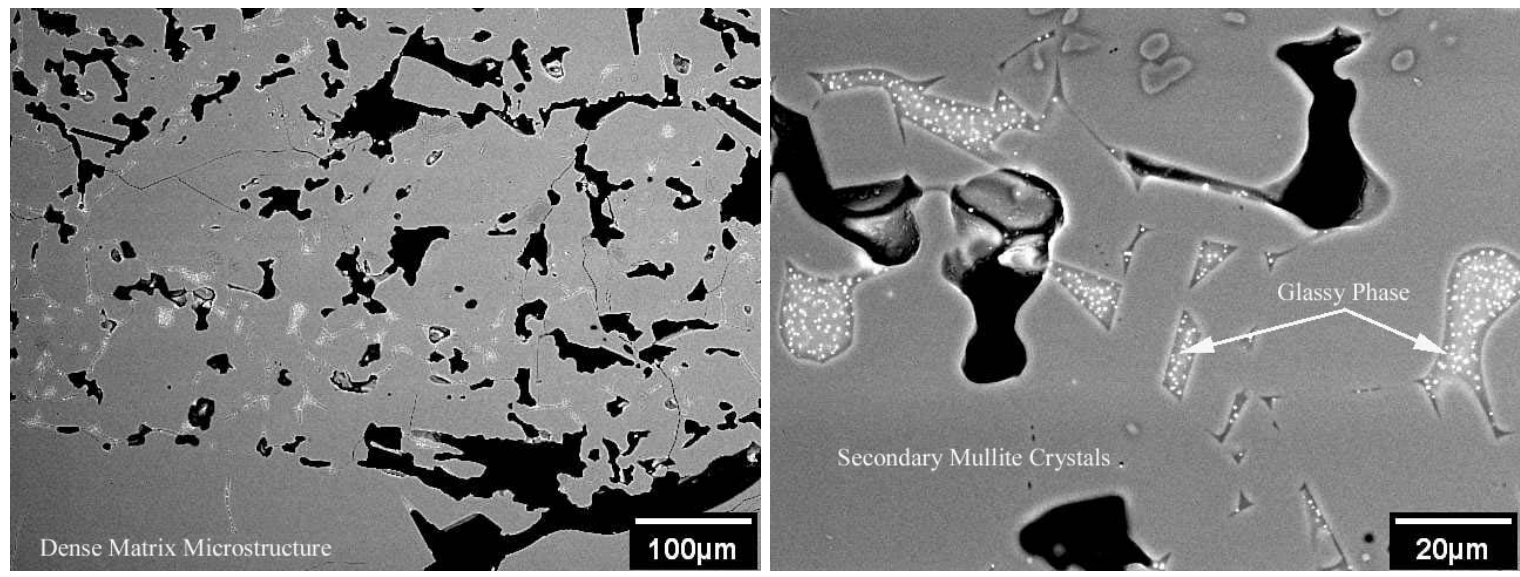

Figure 38. Scanning electron microscopy of BP Mullite.

\section{DURITAL S75}

The microstructure of this material consists of non-fused mullite grains (pinkish purple in CL image) which were probably derived from andalusite along with tabular and fused alumina grains (light blue in CL image) floating in a matrix of secondary mullite. The mullite matrix contains little or no detectable glass phase and no glass was found at the mullite crystal 
boundaries. This microstructure is shown in Figure 39. The above analysis is supported by XRD as shown in Figure 40 that only shows diffraction lines for mullite (PDF 15-0776) and alumina (PDF 10-0173). SEM (Figure 41) shows mullite grains derived from andalusite along with alumina grains in the dense secondary mullite matrix that has formed between the mullite and alumina grains. The composition of the secondary mullite crystals was found through EDS to be stoichiometric.

The mineralogy and microstructure of the crept sample was similar to that of the original material as shown in Figure 39 and Figure 40.

(a)
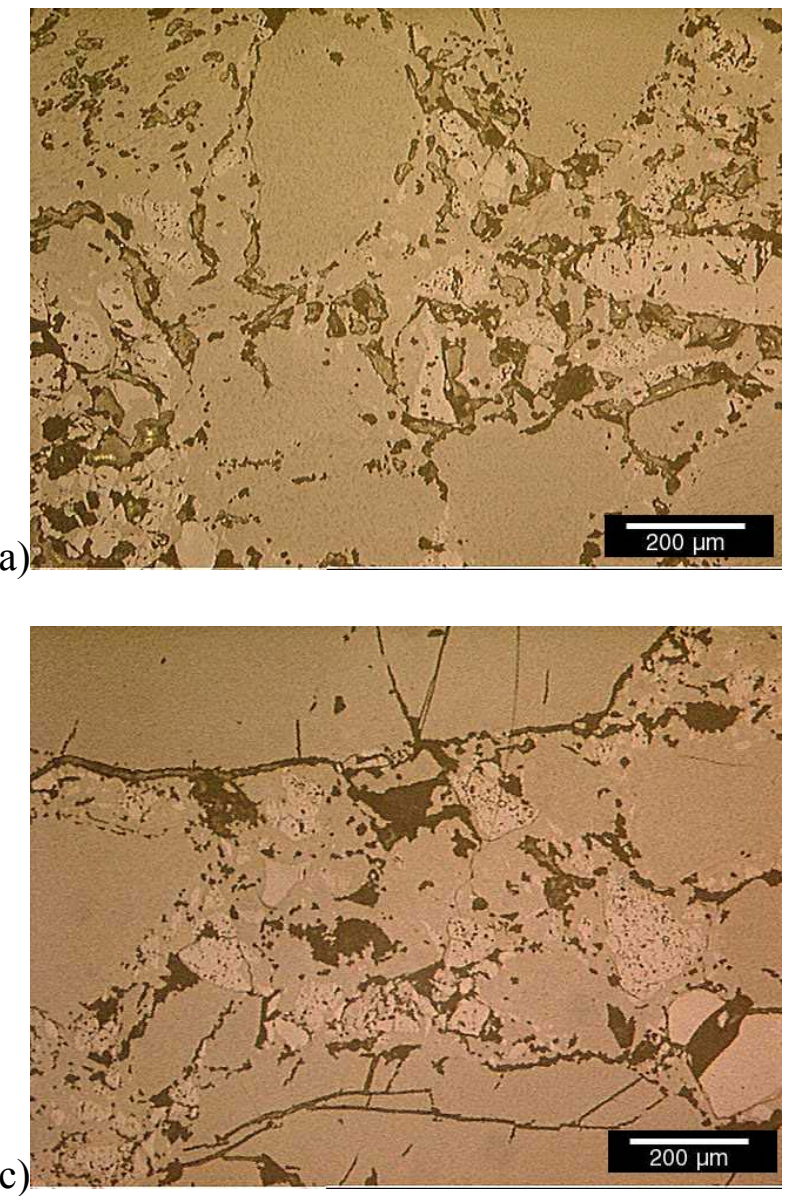
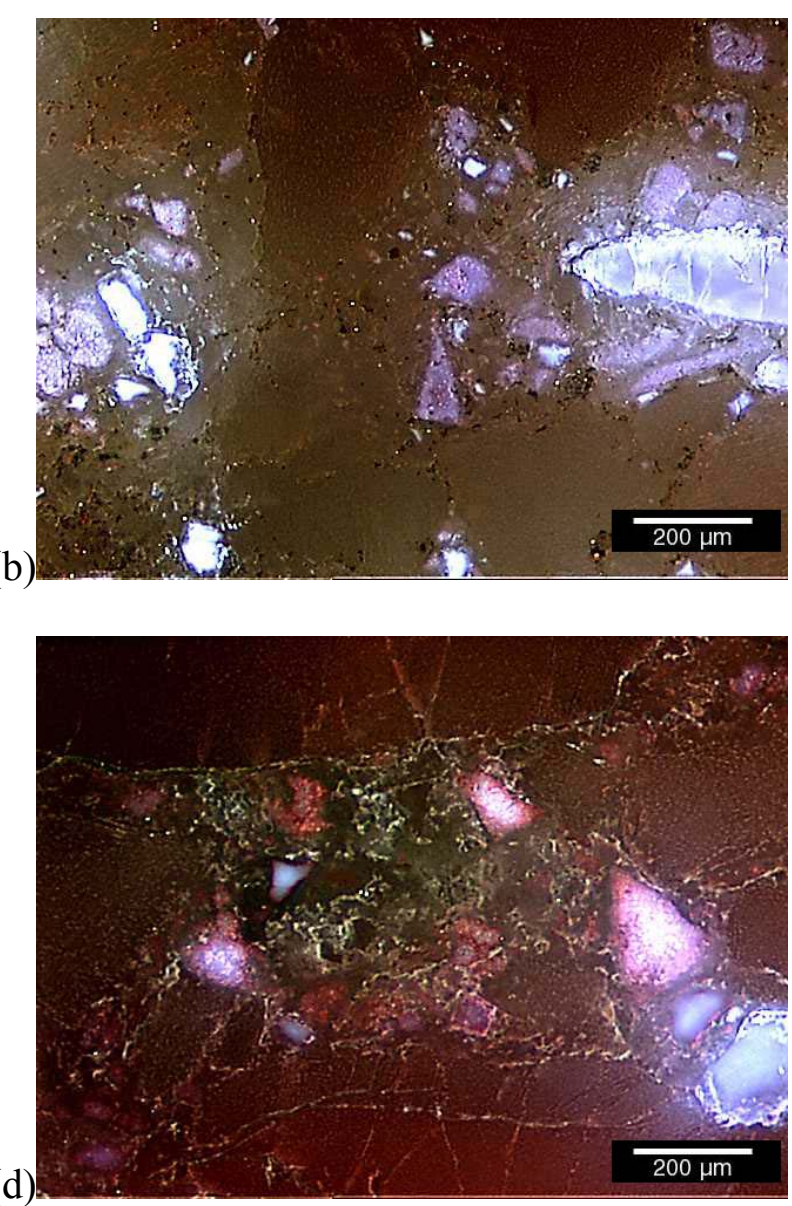

Figure 39. RL and CL microscopy of DURITAL S75.

( $\mathrm{a}$ and $\mathrm{b}$ - "as-received", c and $\mathrm{d}-$ crept at $1450^{\circ} \mathrm{C}$ ) 


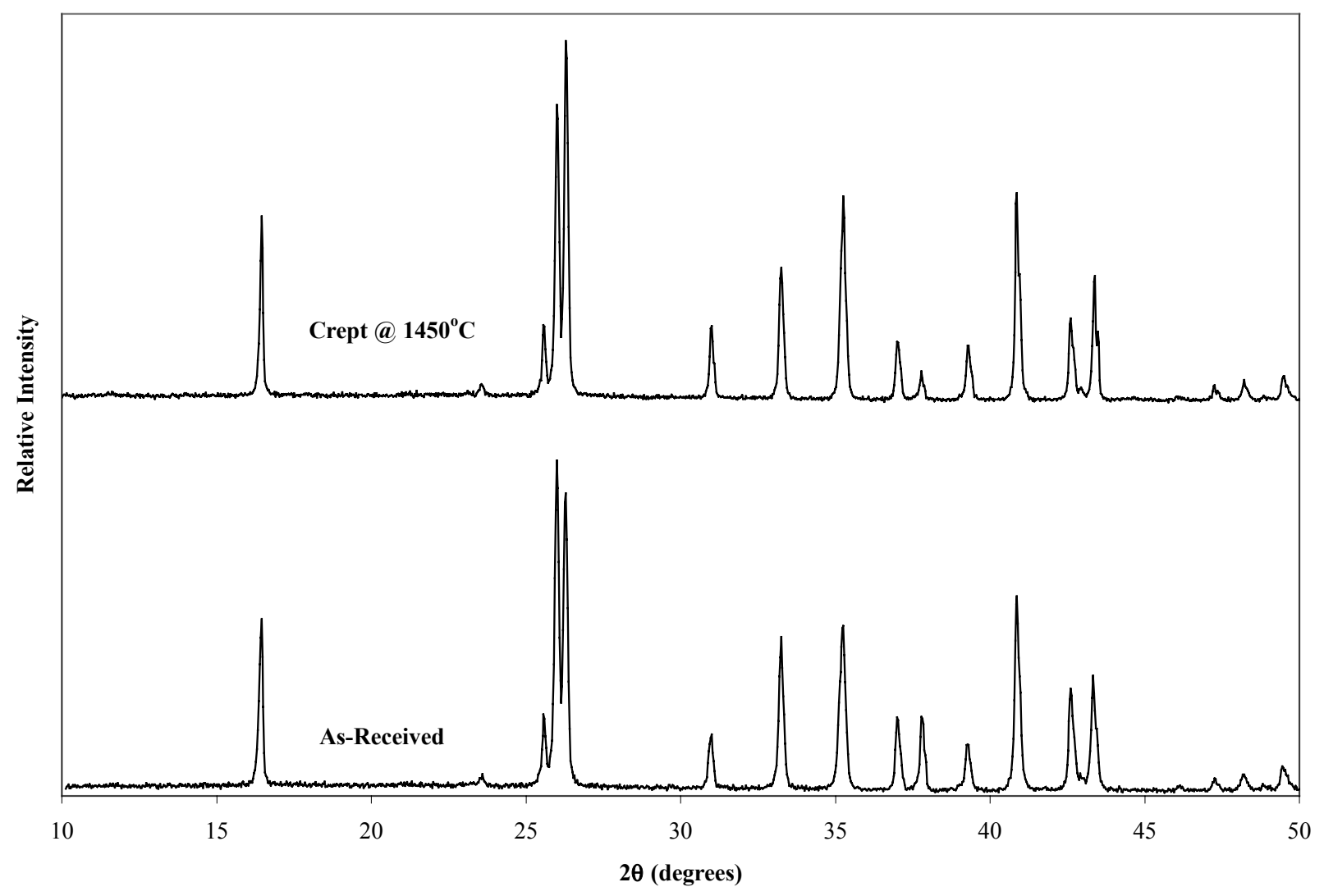

Figure 40. X-ray diffraction spectra of DURITAL S75.
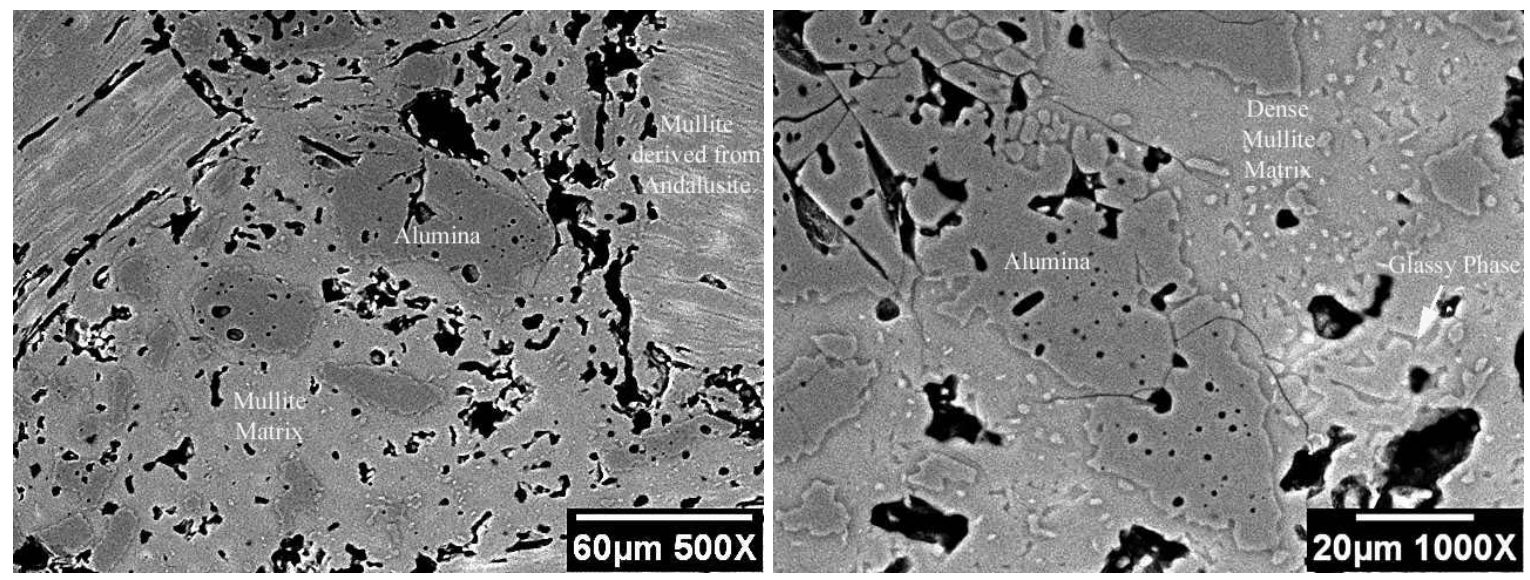

Figure 41. Scanning electron microscopy of DURITAL S75.

\section{Frimul F}

This material contains fused mullite aggregates (darker bluish purple in CL image) floating in a very glassy matrix of secondary mullite (light violet mullite matrix with whitish glassy phase in CL image). Also, small mullite grains are found in the glassy matrix which may be original fine fused mullite grains held by glassy bond or may be secondary mullite developed 
during firing. This microstructure is shown in Figure 42. Chemical analysis is supported by XRD as shown in Figure 43 that shows crystalline mullite (PDF 15-0776) and traces of alumina (PDF 10-0173). SEM (Figure 44) shows the morphology of the fine mullite grains in the glassy matrix along with mullite crystals of stoichiometric composition and in a glassy bond phase composed of $\mathrm{K}_{2} \mathrm{O}, \mathrm{CaO}$, and $\mathrm{TiO}_{2}$.

The mineralogy and microstructure of the crept sample was very similar to that of the original material as shown in Figure 42 and Figure 43.

(a)
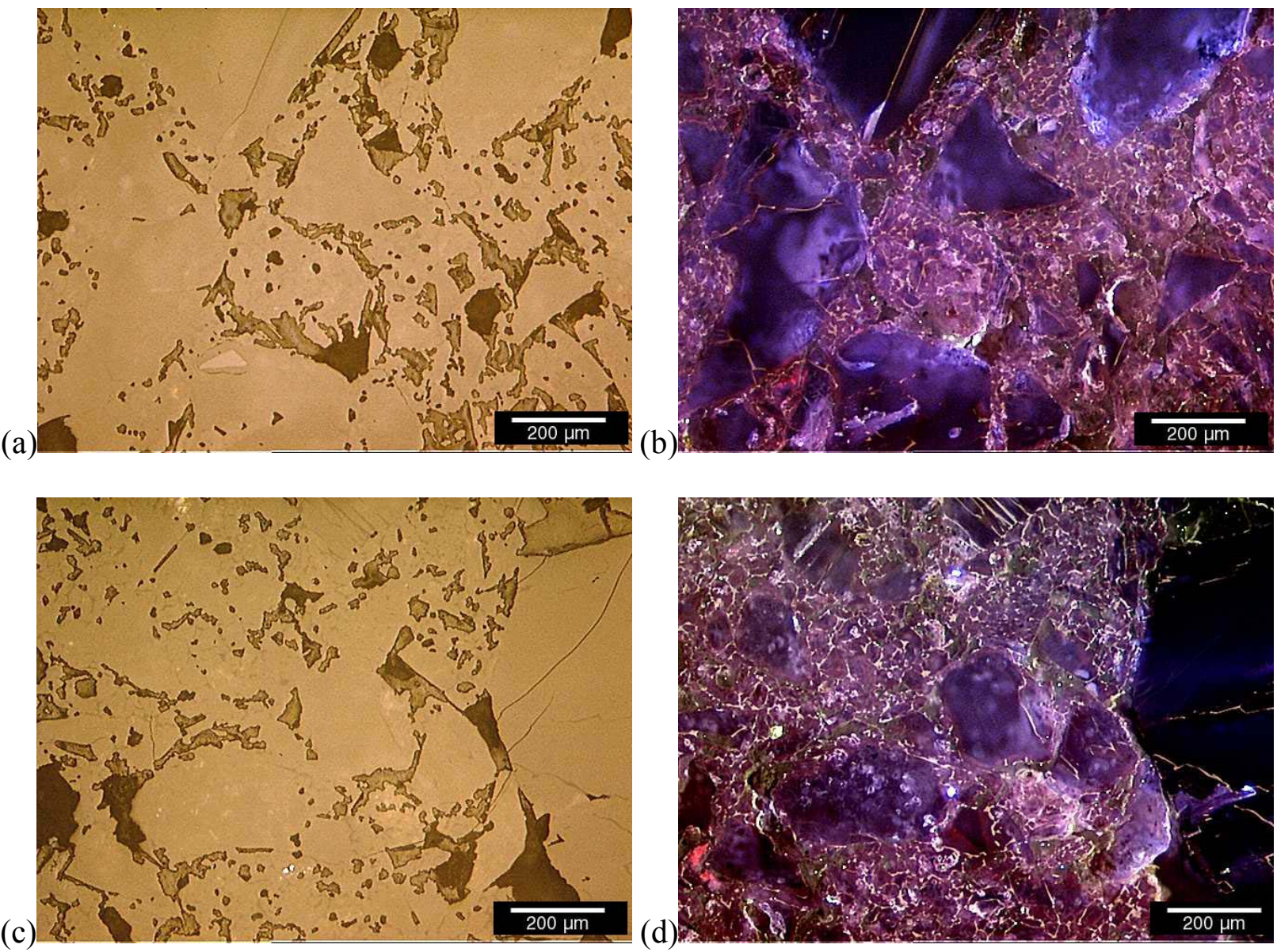

Figure 42. RL and CL microscopy of Frimul F. (a and b - "as-received", c and d - crept at $1450^{\circ} \mathrm{C}$ ) 


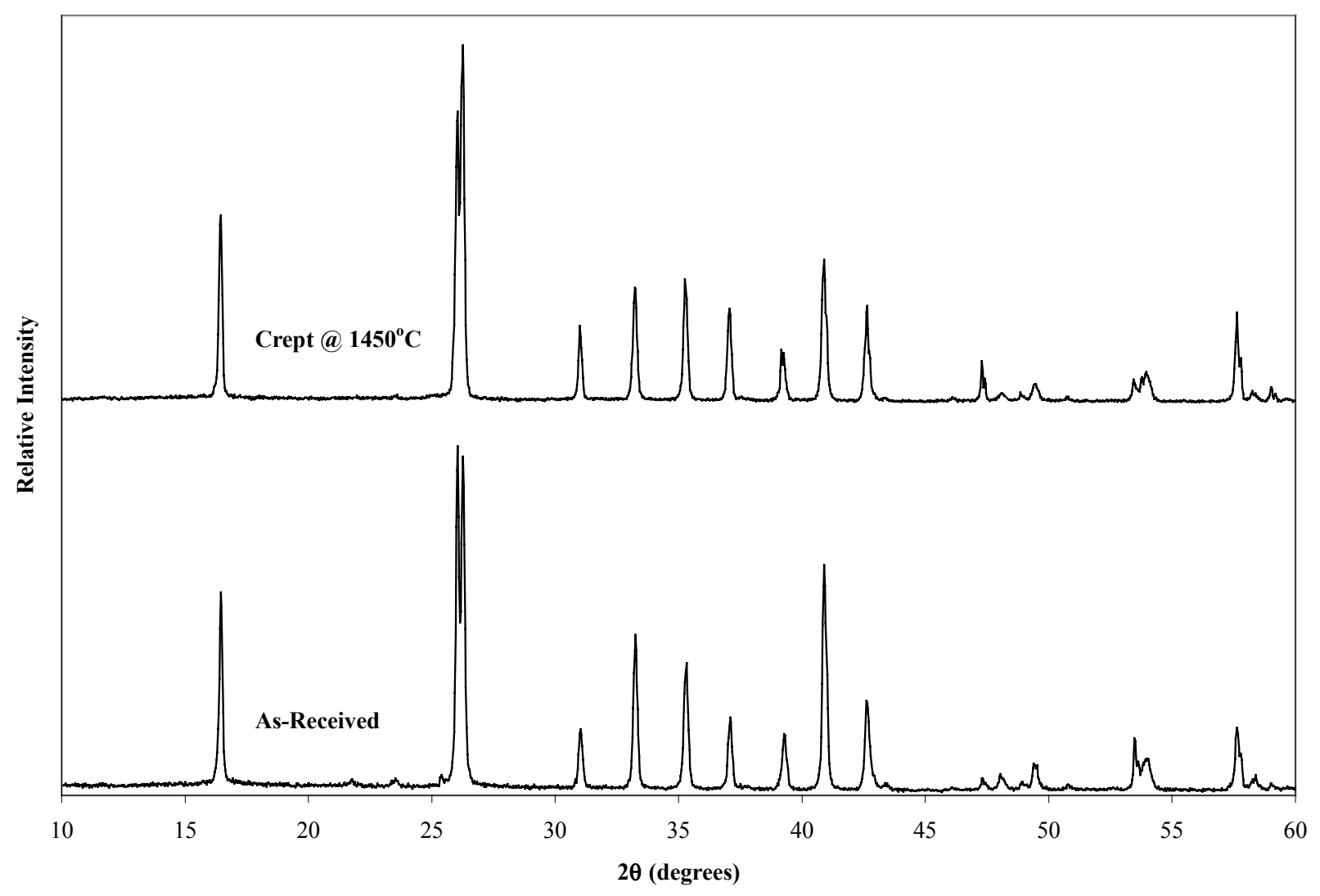

Figure 43. X-ray diffraction spectra of Frimul F.
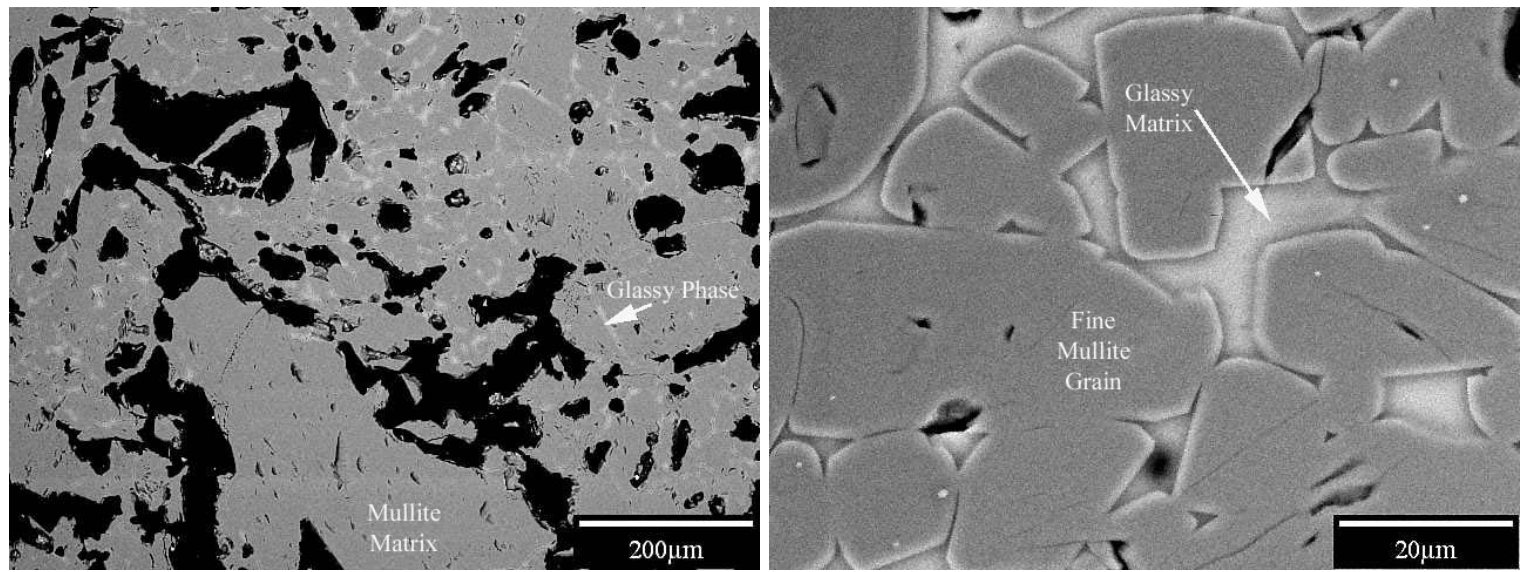

Figure 44. Scanning electron microscopy of Frimul F.

\section{GEM}

This refractory contains large and medium sized fused mullite grains (blue in CL image) in a secondary mullite matrix (lighter phase in CL image) as shown in Figure 45. The mullite matrix was found to contain amorphous phase (white in CL image), but no devitrification product or cristobalite was formed. This analysis is supported by XRD as shown in Figure 46 
that shows only crystalline mullite (PDF 15-0776). SEM (Figure 47) shows large primary mullite crystals and smaller $(3-5 \mu \mathrm{m})$ secondary mullite crystals enclosed in an amorphous matrix. The glassy matrix has a similar composition to the mullite crystals with small amounts of $\mathrm{Na}_{2} \mathrm{O}, \mathrm{CaO}$, and $\mathrm{TiO}_{2}$.

The mineralogy and microstructure of the crept sample was similar to that of the original material as shown in Figure 45 and Figure 46.

(a)

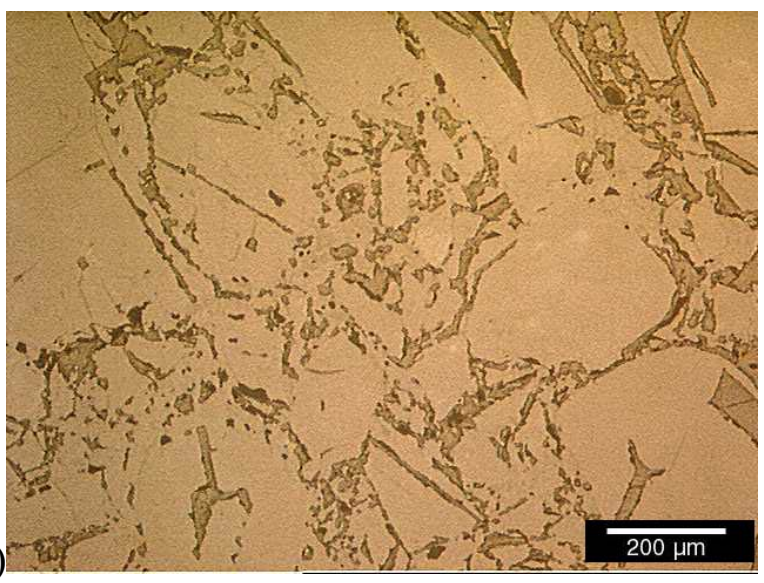

(c)

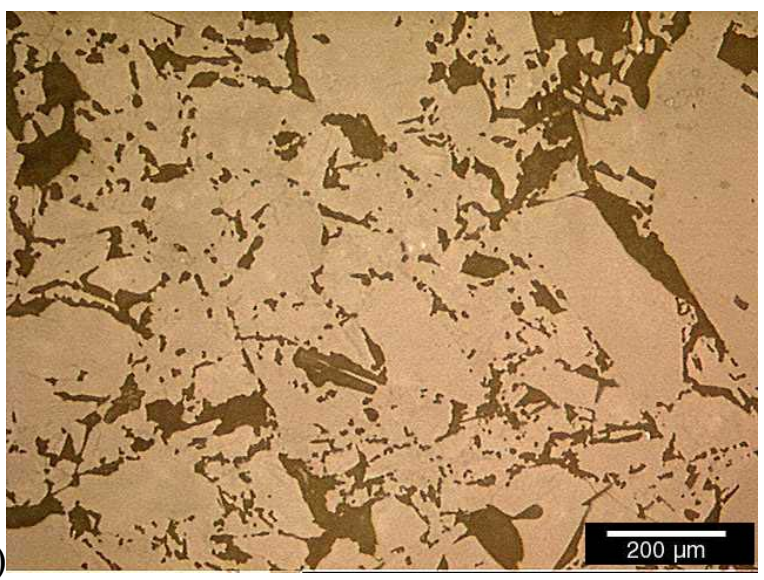

(b)

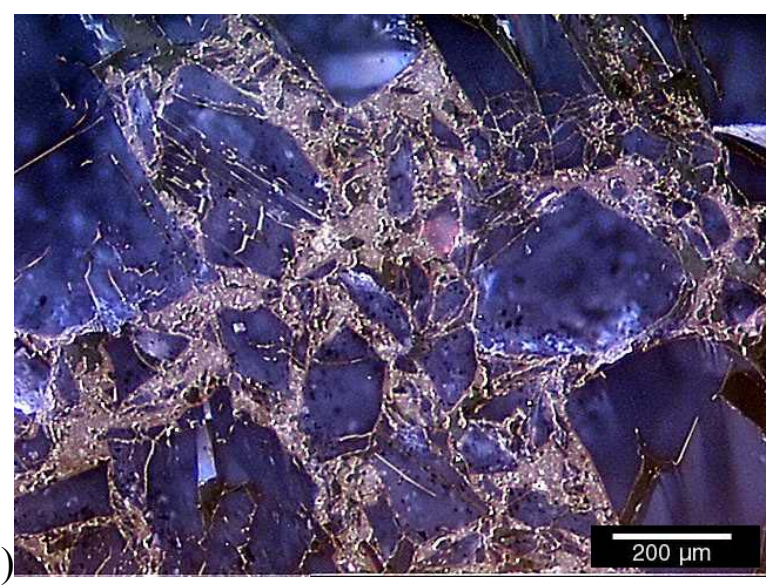

(d)

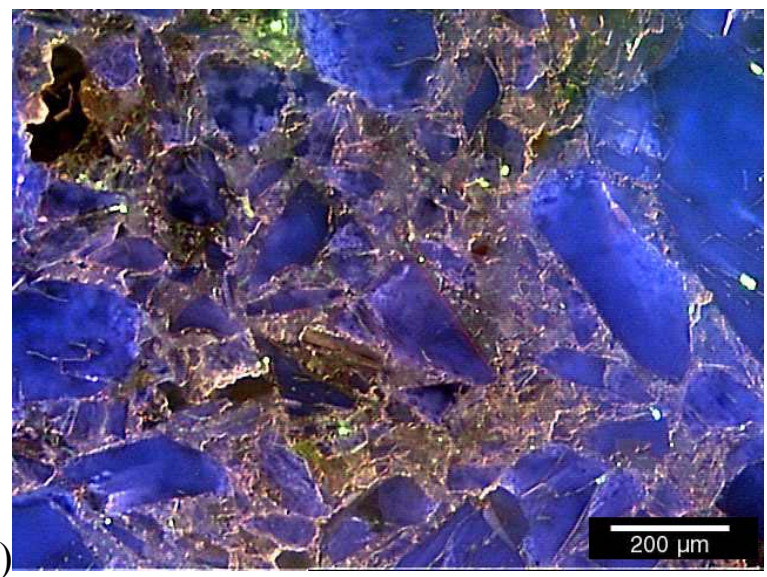

Figure 45. RL and CL microscopy of GEM.

(a and b - "as-received", c and d - crept at $1450^{\circ} \mathrm{C}$ ) 


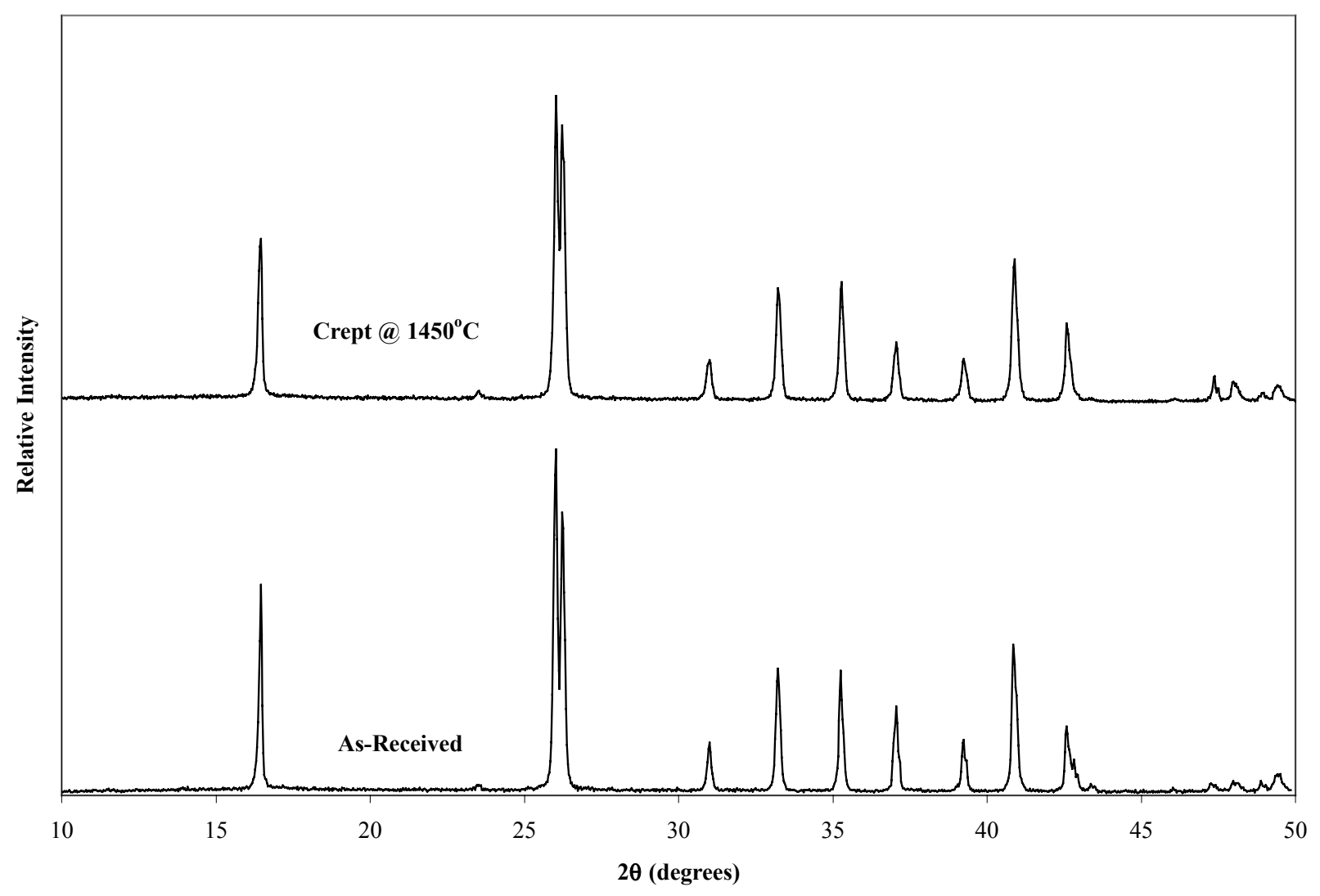

Figure 46. X-ray diffraction spectra of GEM.
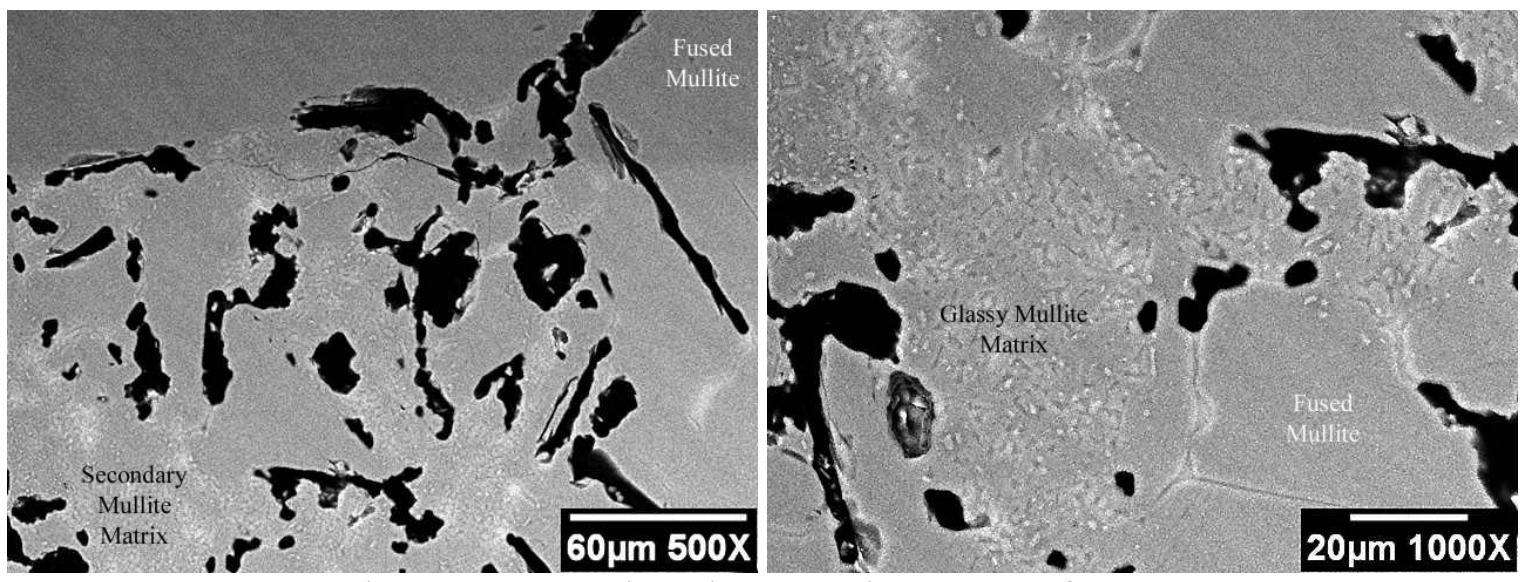

Figure 47. Scanning electron microscopy of GEM.

\section{HF 17}

The microstructure of this material contains large fused mullite grains (dark purple or blue in CL image) in a highly porous matrix of fine fused mullite grains (light purple in CL image) plus very tiny alumina crystals (pink in CL image) as shown in Figure 48. This analysis is supported by XRD as shown in Figure 49 that shows crystalline phases of mullite (PDF 15- 
0776) and alumina (PDF 10-0173). SEM (Figure 50) shows the secondary mullite crystals are developed and observed as agglomerates, which are sintered and virtually devoid of glassy bonding phase. The secondary mullite crystals were found to be nearly stoichiometric in composition through EDS.

The mineralogy of the crept sample was very similar to that of the original material as shown in Figure 49, but the microstructure (Figure 48) appears to be more compact and sintered (possibly due to compression).

(a)
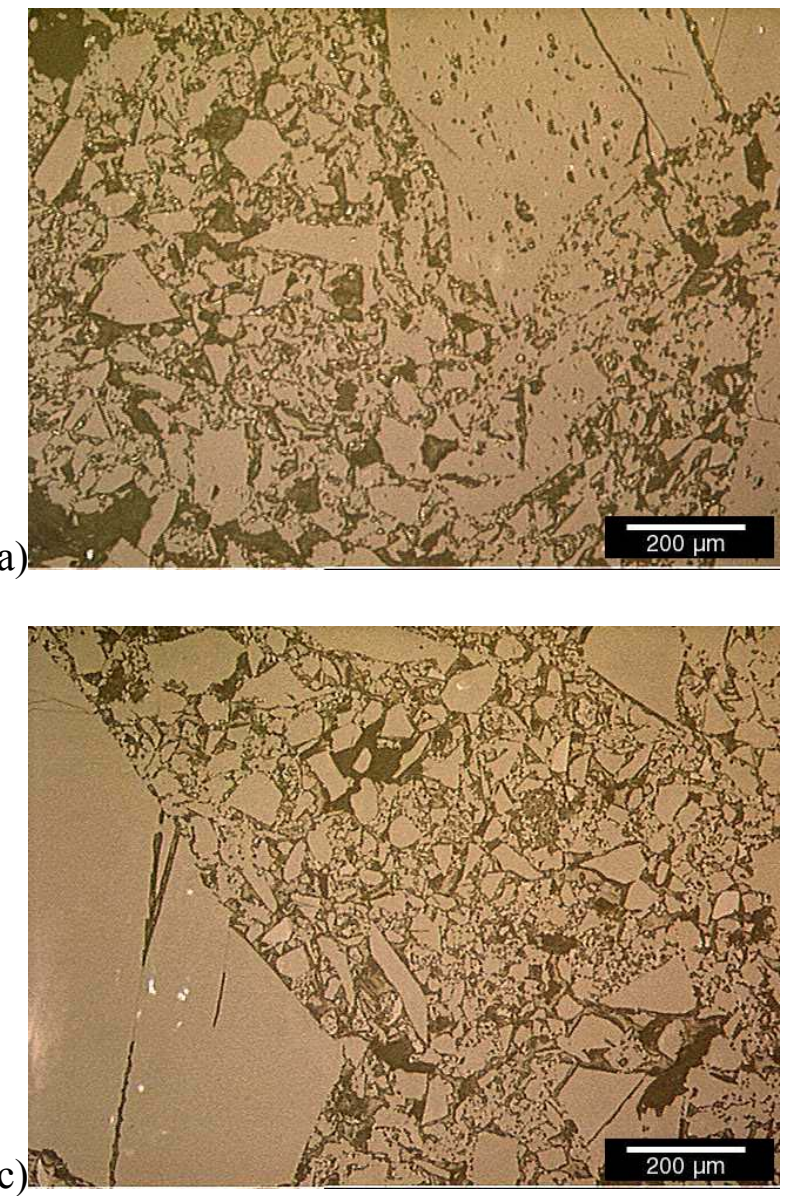

(b)

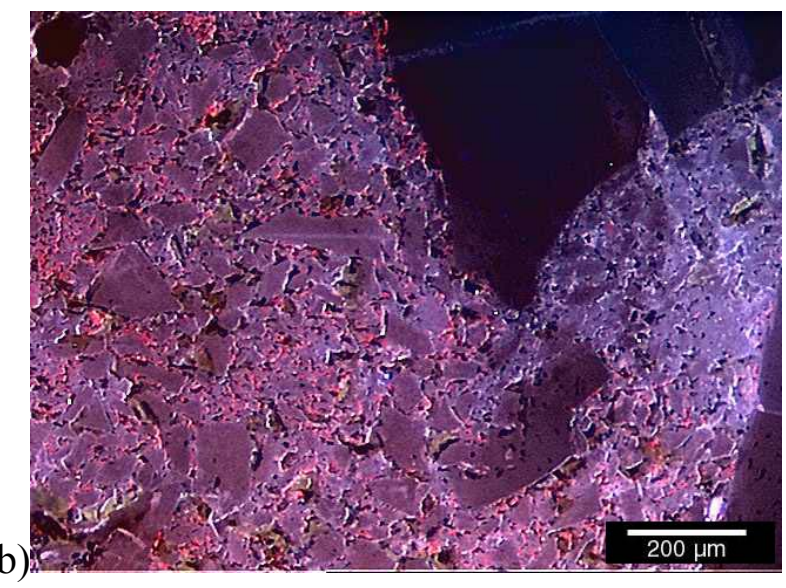

(d)

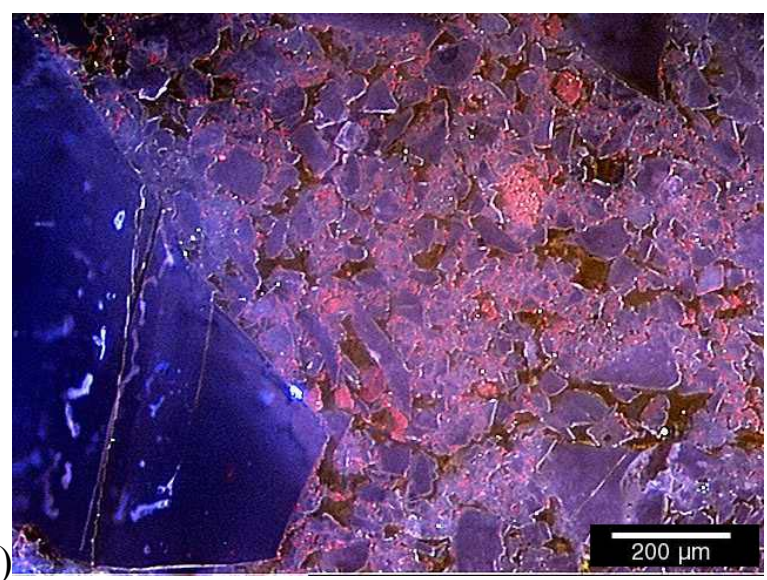

Figure 48. RL and CL microscopy of HF 17.

(a and b - "as-received", c and d - crept at $1450^{\circ} \mathrm{C}$ ) 


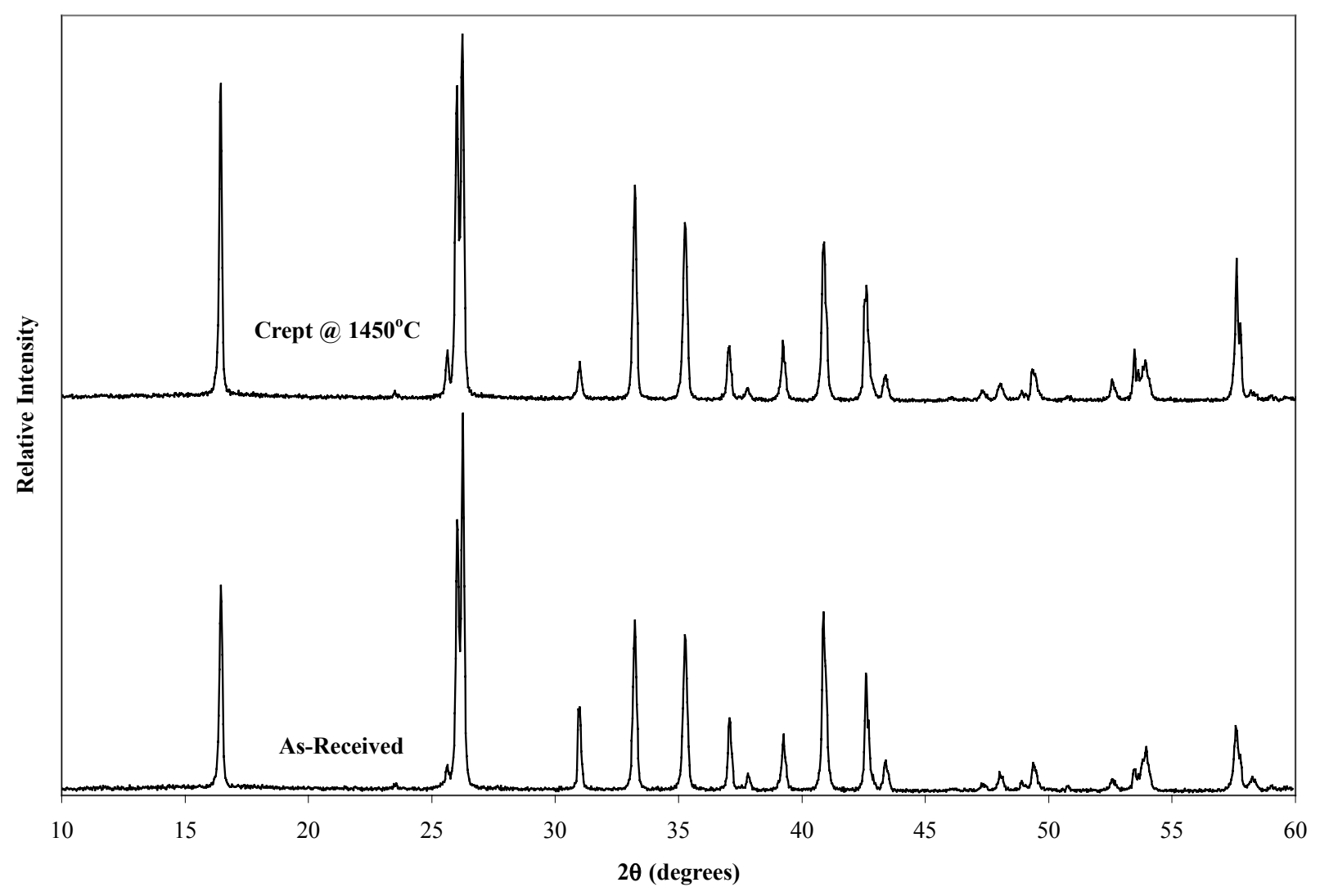

Figure 49. X-ray diffraction spectra of HF 17.
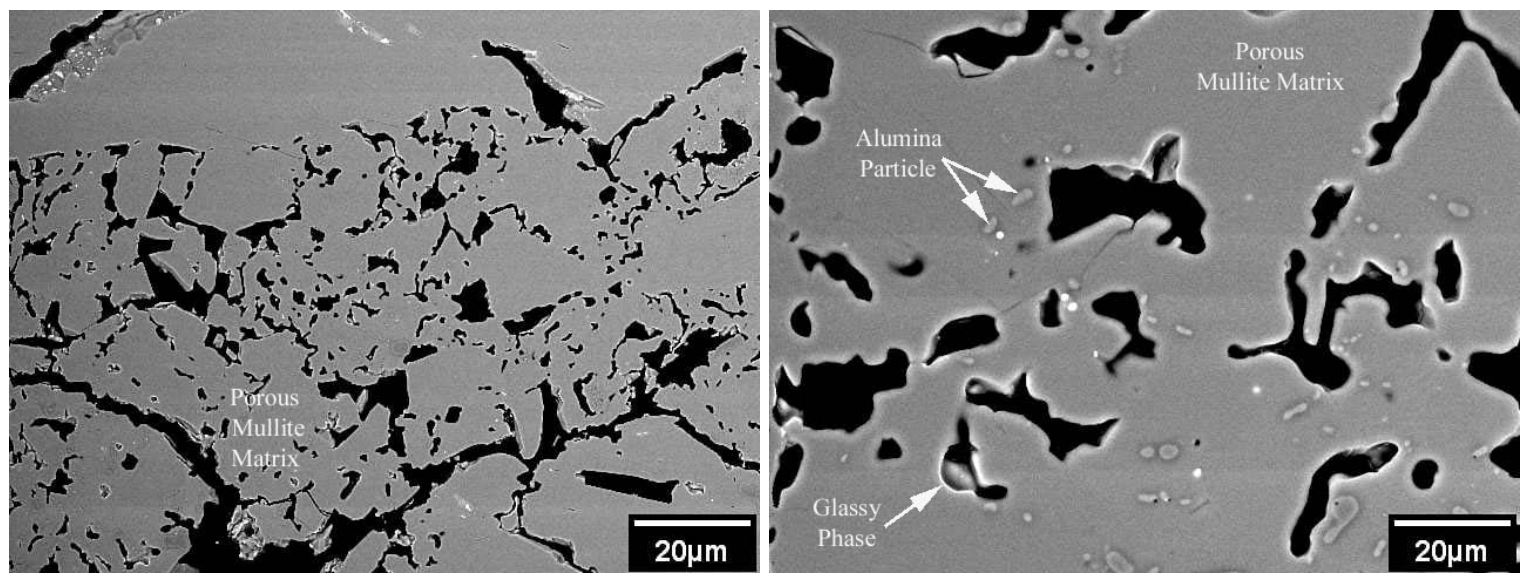

Figure 50. Scanning electron microscopy of HF 17.

\section{MU75AF}

This material contains large fused mullite grains or aggregates with round morphology (dark purple in the CL image) in a fine "granular" mullite (pinkish in CL image) and glassy matrix (white in CL image) as shown in Figure 51. Trace amounts of alumina particles were also observed in the matrix but XRD analysis in Figure 52 showed only mullite (PDF 15-0776) 
diffraction lines were detected. SEM (Figure 53) shows round mullite grain morphology and the presence of large amounts of glassy phase in the mullite bond area. The composition of the mullite grains was found through EDS to be stoichiometric while the glassy phase was found to contain $\mathrm{K}_{2} \mathrm{O}$ and $\mathrm{Na}_{2} \mathrm{O}$ along with trace amounts of $\mathrm{TiO}_{2}$ and $\mathrm{CaO}$.

The mineralogy and microstructure of the crept sample was similar to that of the original material as shown in Figure 51 and Figure 52.

(a)
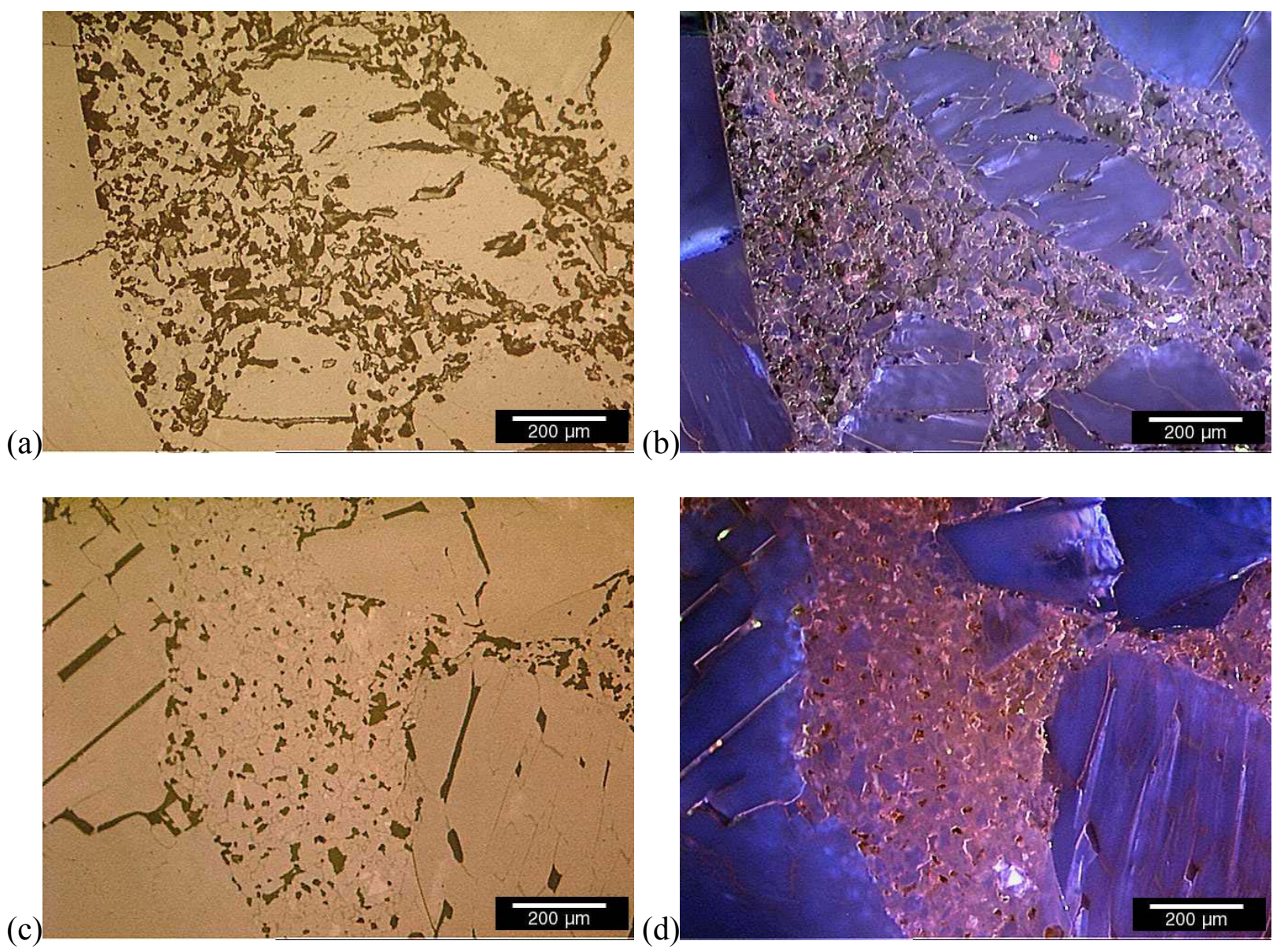

Figure 51. RL and CL microscopy of MU75AF. (a and b- "as-received", c and d - crept at $1450^{\circ} \mathrm{C}$ ) 


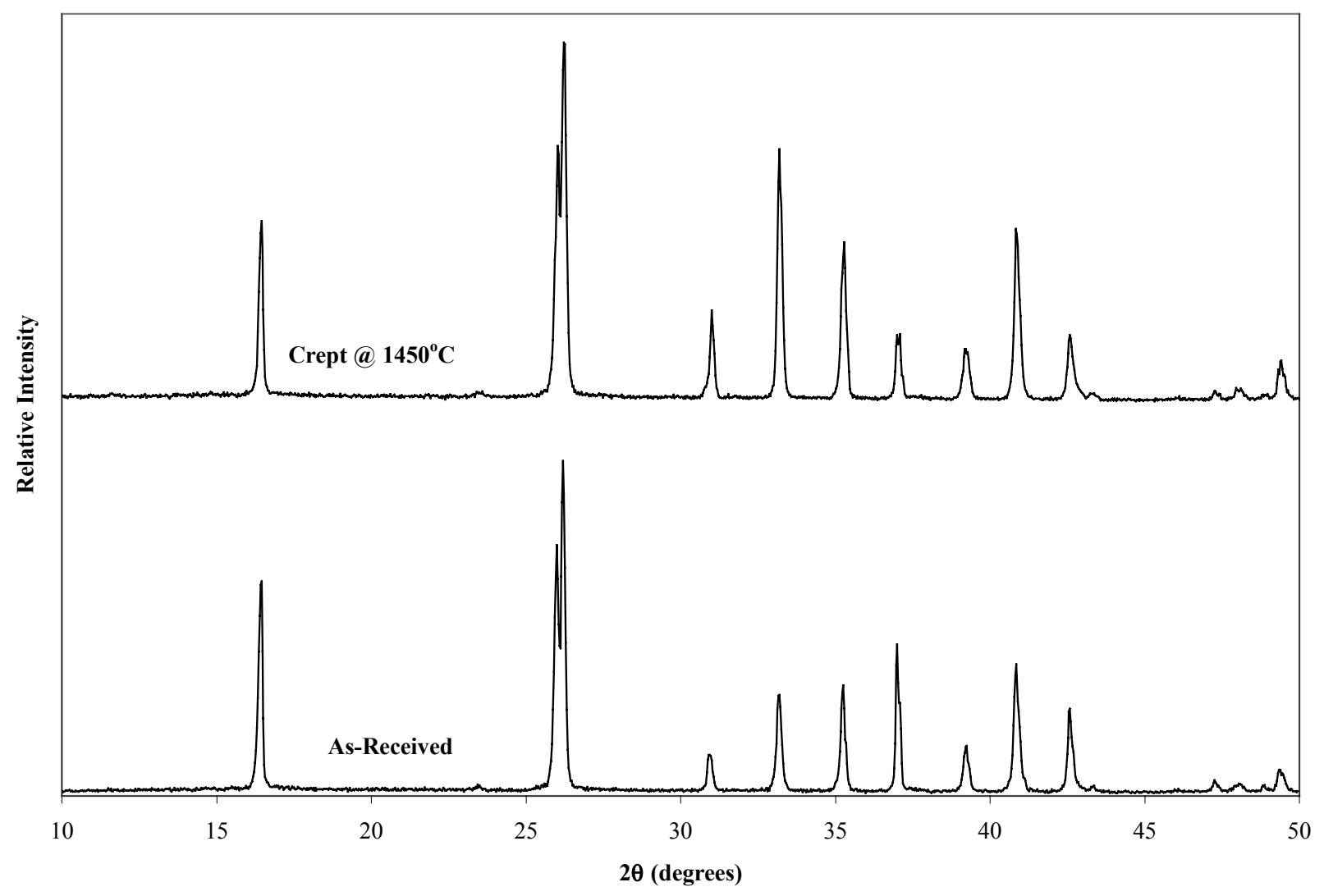

Figure 52. X-ray diffraction spectra of MU75AF.
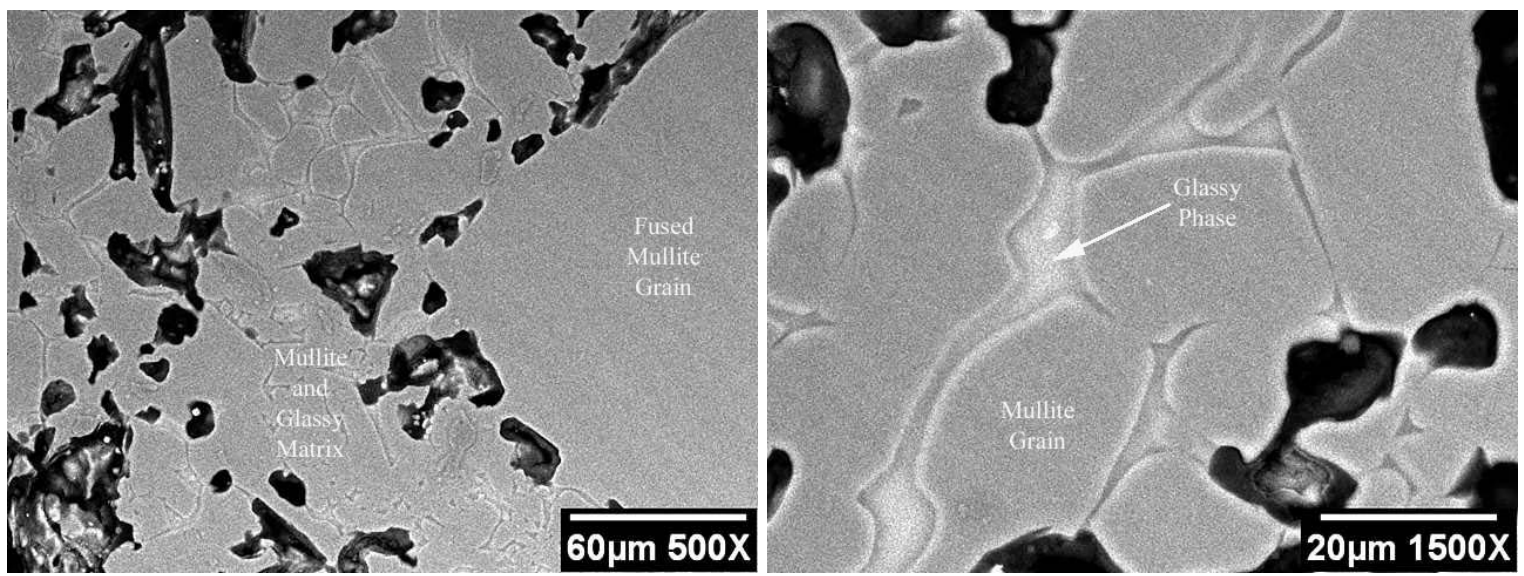

Figure 53. Scanning electron microscopy of MU75AF.

\section{SL75AD}

This refractory is composed of andalusite grains partially converted to mullite along with alumina grains and fine fused grain mullite added as raw grains. The resulting microstructure is a secondary mullite matrix (light purple or gray in CL image) formed around and between partially mullitized andalusite grains (red in the CL image), large fused alumina grains (medium 
gray in CL image), and fine fused mullite grains (dark purple or gray in CL image). Further, the andalusite grains contain free quartz that is converted to cristobalite during firing. This microstructure is shown in Figure 54. The analysis above is supported by XRD as shown in Figure 55 that contains diffraction lines for andalusite (PDF 39-0376), mullite (PDF 15-0776), alumina (PDF 10-0173), and cristobalite (PDF 39-1425). SEM (Figure 56) reveals that the fine mullite grains in the matrix are of stoichiometric composition and have corrosional surface layers in contact with a glassy phase. The composition of the glassy matrix phase was found by EDS to contain $\mathrm{Na}_{2} \mathrm{O}, \mathrm{MgO}, \mathrm{CaO}, \mathrm{K}_{2} \mathrm{O}$, and $\mathrm{TiO}_{2}$, which may be derived from natural andalusite during firing.

(a)
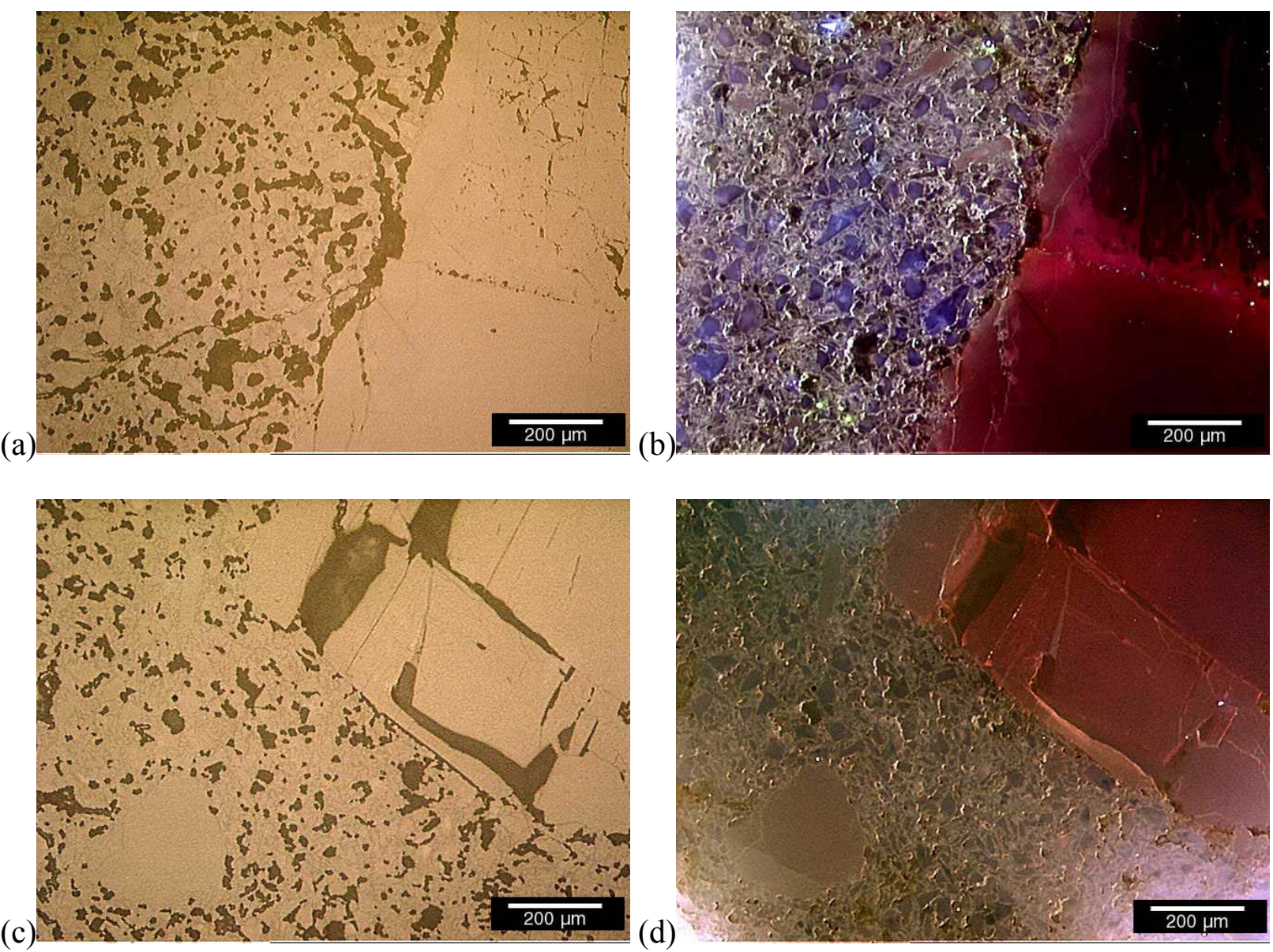

Figure 54. RL and CL microscopy of SL75AD.

( $\mathrm{a}$ and $\mathrm{b}-$ "as-received", $\mathrm{c}$ and $\mathrm{d}-\mathrm{crept}$ at $1450^{\circ} \mathrm{C}$ )

The mineralogy of the crept sample was different than that of the original material as shown in Figure 55. All of the original andalusite grains are converted to mullite aggregates and 
the amount of glassy phase has increased. This results in a disappearance of the diffraction lines for andalusite at $2 \theta$ values of $16.00^{\circ}, 19.75^{\circ}, 22.75^{\circ}, 25.25^{\circ}, 32.25^{\circ}, 36.00^{\circ}$, and $41.50^{\circ}$. Yet, as shown in Figure 54, the overall microstructure of the crept sample is similar to that of the original material.

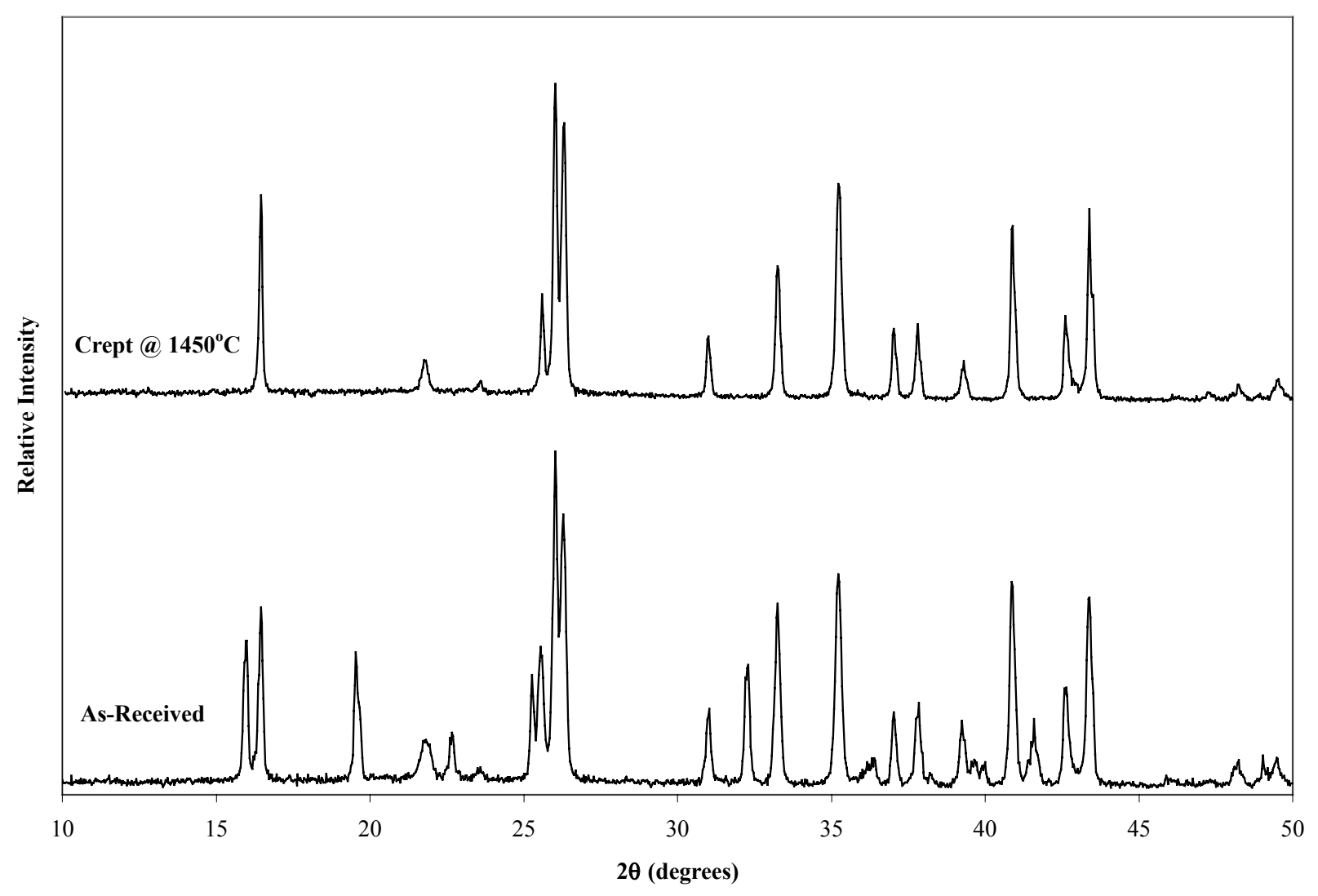

Figure 55. X-ray diffraction spectra of SL75AD.
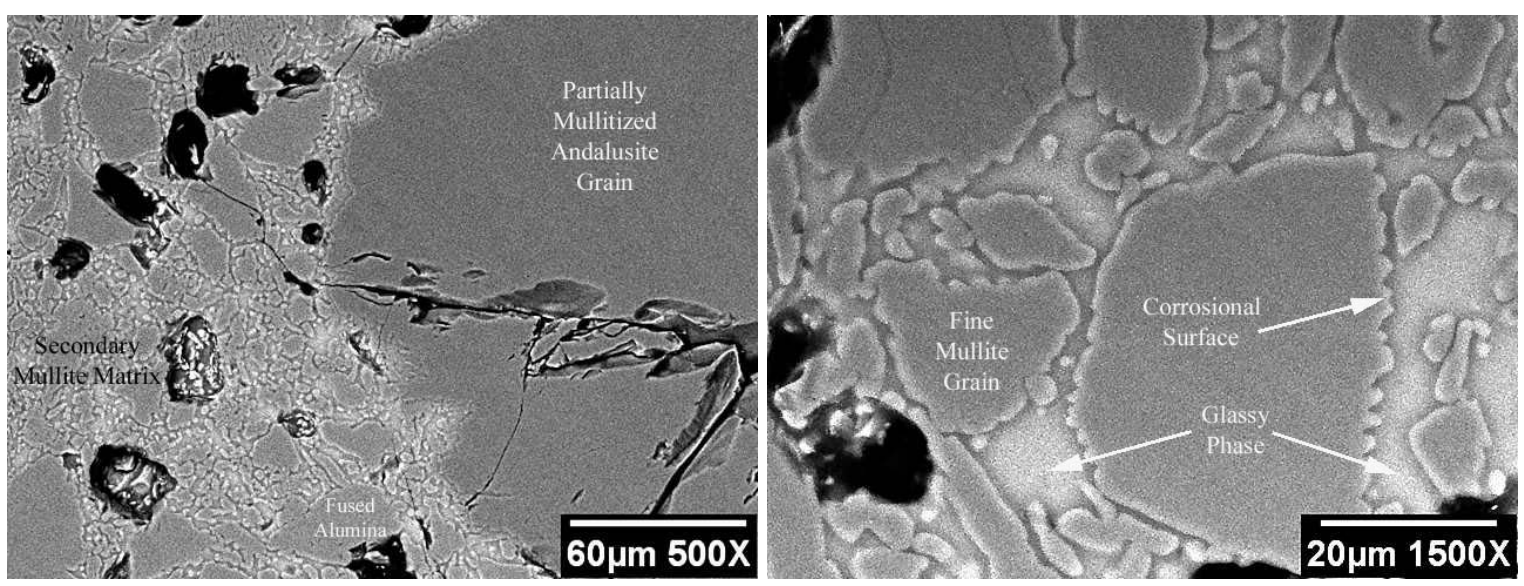

Figure 56. Scanning electron microscopy of SL75AD. 


\section{UFALA UCR}

The microstructure of this refractory is unique. It consists entirely of finely crystalline mullite aggregates formed through the calcination of andalucite or kyanite (red in CL image) in a fine crystalline mullite matrix (grayish/green in CL image) as shown in Figure 57. The mullite matrix was found to contain a large number of micro-fissures and fine pores along with a large amount of glassy phase (white in CL image). XRD of the "as-received" material produces only mullite (PDF15-0776) diffraction lines as shown in Figure 58. SEM (Figure 59) shows a distinct microstructure of skeletonized mullite containing elliptical and spherical pores characteristic of mullite derived from andalucite. Contrary to this, mullite present in the matrix has a more prismatic morphology and a variable crystal size with most crystals being small and needle-like but some crystals having a large rectangular shape due to crystal growth. Through EDS, the prismatic mullite crystals were found to contain $\mathrm{TiO}_{2}$ impurities and the glassy phase to contain $\mathrm{K}_{2} \mathrm{O}, \mathrm{CaO}$, and $\mathrm{TiO}_{2}$.

The mineralogy of the crept sample was the same as that of the original material with the addition of cristobalite (PDF 39-1425) being present in the structure (diffraction peak at $22^{\circ}$ ) as shown in Figure 58. The microstructure of the crept sample, as shown in Figure 57, is also slightly modified from that seen in the original material with a reduction in the amount of porosity present and the elimination of the micro-fissures. 
(a)
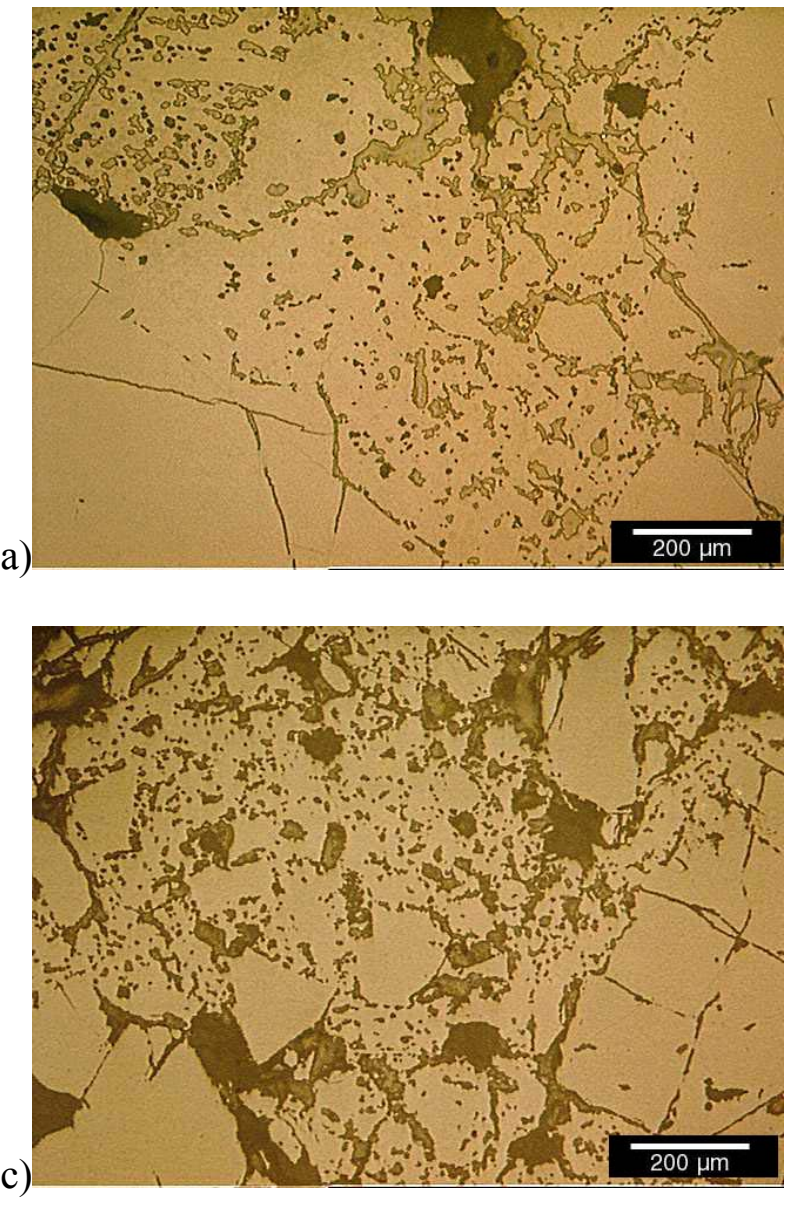

(b)

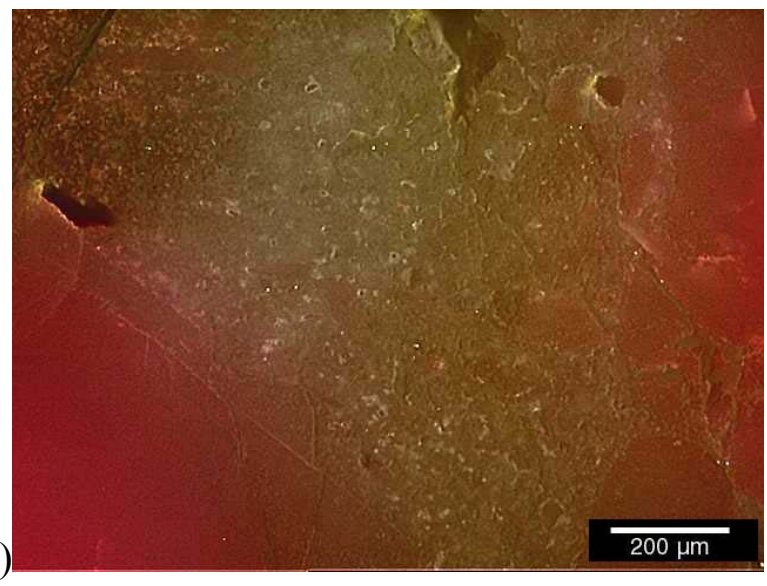

(d)

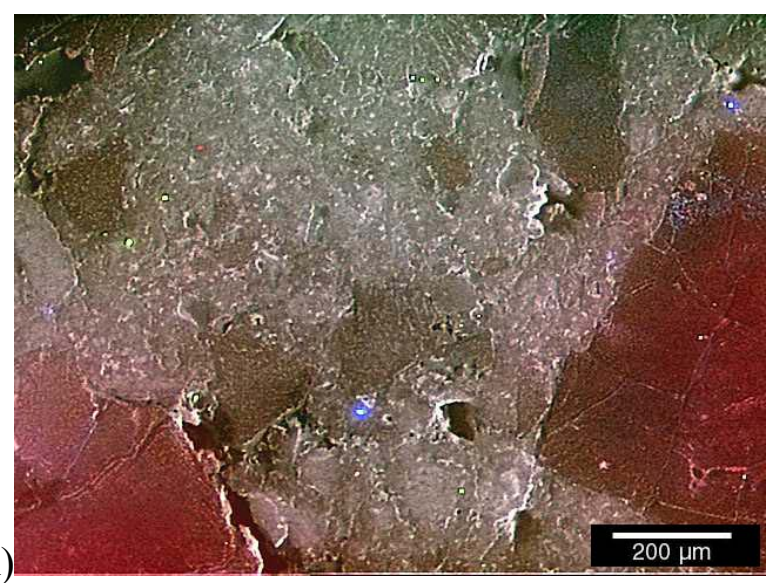

Figure 57. RL and CL microscopy of Ufala UCR. (a and b - "as-received", c and d-crept at $1450^{\circ} \mathrm{C}$ ) 


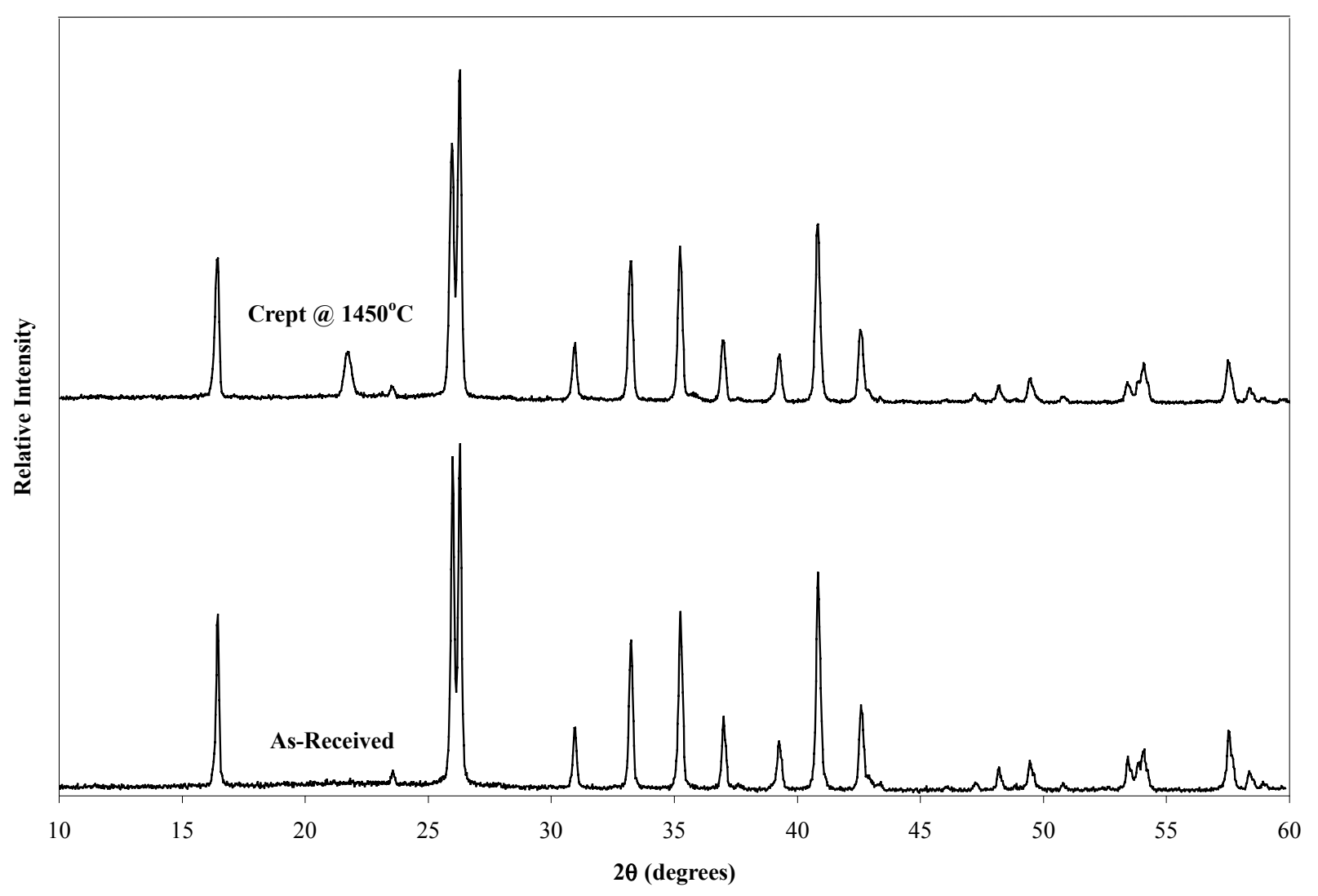

Figure 58. X-ray diffraction spectra of Ufala UCR.

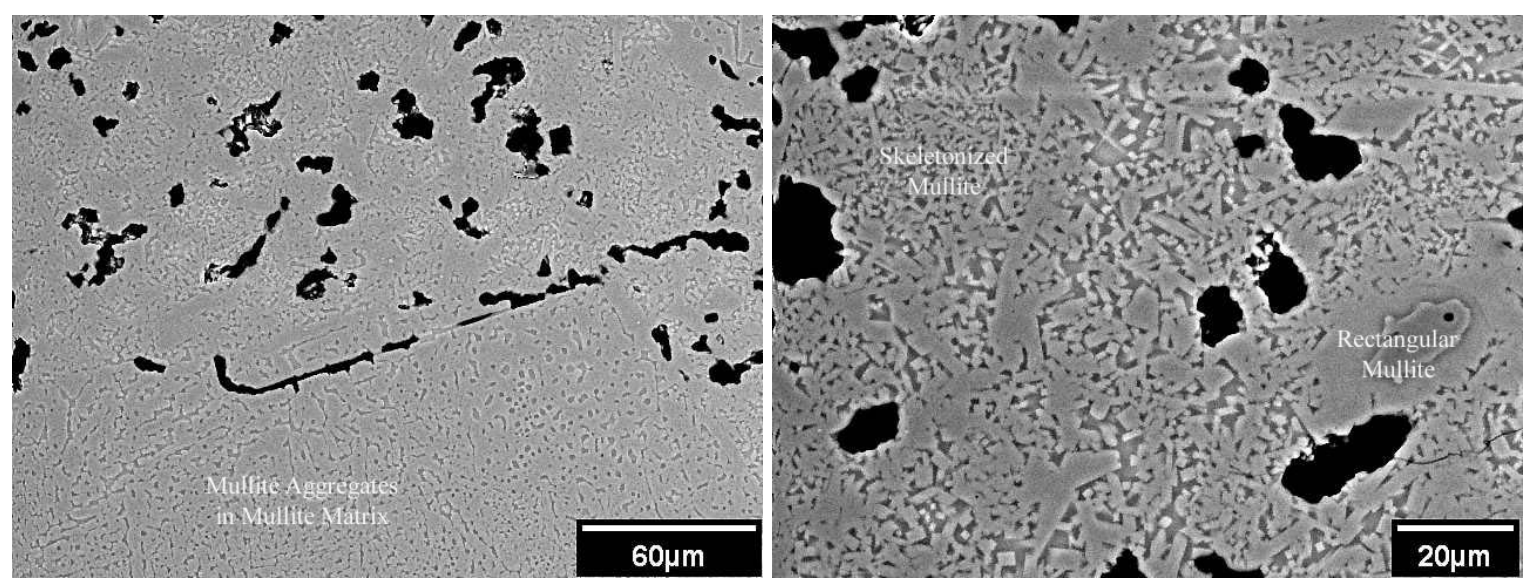

Figure 59. Scanning electron microscopy of Ufala UCR.

\section{ZED FMC}

This material consists entirely of large, medium and fine fused mullite grains (dark and light blue in CL image). The matrix between the large grains contains fine fused mullite particles (pinkish red in CL image) that are not well sintered and therefore, only small amounts of secondary mullite bond have formed between them. Also, the matrix is very porous and 
contains large amounts of micro-fissures along with small amounts of alumina and zirconia (white spots in CL image). The resulting microstructure is seen in Figure 60. This analysis is supported by XRD as shown in Figure 61 which shows diffraction lines for mullite (PDF 150776) and trace alumina (PDF 10-0173) phases. SEM (Figure 62) shows very small amounts of glass formation in the structure along with secondary mullite crystals with a crystal size on the order of 1 to $2 \mu \mathrm{m}$. Through EDS it was found that the glassy bonding phase is silica rich and contains only very small amounts of $\mathrm{CaO}$ impurities.

The mineralogy of the crept sample was identical to that of the original material as shown in Figure 61. Yet, as shown in Figure 60, the overall microstructure of the crept sample is more compact and the total amount of porosity present is lower than that of the original material.

(a)

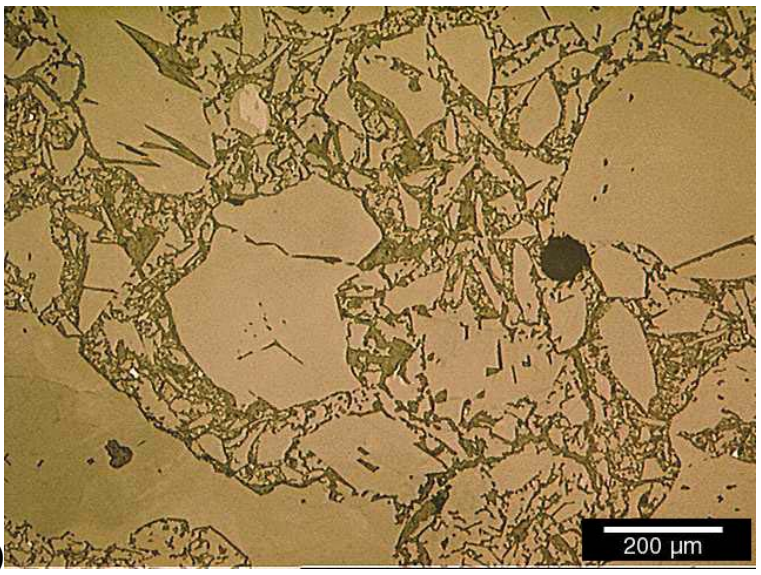

(c)

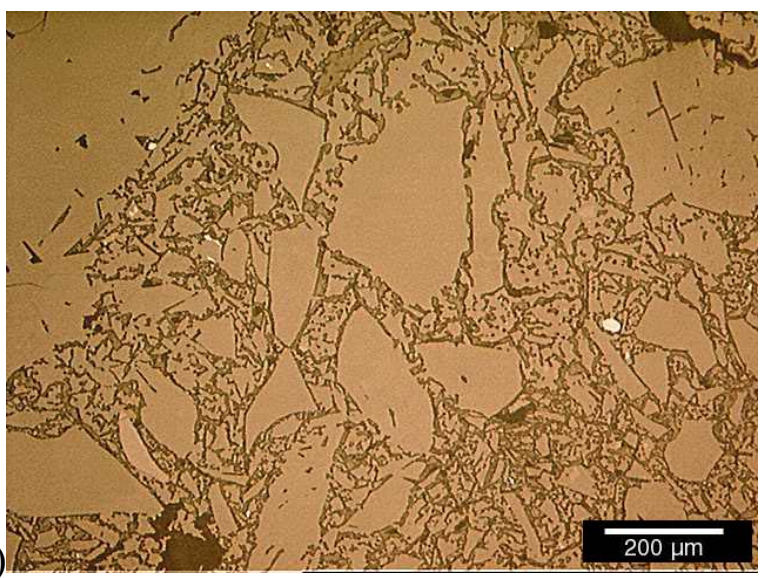

(b)

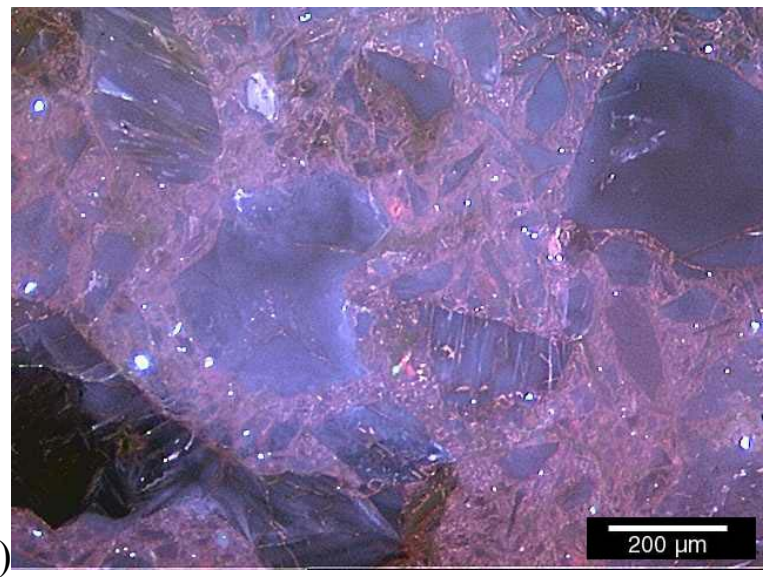

(d)

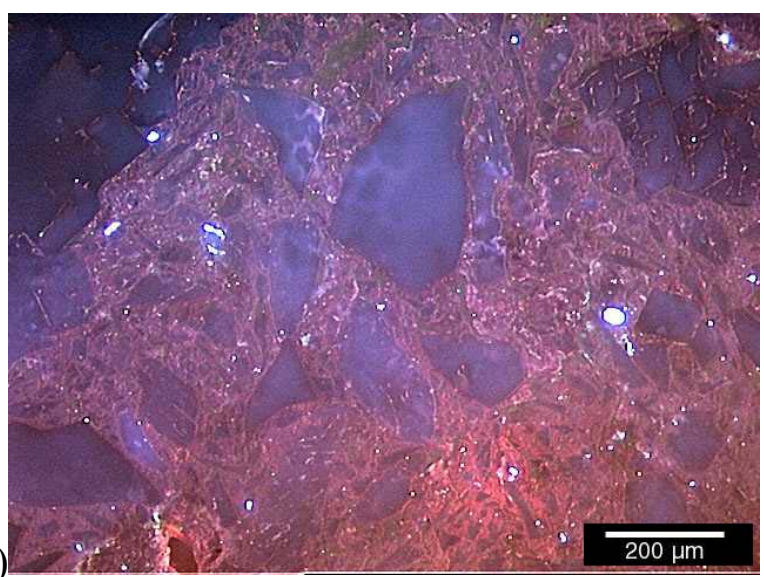

Figure 60. RL and CL microscopy of ZED FMC. ( $\mathrm{a}$ and b- "as-received", c and d - crept at $1450^{\circ} \mathrm{C}$ ) 


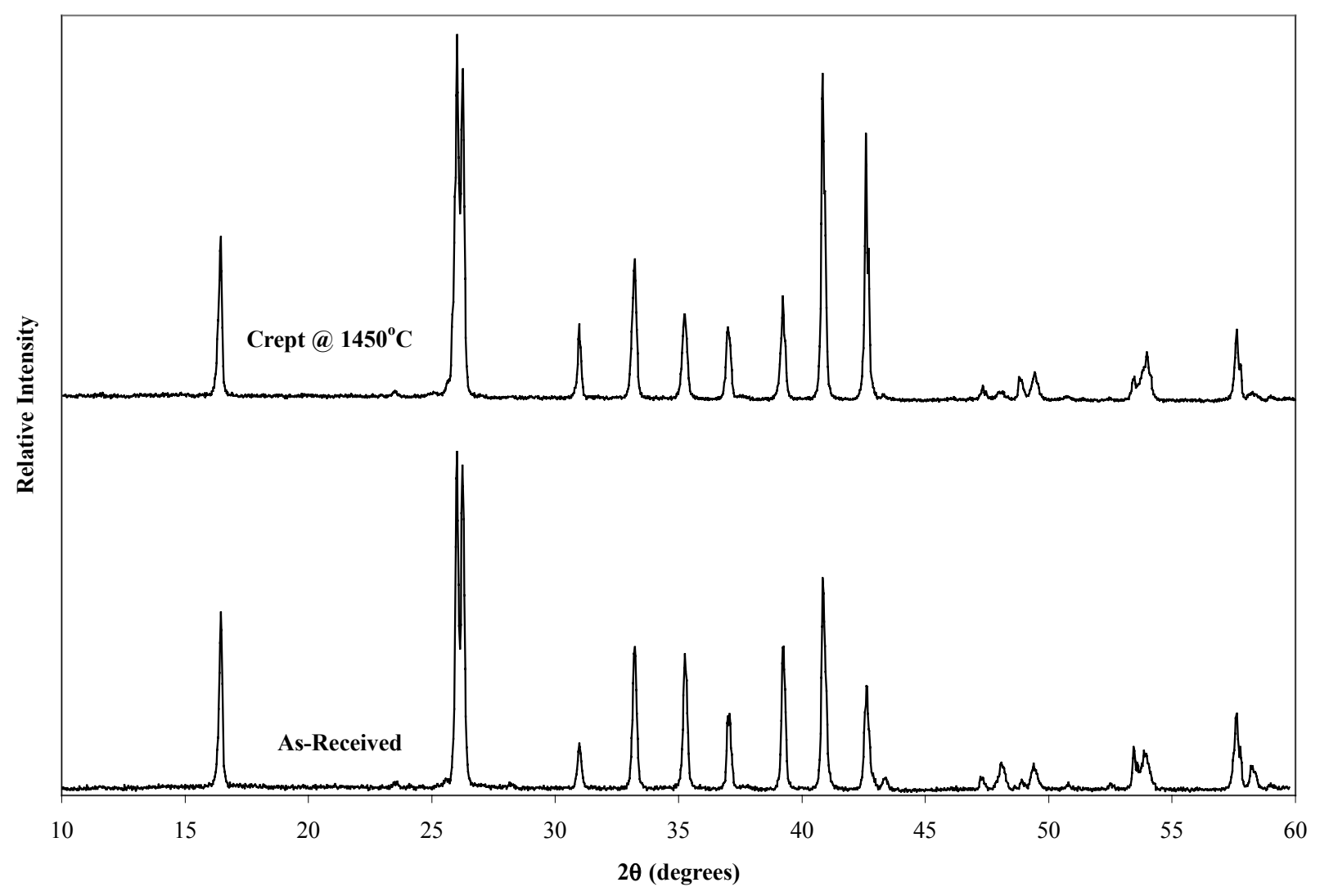

Figure 61. X-ray diffraction spectra of ZED FMC.

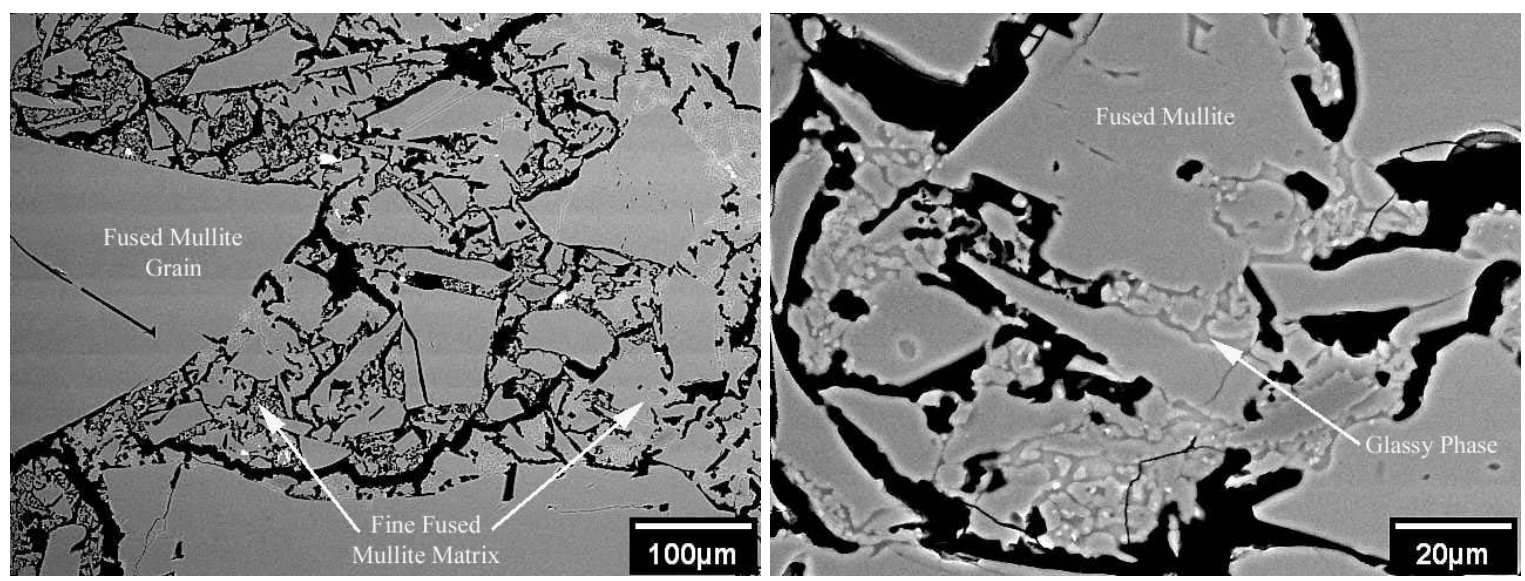

Figure 62. Scanning electron microscopy of ZED FMC.

\section{ZED FM}

The microstructure of this material contains primarily fused mullite grains (purple in the CL image) similar to the ZED FMC and trace amounts of alumina (red in CL image) and zirconia particles (bright white spots in CL image) as shown in Figure 63. In this material, particle to particle bonding is better developed than in the ZED FMC and more glassy phase 
(white in CL image) is present. This analysis is supported by XRD as shown in Figure 64 which shows diffraction lines for mullite (PDF 15-0776) and trace alumina (PDF 10-0173) phases. SEM (Figure 65) shows strong mullite and glassy bond microstructures. The composition of the mullite bond was found through EDS to be stoichiometric while the glassy bond was found to contain higher amounts of $\mathrm{CaO}$ than expected.

The mineralogy and microstructure of the crept sample was identical to that of the original material as shown in Figure 63 and Figure 64.

(a)

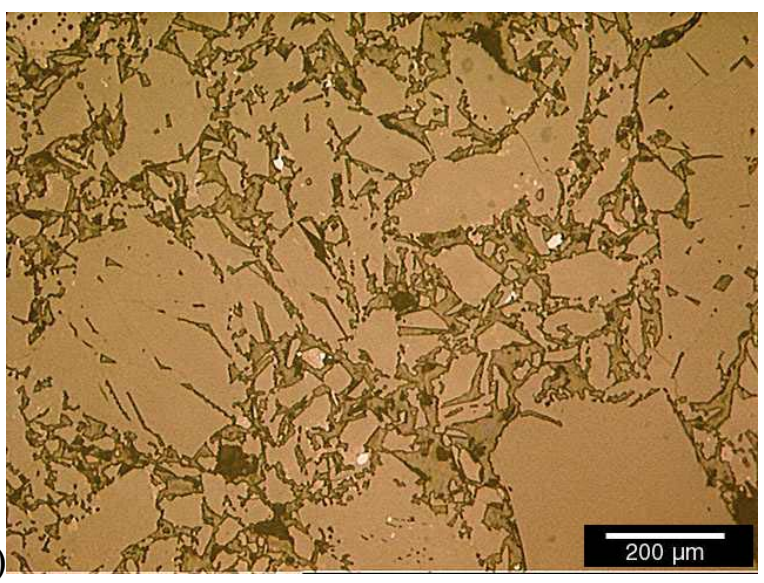

(b)
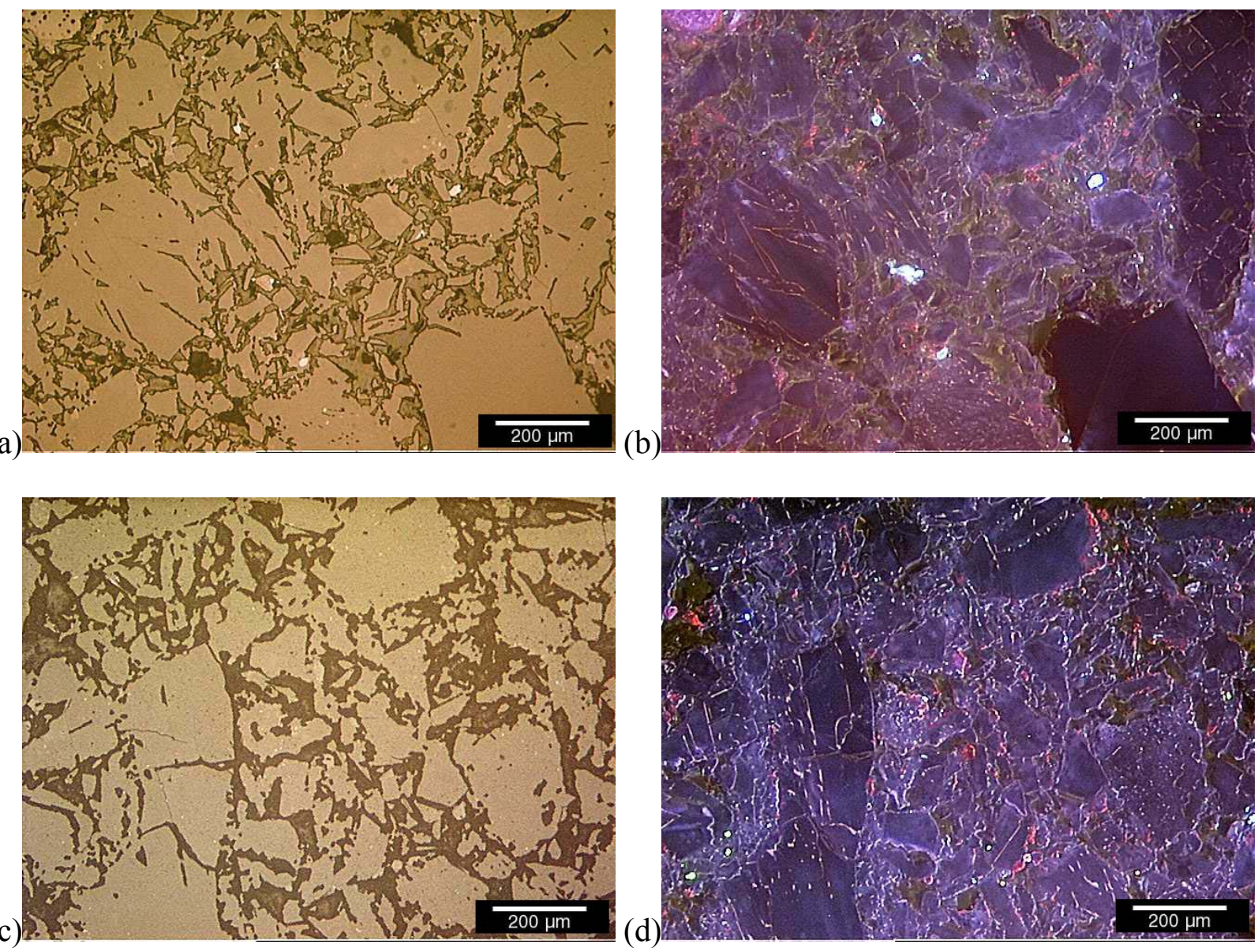

(d)

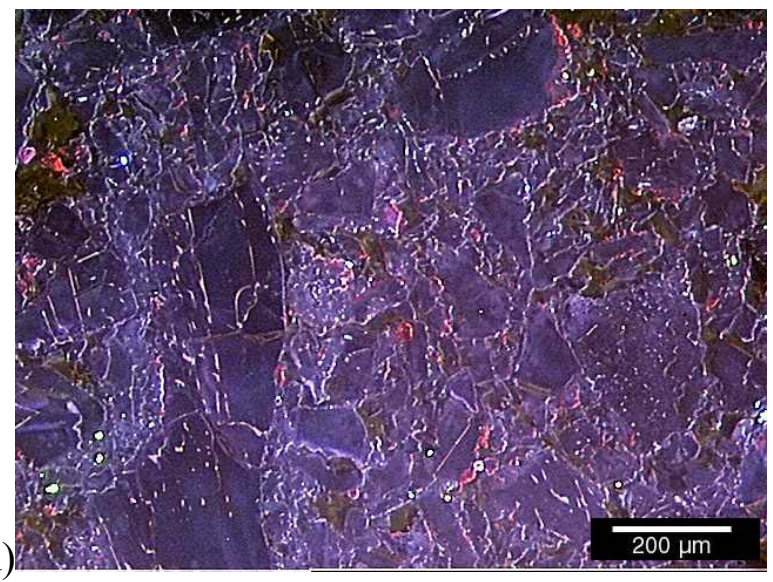

Figure 63. RL and CL microscopy of ZED FM. (a and b- "as-received", c and d-crept at $1450^{\circ} \mathrm{C}$ ) 


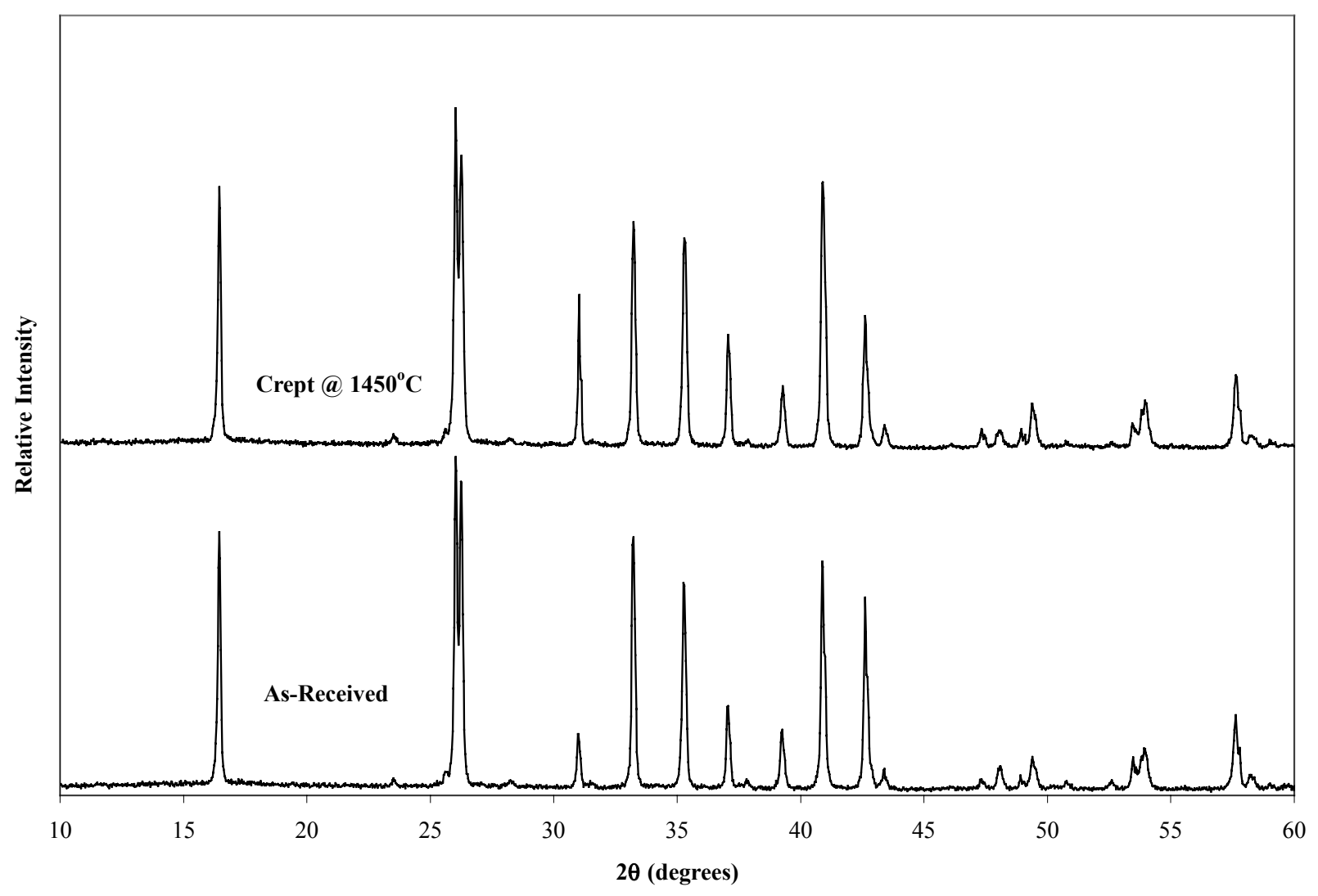

Figure 64. X-ray diffraction spectra of ZED FM.
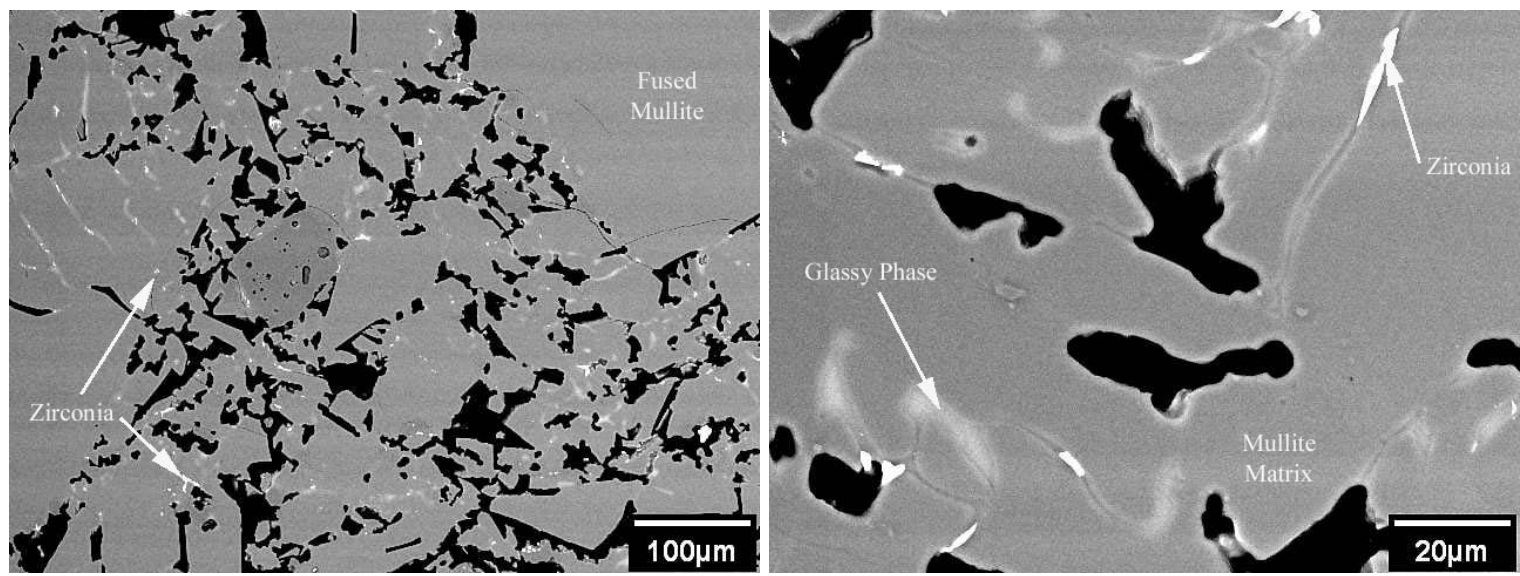

Figure 65. Scanning electron microscopy of ZED FM. 


\subsection{EFFECT OF TEMPERATURE}

Eight of the ten refractory specimens exhibited similar behavior, with the ZED FMC and ZED FM showing extraneous amounts of change $(\approx 8.5 \%)$ in mass and volume due to thermal exposure. The other eight brands showed less than $0.2 \%$ change in mass and less than $0.6 \%$ change in volume. This resulted in less than a $0.5 \%$ change in overall density for all samples including the the ZED FM and FMC brands. Results are shown in Figure 66 through Figure 68.
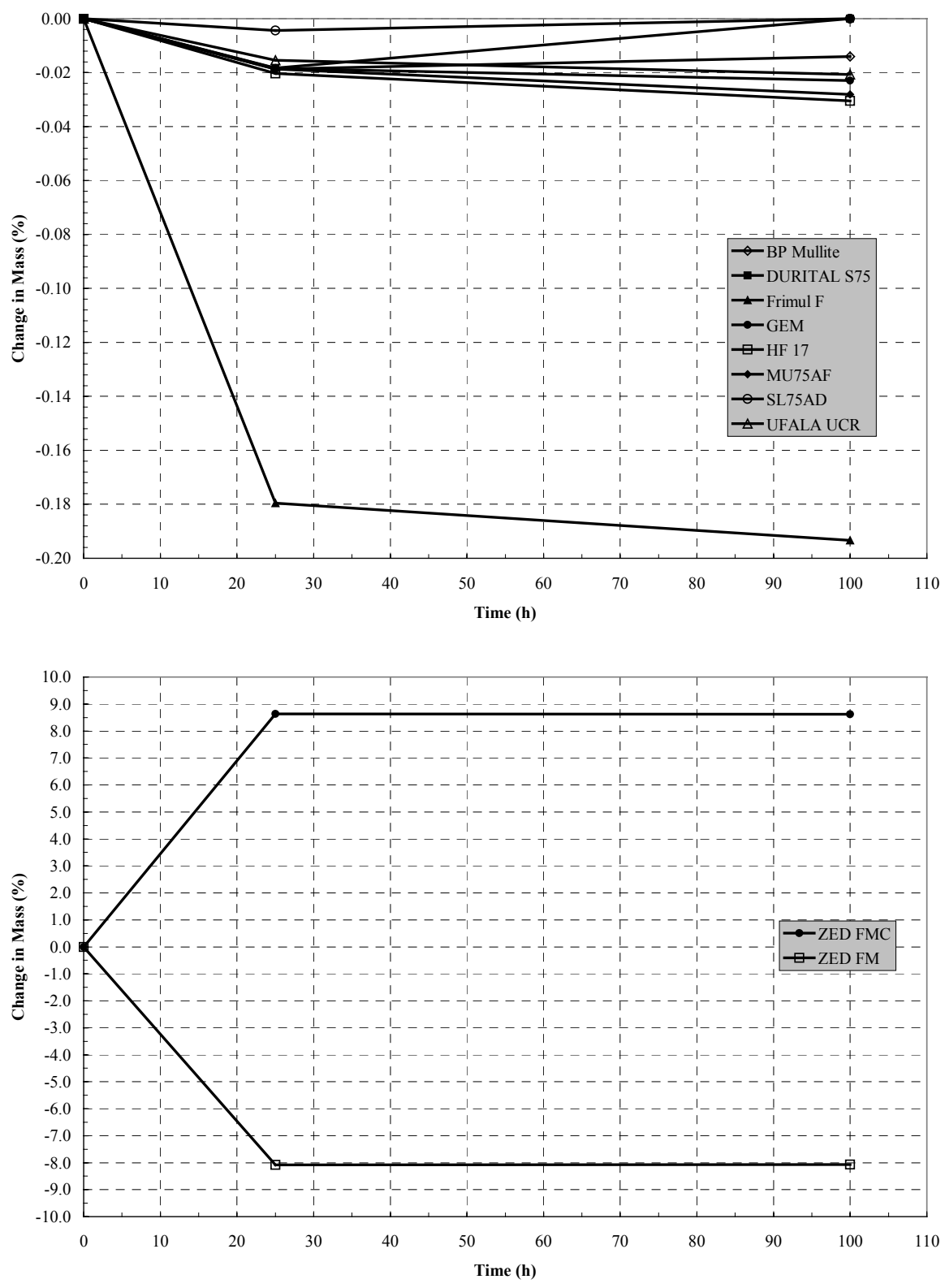

Figure 66. Change in mass of "aged" specimens as a function of time. 

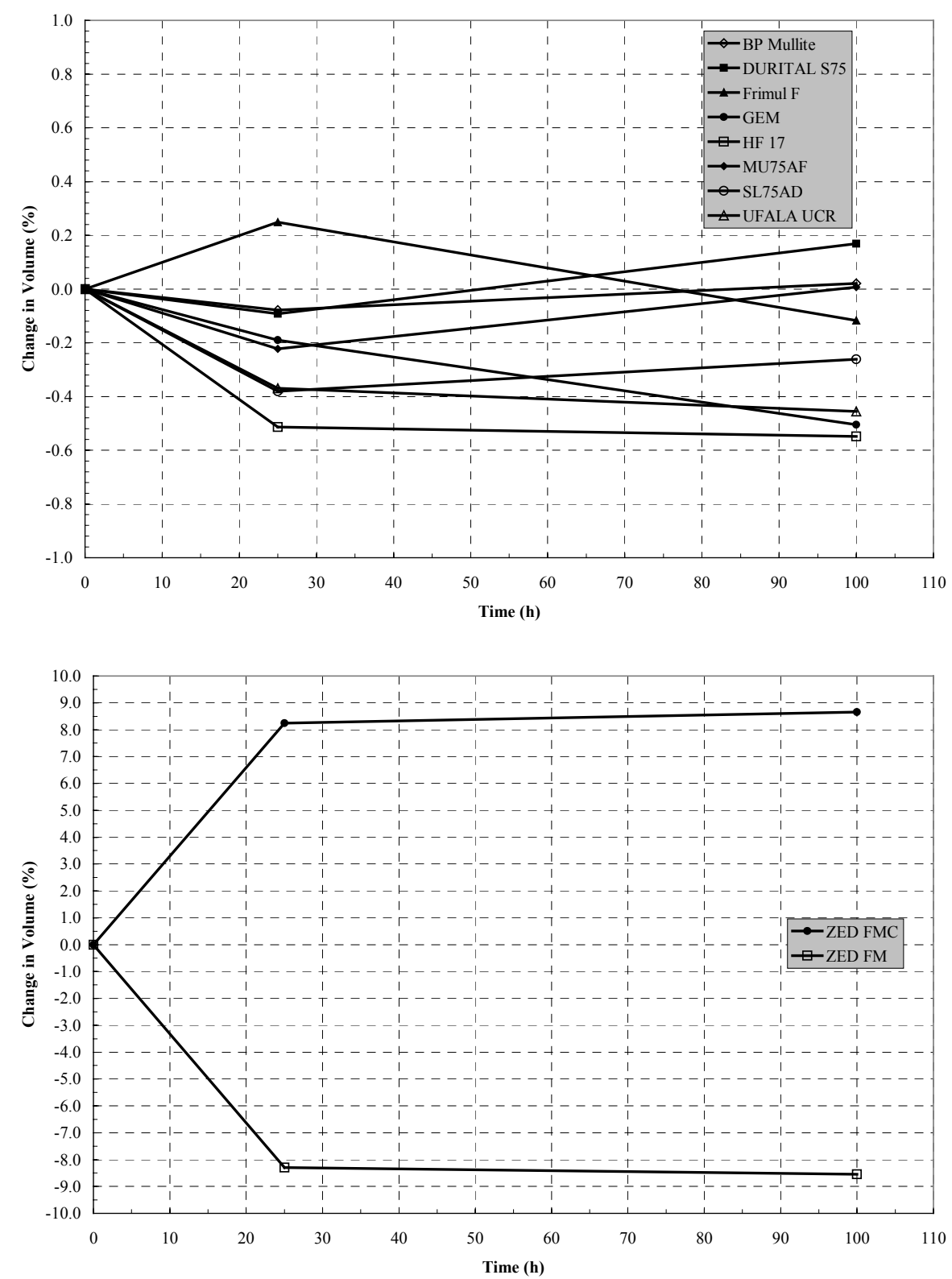

Figure 67. Change in volume of "aged" specimens as a function of time. 

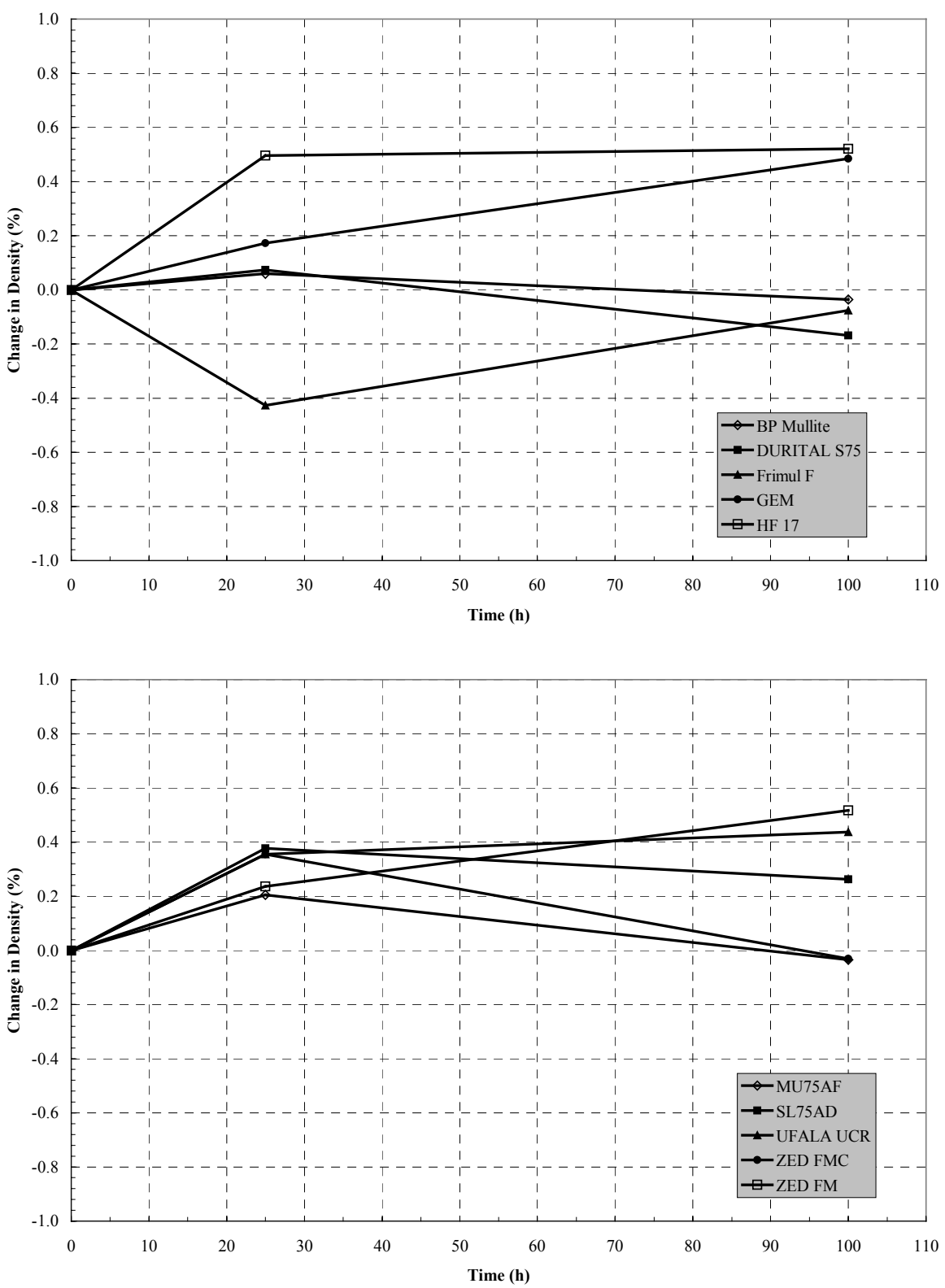

Figure 68. Change in density of "aged" specimens as a function of time.

It should be noted that the two Minteq brands along with the Frimul F brand all possess activation energies associated with vitreous silica as discussed above. These brands also exhibit the largest changes in mass, which may indicate that the silica plays some role in the temperature induced mass changes. 


\section{CONCLUSIONS}

- The amount of compressive creep for the BP Mullite, Durital S75, and Frimul F brands was found to be low at temperatures between $1300-1450^{\circ} \mathrm{C}\left(2370-2640^{\circ} \mathrm{F}\right)$ and at compressive stresses between 0.2 and 0.6 MPa (29-87 psi). Creep rates were on the order of $10^{-11} \mathrm{~s}^{-1}$ at the lower test temperature and on the order of $10^{-10} \mathrm{~s}^{-1}$ at the higher test temperature. Only one specimen per condition was tested so the authors were unable to statistically conclude that any one of these three brands had superior creep resistance to the others; however, if differences do indeed exist, then they are believed to be insignificant.

- The amount of compressive creep for the GEM, HF 17, MU75AF, and ZED FM brands was found to be slightly higher than that seen for the three refractories listed above, but still low at $1300-1450^{\circ} \mathrm{C}$ and $0.2-0.6 \mathrm{MPa}$. Creep rates were on the order of $10^{-10} \mathrm{~s}^{-1}$ at the lower test temperature and on the order of $10^{-9} \mathrm{~s}^{-1}$ at the higher test temperature. It should be noted that the GEM brand specimen showed higher amounts of creep than the other three brands in this group and a low stress exponent (0.4). This places its behavior closer to that described next for the brands exhibiting significant amounts of creep. Again, only one specimen per condition was tested so the authors were unable to statistically conclude that any one of the other three brands had superior creep resistance to the others; however, if differences do indeed exist, then they are believed to be insignificant.

- The amount of compressive creep for the SL75AD, UFALA UCR, and ZED FMC brands was found to be significant at $1375-1450^{\circ} \mathrm{C}$ and at 0.4 and $0.6 \mathrm{MPa}$. Creep rates were on the order of $10^{-9} \mathrm{~s}^{-1}$ at the lower test temperature and on the order of $10^{-8} \mathrm{~s}^{-1}$ at the higher test temperature. It should be noted that all three of these brands exhibited low stress exponents $(<0.5)$ and changes in chemistry or microstructure due to the creep testing conditions. Again, only one specimen per condition was tested so the authors were unable to statistically conclude that any one of these three brands had superior or inferior creep resistance to the others; however, if differences do indeed exist, then they are believed to be insignificant.

- Durital S75 was found to have a stress exponent of 2.4 indicating that the rate controlling mechanism may be grain boundary creep. This is opposed to diffusion controlled or Coble creep, which is expected to be the rate controlling mechanism in the Frimul F, HF 17, and MU75AF brands which exhibited a stress exponent of approximately unity. 
- It is believed that the low stress exponents seen for the BP Mullite, GEM, SL75AD, UFALA UCR, ZED FMC, and ZED FM brands is due to a non-steady state condition existing during the entire extent of testing. This condition is a consequence of contraction or time-hardening effects occurring during testing and the samples never reaching a state of equilibrium. The result is measurement of creep due to the applied compressive stress coupled with contraction of the sample due to time-hardening effects. Therefore, the assumption of a single deformation mechanism being active at all temperatures and stresses is not valid and multi-linear regression falsely yields extremely low stress exponent values.

- Those brands which possessed high levels of matrix porosity (HF 17, UFALA UCR, and ZED FMC) all showed compaction of the microstructure due to creep testing. This is believed to be the reason for the poor creep resistance of the UFALA UCR and ZED FMC brands. In addition, the UFALA UCR sample was found to possess a fine grain size, which could have contributed to the increased creep rate.

- SL75AD was found to be composed of andalusite grains containing free quartz, which was converted to cristobalite during firing. Further, the andalusite grains are fully converted to mullite during creep testing and the amount of glassy phase increased. These events in combination may lead to the brand's poor creep resistance.

- Activation energies for the various refractory brands ranged from 50 to $223 \mathrm{kcal} / \mathrm{mol}$. Although no direct correlation between the magnitude of the activation energy and the amount of creep exhibited by a particular brand could be drawn from the data, it is known that materials possessing a high activation energy will have greater sensitivity to temperature than those possessing a lower activation energy. It should also be noted that the values for many of the calculated activation energies correspond to the activation energy of vitreous silica. This would indicate that the glassy phases in these brands affect the overall creep behavior of the material.

- The distinction of a brand being fused-grained or non-fused grained mullite did not appear to have a bearing on the creep resistance of the individual brands. 
- Room temperature thermal conductivity values were similar for all ten brands of mullite with the average being on the order of $3.1 \mathrm{~W} / \mathrm{mK}\left(21.5\right.$ (Btu*in.) $/\left(\mathrm{hr}^{*} \mathrm{ft}^{2}{ }^{2 * 0} \mathrm{~F}\right)$ ). Frimul $\mathrm{F}$ was found to have the highest thermal conductivity at just below $3.5 \mathrm{~W} / \mathrm{mK} \quad(24.3$ (Btu*in.) $\left./\left(\mathrm{hr} .{ }^{*} \mathrm{ft}^{2}{ }^{20} \mathrm{~F}\right)\right)$. SL75AD, UFALA UCR and ZED FM were found to have the lowest thermal conductivities at around $2.5 \mathrm{~W} / \mathrm{mK}\left(17.4(\mathrm{Btu} * \mathrm{in}) /.\left(\mathrm{hr} .{ }^{*} \mathrm{ft}^{2}{ }^{\circ} \mathrm{F}\right)\right)$.

- Eight of the ten refractory brands showed less than $0.2 \%$ change in mass and less than $0.6 \%$ change in volume due thermal aging in the absence of an applied load. The two exceptions, ZED FM and ZED FMC, exhibited extraneous amounts of change $(\approx 8.5 \%)$ in both mass and volume due to thermal exposure. All samples showed less than $0.5 \%$ change in bulk density.

- The corrosion rates of the ten mullite brands could not be determined through the use of ASTM C987, but it was determined visually that only minimal amounts of recession occurred due to exposure as defined by the ASTM lid test. 


\section{ACKNOWLEDGEMENT}

The authors wish to thank M. K. Ferber and J. Keiser of ORNL for reviewing the manuscript and for their helpful comments. The authors are also indebted to

- the following individuals for supplying the mullite refractories: Paul Hutchinson (DSF Refractories \& Minerals), Michael Nelson (Corhart Refractories), Larry Stover (Minteq International), D. J. Thomas, (VGT-DYKO Industrial Ceramics), Jim Houp (National Refractories \& Minerals), and Don McIntyre (NARCO);

- the guidance provided by the Glass Industry Advisory Committee, which is comprised of the following individuals: Larry Kotacska (Corning), Al Poolos (Owens-Brockway), Randy Sturtz (Owens-Corning), Warren Curtis (PPG), Jim Shell (Techneglas), Mike Nelson (Corhart), Steve Winder (UKSS), John Tracey/Dilip (Patel VRD-Americas), and Bob Moore (University of Missouri-Rolla);

- ORNL/HTML machinists L. O'Rourke, T. Jenkins, and R. Parten for the specimen preparation; and

-DOE/OIT/AIM Program Manager C. Sorrell for his support of this project. 


\section{REFERENCES}

[1] L.S. Longenecker, "Chapter 21 Mullite Refractories", Refractories In The Glass Industry. Editor: A.G. Pincus, Magazines for Industry, Inc. (1980).

[2] Crown Refractories for Glass Manufacturing with Oxygen-Fuel Combustion. Teltech Resource Network Corporation, (1996).

[3] Refractories Handbook. The Technical Association of Refractories, Japan, (1998).

[4] A. A. Wereszczak, "Which Superstructure Refractories Do Glassmakers Desire Creep Data For?" Glass Industry, pp. 17-18, 24, November (1998).

[5] A.A. Wereszczak, M. Karakus, K.C. Liu, B.A. Pint, R.E. Moore, and T.P. Kirkland, Compressive Creep Performance and High Temperature Dimensional Stability of Conventional Silica Refractories. Oak Ridge National Laboratory Internal Report (ORNL/TM-13757), 1999.

[6] "Standard Test Method of Measuring the Thermal Expansion and Creep of Refractories Under Load," ASTM C832, Vol. 15.01, American Society for Testing and Materials, West Conshohocken, PA, 1998.

[7] K. C. Liu, C. O. Stevens, C. R. Brinkman, and N.E. Holshauser, "A Technique to Achieve Uniform Stress Distribution in Compressive Creep Testing of Advanced Ceramics at High temperatures," Journal of Engineering for Gas Turbines and Power, 119 500-505 (1997).

[8] K. C. Liu and J. L. Ding, "Mechanical Extensometer for High Temperature Tensile Testing of Ceramics," Journal of Testing and Evaluation, 21 406-413 (1993).

[9] S. Shin and O. Buyukozturk, Material Property Development for Refractories, US DOE Report ORNL/Sub/79-07862/02 (1990).

[10] "Standard Test Method for Load Testing Refractory Brick at High Temperatures," ASTM C16, Vol. 15.01, American Society for Testing and Materials, West Conshohocken, PA, 1998.

[11] F. H. Norton, The Creep of Steel at High Temperature, McGraw Hill, New York, 1929.

[12] A. A. Wereszczak, T. P. Kirkland, and W. F. Curtis, "Creep of $\mathrm{CaO} / \mathrm{SiO}_{2}-\mathrm{Containing} \mathrm{MgO}$ Refractories," Journal of Materials Science, Vol. 34, (1999). 
[13] "Standard Practice for Vapor Attack on Refractories for Furnace Superstructures," ASTM C987, Vol. 15.01, American Society for Testing and Materials, West Conshohocken, PA, 1998.

[14] S.E. Gustafsson, "Transient plane source techniques for thermal conductivity and thermal diffusivity measurements of solid materials" Review of Scientific Instruments. Vol. 62, No. 3, pp. 797-804, March (1991).

[15] M. Karakus and R. E. Moore, "CLM - A New Technique for Refractories," Ceramic Bulletin, 77 55-61 (1998).

[16] G. Hetherington, J.H. Jack, and J.C. Kennedy, "The Viscosity of Vitreous Silic," Physics and Chemistry of Glasses, 5 130-136 (1964).

[17] F.E. Wagstaff, "Crystallization and Melting Kinetics of Cristobalite," Journal of the American Ceramic Society, 52 650-654 (1969). 


\section{APPENDIX A}

\begin{tabular}{|c|c|c|c|c|c|c|c|c|c|}
\hline $10-0173$ & & & & Wave & elen & $=1.5405$ & & & i \\
\hline Al203 & $2 \theta$ & Int & $\mathbf{h}$ & k & 1 & $2 \theta$ & Int & h & k \\
\hline Aluminum 0xide & 25.583 & 75 & 0 & 1 & 2 & 109.516 & $<1$ & 3 & \\
\hline & 35.134 & 90 & 1 & 0 & 4 & 109.827 & $<1$ & 1 & \\
\hline & 37.782 & 40 & 1 & 1 & 0 & 111.023 & 4 & 3 & 1 \\
\hline Corundum, syn & 41.682 & $<1$ & 0 & 0 & 6 & 114.119 & 4 & 2 & 2 \\
\hline $\begin{array}{lllll}\text { Rad.: CuKa1 } & \lambda: 1.5405 & \text { Filter: } \mathrm{Ni} & \text { Beta } & \mathrm{d}-\mathrm{sp}:\end{array}$ & $\begin{array}{l}43.360 \\
46.181\end{array}$ & $\begin{array}{r}100 \\
2\end{array}$ & $\begin{array}{l}1 \\
2\end{array}$ & $\begin{array}{l}1 \\
0\end{array}$ & $\begin{array}{l}3 \\
2\end{array}$ & $\begin{array}{l}116.134 \\
116.623\end{array}$ & 14 & 3 & 2 \\
\hline I/Icor.: $\quad 1.00$ & 52.549 & 45 & 0 & 2 & 4 & 117.894 & 8 & 4 & 11 \\
\hline Ref: Natl. Bur. Stand. (U.S.), Circ. 539, 9. 3 (1960) & 57.515 & 80 & 1 & 1 & 6 & 120.226 & $<1$ & 2 & 3 \\
\hline & 59.765 & 4 & 2 & 1 & 1 & 122.063 & 4 & 4 & 1 \\
\hline S.G.: R R $\overline{3} c(167)$ & $\begin{array}{l}61.341 \\
66.544\end{array}$ & $\begin{array}{r}8 \\
30\end{array}$ & $\begin{array}{l}0 \\
2\end{array}$ & 1 & 8 & $\begin{array}{l}127.722 \\
129.907\end{array}$ & 12 & 1 & 31 \\
\hline & 68.193 & 50 & 3 & 0 & $\begin{array}{l}4 \\
0\end{array}$ & $\begin{array}{l}129.907 \\
131.138\end{array}$ & $\begin{array}{l}4 \\
4\end{array}$ & $\begin{array}{l}3 \\
2\end{array}$ & $\begin{array}{lll}0 & 1 \\
0 & 1\end{array}$ \\
\hline c: 12.991 & 70.354 & 2 & 1 & 2 & 5 & 136.151 & 22 & 1 & 4 \\
\hline mp: 2050 & 74.263 & 4 & 2 & 0 & 8 & 142.383 & 4 & 1 & 11 \\
\hline Ref: Ibid. & 76.877 & 16 & 1 & 01 & 10 & 145.194 & 11 & 4 & 01 \\
\hline & 77.223 & 8 & 1 & 1 & 9 & 149.271 & 7 & 0 & 5 \\
\hline & 80.688 & 8 & 2 & 2 & 0 & 150.227 & 14 & 1 & 01 \\
\hline SS/FOM: $F_{30}=50(.0188 .32)$ & $\begin{array}{l}83.213 \\
84.371\end{array}$ & $\begin{array}{r}<1 \\
6\end{array}$ & $\begin{array}{l}3 \\
2\end{array}$ & $\begin{array}{l}0 \\
2\end{array}$ & $\begin{array}{l}6 \\
3\end{array}$ & 152.426 & 13 & 3 & \\
\hline 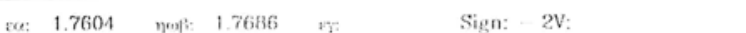 & 85.177 & 2 & 1 & 3 & 1 & & & & \\
\hline 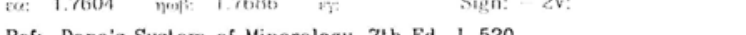 & 86.371 & 6 & 3 & 1 & 2 & & & & \\
\hline Ref: Dana's System of Mineralogy. 7th Ed.. 1. 520 & 86.457 & 4 & 1 & 2 & 8 & & & & \\
\hline & $\begin{array}{l}89.013 \\
90.658\end{array}$ & $\begin{array}{l}8 \\
4\end{array}$ & $\begin{array}{l}0 \\
0\end{array}$ & $\begin{array}{lll}2 & 1 \\
0 & 1\end{array}$ & $\begin{array}{l}10 \\
12\end{array}$ & & & & \\
\hline Color: Bluc & 91.197 & 8 & 1 & 3 & 4 & & & & \\
\hline Pattern taken at $26 \mathrm{C}$. Sample annealed at $1100 \mathrm{C}$ for four hours & 95.255 & 14 & 2 & 2 & 6 & & & & \\
\hline in an $\mathrm{Al} 203$ crucible. Spectroscopic analysis showed $<0.1 \% \mathrm{~K} . \mathrm{Na}$. & 98.401 & 2 & 0 & 4 & 2 & & & & \\
\hline $\mathrm{Si} ;<0.01 \% \mathrm{Ca}, \mathrm{Cu}, \mathrm{Fe}, \mathrm{Mg} . \mathrm{Pb} ;<0.001 \% \mathrm{~B}$, Cr, Li, Mn. Ni. Also called: & 101.086 & 12 & 2 & 11 & 10 & & & & \\
\hline ruby. Also called: sapphire. Al2 03 type. Corundum group. & 102.782 & $<1$ & 1 & 11 & 12 & & & & \\
\hline $\begin{array}{l}\text { corundum subgroup. Also called: alumina.Also called: } \\
\text { diamonite.PSC: hR10. Mwt: } 101.96 \text {. Volume[CD]: } 254.70 \text {. }\end{array}$ & 103.339 & 4 & 4 & 0 & 4 & & & & \\
\hline
\end{tabular}

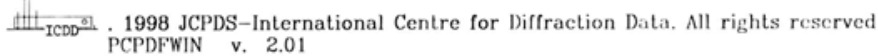

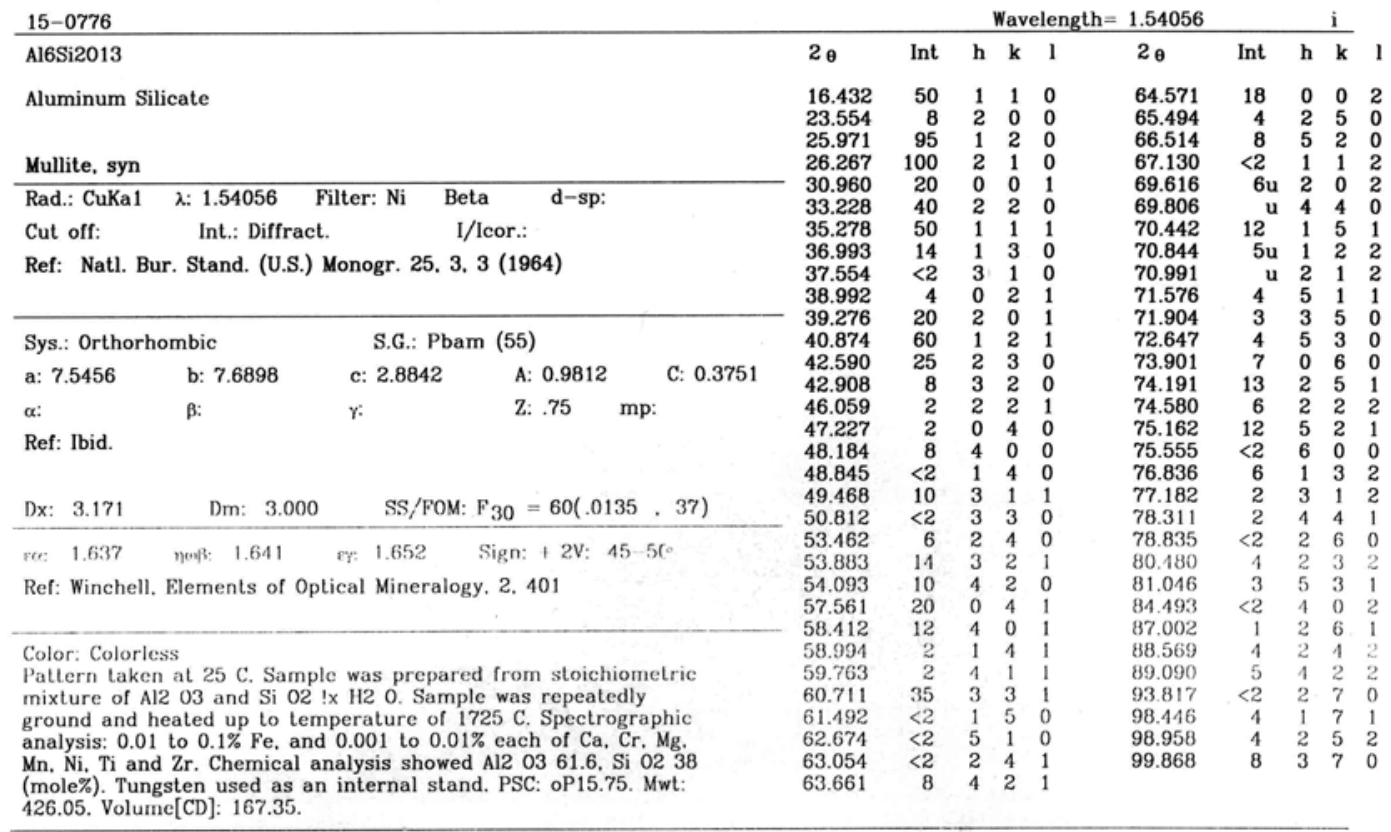

t1 $\mathrm{H}_{\mathrm{TCD}}$ - 1998 JCPDS-International Centre for Diffraction Data. All rights reserved

PCPDFWIN v. 2.01 


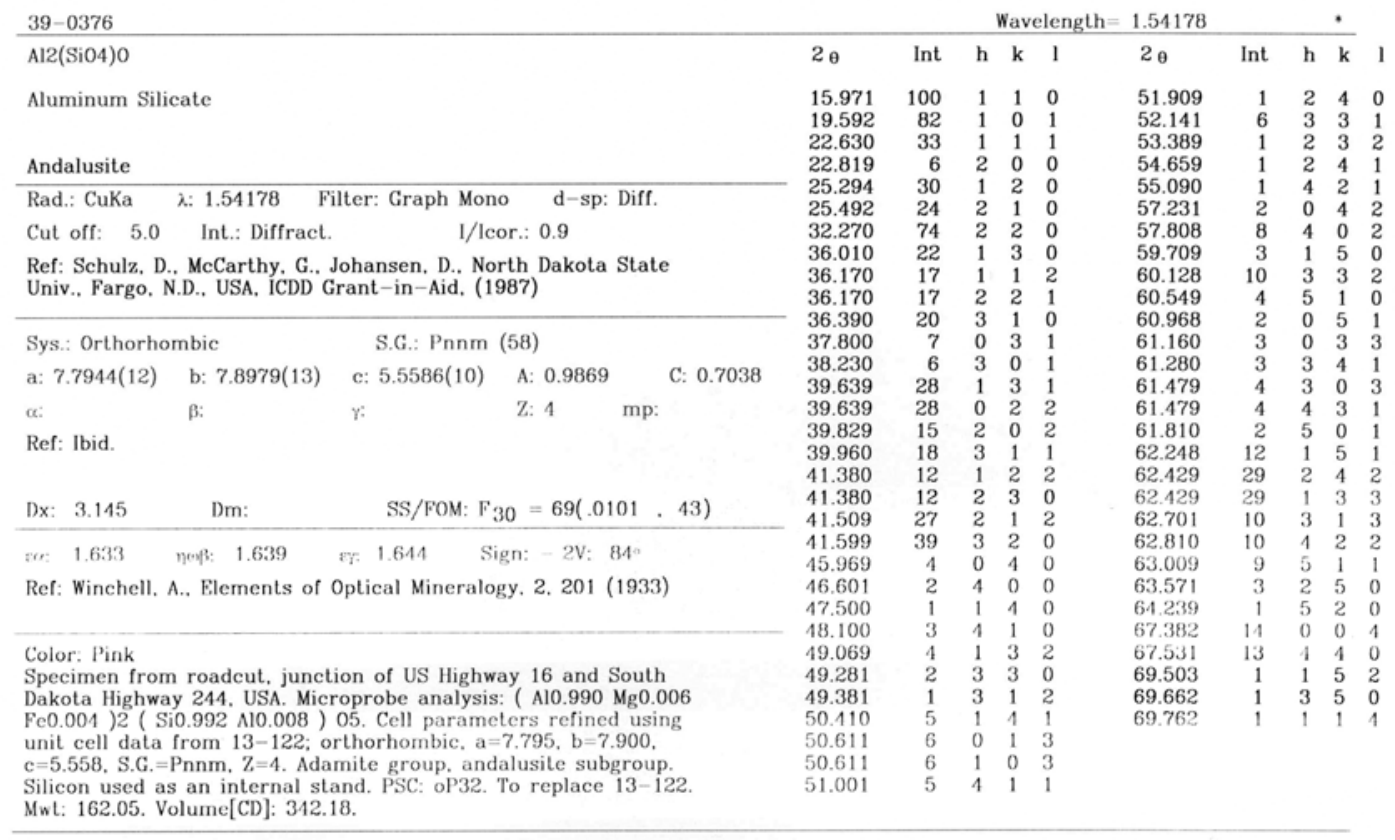

th 1900 JCPDS-International Centre for Diffraction Data. All rights reserved PCPDFWIN v. 2.01

\begin{tabular}{|c|c|c|c|c|c|c|c|c|c|c|}
\hline $39-1425$ & & & & Vave & len & 1.54178 & & & , & \\
\hline $\mathrm{SiO} 2$ & $2 \theta$ & Int & h & k & 1 & $2 \theta$ & Int & $\mathbf{h}$ & k & 1 \\
\hline Silicon 0xide & 22.00 & 100 & 1 & 0 & 1 & 77.383 & $<1$ & 2 & 2 & 4 \\
\hline & 25.340 & $<1$ & 1 & 1 & 0 & 78.092 & $<1$ & 4 & 0 & \\
\hline Cristobalite. syn & 28.461 & 8 & 1 & 1 & 1 & 79.467 & 1 & 4 & 1 & 0 \\
\hline $\begin{array}{l}\text { Cristobalite. syn } \\
\text { Rad.: CuKal } \lambda: 1.540598 \text { Filter: Graph Mono } \mathrm{d} \text {-sp: Diff. }\end{array}$ & $\begin{array}{l}31.487 \\
36.109\end{array}$ & $\begin{array}{r}9 \\
13\end{array}$ & $\begin{array}{l}1 \\
2\end{array}$ & $\begin{array}{l}0 \\
0\end{array}$ & $\begin{array}{l}2 \\
0\end{array}$ & $\begin{array}{l}81.225 \\
81.938\end{array}$ & $\begin{array}{r}1 \\
<1\end{array}$ & $\begin{array}{l}3 \\
2\end{array}$ & $\begin{array}{l}2 \\
1\end{array}$ & \\
\hline 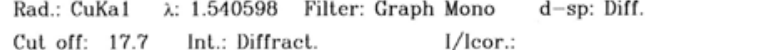 & 36.410 & 4 & 1 & 1 & 2 & 82.961 & $<1$ & 3 & 1 & 4 \\
\hline Cut off: 17.7 Int.: Diffract. $\quad$ I/Icor.: & 38.441 & $<1$ & 2 & 0 & 1 & 83.698 & $<1$ & 3 & 3 & 1 \\
\hline $\begin{array}{l}\text { Ref: Wong-Ng. W., McMurdie. H., Paretzkin, B., Hubbard, C.. } \\
\text { Dragoo. A., NBS, Gaithersburg. MD, USA, ICDD Grant-in-Aid. }\end{array}$ & $\begin{array}{l}42.690 \\
44.879 \\
47.101\end{array}$ & $\begin{array}{l}2 \\
2 \\
4\end{array}$ & $\begin{array}{l}2 \\
2 \\
1\end{array}$ & $\begin{array}{l}1 \\
0 \\
1\end{array}$ & $\begin{array}{l}1 \\
2 \\
3\end{array}$ & $\begin{array}{l}87.924 \\
89.207 \\
89.367\end{array}$ & $\begin{array}{r}<1 \\
1 \\
1\end{array}$ & $\begin{array}{l}3 \\
4 \\
1\end{array}$ & $\begin{array}{l}3 \\
2 \\
1\end{array}$ & \\
\hline (1988) & 48.651 & 4 & 2 & 1 & 2 & & & & & \\
\hline S.G.: P4 ${ }_{1}{ }_{1} 2(92)$ & 51.983 & $<1$ & 2 & 2 & 0 & & & & & \\
\hline $\begin{array}{ll}\text { a: } 4.9732(4) \quad \text { b: } & \text { c: } 6.9236(8) \quad \text { A: }\end{array}$ & $\begin{array}{l}52.913 \\
54.201\end{array}$ & $\begin{array}{r}<1 \\
2\end{array}$ & $\begin{array}{l}0 \\
2\end{array}$ & $\begin{array}{l}0 \\
0\end{array}$ & $\begin{array}{l}4 \\
3\end{array}$ & & & & & \\
\hline$\alpha: \quad \beta: \quad \gamma: \quad$ Z: 4 & 56.267 & $<1$ & 1 & 0 & 4 & & & & & \\
\hline Ref: Wong-Ng. W et al.. Powder Diffraction. 3. 253 (1988) & $\begin{array}{l}57.132 \\
57.555\end{array}$ & $\begin{array}{l}3 \\
1\end{array}$ & $\begin{array}{l}3 \\
2\end{array}$ & $\begin{array}{l}0 \\
1\end{array}$ & $\begin{array}{l}1 \\
3\end{array}$ & & & & & \\
\hline & 58.729 & $<1$ & 3 & 1 & 0 & & & & & \\
\hline SS/FOM: $F_{30}=84(.0100,36)$ & 58.919 & $<1$ & 2 & 2 & 2 & & & & & \\
\hline & $\begin{array}{l}60.355 \\
62.072\end{array}$ & 2 & 3 & 1 & 1 & & & & & \\
\hline $\begin{array}{l}\text { Color: Colorless } \\
\text { The temperature was } \sim 25 \mathrm{C} \text {. Cristobalite was prepared by the }\end{array}$ & 62.072 & 2 & 3 & 0 & 2 & & & & & \\
\hline $\begin{array}{l}\text { The temperature was } \sim 25 \mathrm{C} \text {. Cristobalite was prepared by the } \\
\text { Trans Tech Company using Berkeley } 5 \text { micron MIN-U-SII.(R). A two }\end{array}$ & $\begin{array}{l}65.158 \\
65.707\end{array}$ & & $\begin{array}{l}3 \\
2\end{array}$ & 1 & 2 & & & & & \\
\hline Trans Tech Company using Berkeley 5 micron MIN-U-SIL.(R). A two & $\begin{array}{l}65.707 \\
66.871\end{array}$ & 1 & $\begin{array}{l}2 \\
2\end{array}$ & $\begin{array}{l}0 \\
2\end{array}$ & $\begin{array}{l}1 \\
3\end{array}$ & & & & & \\
\hline kilogram sample was heated at $1600 \mathrm{C}$ for eight hours. The sample & $\begin{array}{l}60.871 \\
68.736\end{array}$ & 2 & $\begin{array}{l}2 \\
2\end{array}$ & i & 4 & & & & & \\
\hline was then air quenched, treated with $6 \mathrm{~N} \mathrm{HCl}$ and then jet-milled. & 69.481 & $<1$ & 3 & 2 & 1 & & & & & \\
\hline $\begin{array}{l}\text { The }+325 \text { mesh fraction was then removed by sieving. There are a } \\
\text { number of other forms of } \mathrm{Si} 02 \text {. The structure was determined by }\end{array}$ & 69.851 & $<1$ & 3 & 0 & 3 & & & & & \\
\hline $\begin{array}{l}\text { number of other forms of Si } 02 \text {. The structure was determined by } \\
\text { Peacor (1). } 02 \mathrm{Si} \text { type. Tungsten. fluorophlogopite used as an }\end{array}$ & 70.604 & 1 & 1 & 0 & 5 & & & & & \\
\hline internal stands. PSC: tP12. To replace $11-695$ and validated by & $\begin{array}{l}72.755 \\
73.974\end{array}$ & $\begin{array}{l}1 \\
1\end{array}$ & $\begin{array}{l}3 \\
3\end{array}$ & $\begin{array}{l}1 \\
2\end{array}$ & $\begin{array}{l}3 \\
2\end{array}$ & & & & & \\
\hline calculated pa & & & & & & & & & & \\
\hline
\end{tabular}

\footnotetext{
HCDD 1998 JCPDS-International Centre for Diffraction Data. All rights reserved
PCPDFWIN v. 2.01
} 